NUREG/CR- -5369

TI91 002410

\title{
The Seismic Category I Structures Program Results for FY 1987
}

Manuscript Completed: September 1990

Date Published: October 1990

Prepared by

C. R. Farrar, J. G. Bennett, W. E. Dunwoody, W. E. Raker*

Los Alamos National Laboratory

Los Alamos, NM 87545

\section{Prepared for}

Division of Engineering

Office of Nuclear Regulatory Research

U.S. Nuclear Regulatory Commission

Washington, DC 20555

NRC FIN A7221

*University of New Mexico

Albuquerque, NM 87131

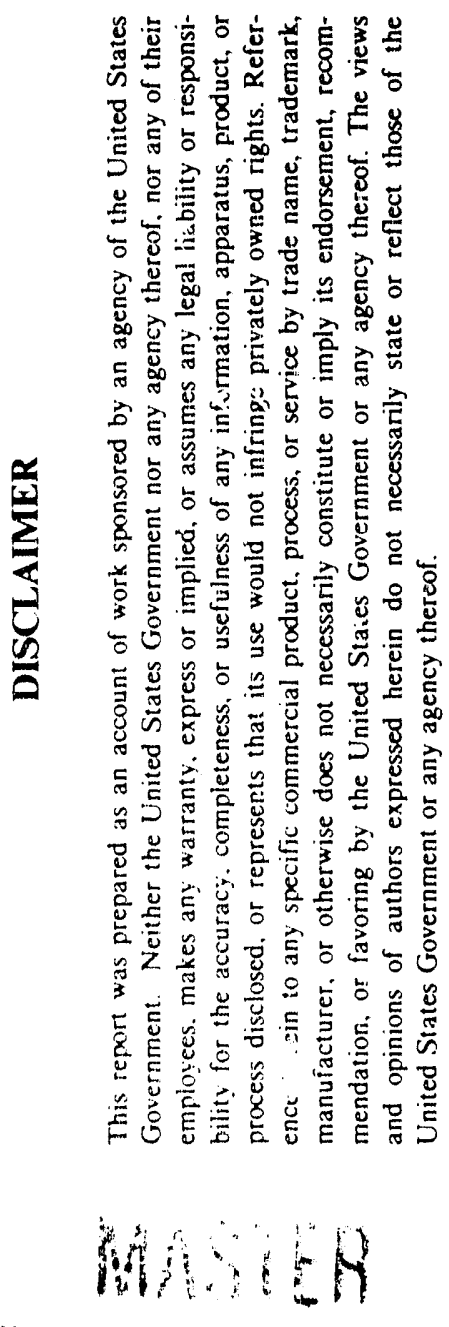




\section{PREVIOUS REPORTS IN THE SERIES}

E. G. Endebrock and R. C. Dove, "Seismic Response of Nonlinear Systems," Los Alamos National Laboratory report LA-8981-MS, NUREG/CR-2310 :September 1981).

E. G. Endebrock, R. C. Dove, and C. A. Anderson, "Margins to Failure Category I Structures Program: Background and Experimental Plan," Los Alamos National Laboratory report LA-9030-MS, NUREG/CR-2347 (December 1981).

E. G. Endebrock, R. C. Dove, and W. E. Dunwoody, "Analysis and Tests on Sma!1Scale Shear Walls--FY 82 Final Report," Los Alamos National Laboratory report LA-10443-MS, NUREG/CR-4274 (September 1985).

R. C. Dove and J. G. Bennett, "Scale Modeling of Reinforced Concrete Category I Structures Subjected to Seismic Loading," Los Alamos National Laroratory report LA-10624-MS, NUREG/CR-4474 (January 1986).

R. C. Dove, J. G. Bennett, C. Farrar, and C. A. Anderson, "Seismic Category I Structures Program Final Report, FY 1983-84," Los Alamos National Laboratory report LA-11013-MS, NUREG/CR-4924 (September 1987).

J. G. Bennett, R. C. Dove, W. E. Dunwoody, E. G. Endebrock, C. R. Farrar, and P. Goldman. "Simulated Seismic Tests on 1/42- and 1/14-Scale Category I

Auxiliary Buildings," Los Alamos National Laboratory report LA-11093-MS, NUREG/CR-4987 'October 1987).

J. G. Bennett, R. C. Dove, W. E. Dunwoody, C. R. Farrar, and P. Goldman, "The Seismic Category I Structures Program: Results for FY 1985," Los Alamos National Laboratory report LA-11117-MS, NUP.EG/CR-4998 (December 1987).

C. R. Farrar and J. G. Bennett, "Experimental Assessment of Damping in Low Aspect Ratio, Reinforced Concrete Shear Wall Structures," Los Alamos National Laboratory report LA-11325-Mj, NUREG/CR-5154 (August 1988).

J. G. Bennett, R. C. Dove, W. E. Dunwoody, C. R. Farrar, and P. Goldman, "The Seismic Category I Structures Program: Results for FY 198E," Los Alamos National Laboratory report LA-11377-MS, NUREG/CR-5182 (September 1988).

C. R. Farrar and C. M. Alvord, "Use of Linear Reduced-Stiffness Analytical Models to Predict Seismic Response of Damaged Concrete Structures: "Los Alamos National Laboratory report LA-11444-MS, NUREG/CR-5237 (May 1989).

C. R. Farrar, J. G. Bennett, W. E. Dunwoody, and W. E. Baker, "Static Load Cycle Testing of a Low-Aspect-Ratio Six-Inch Wall TRG-Type Structure TRG-4-6 $(1.0,0.25), "$ LOS Alamos National Laboratory report LA-11422-MS, NUREG/CR-5222 (June 1989). 


\section{ABSTRACT}

The accomplishments of the Seismic Category I Structures Program for FY 1987 are summarized. These accomplishments include the quasi-static load cycle testing of large shear wall elements, an extensive analysis of previous data to determine if equivalent linear analytical models can predict the response of damaged shear wall structures, and code committee activities. In addition, previous testing and results that led to the FY 1987 program plan are discussed and all previous data relating to shear wall stiffness are summarized. Becauje separate reports have already summarized the experimental and analytical work in FY 1987, this report will briefly highlight this work and the appropriate reports will be referenced for a more detailed discussion. 


\section{TABLE OF CONTENTS}

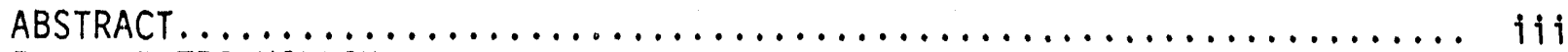

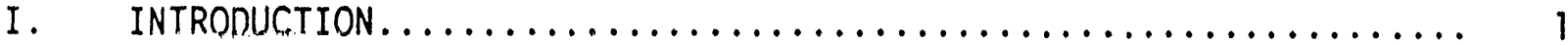

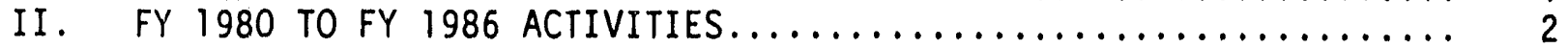

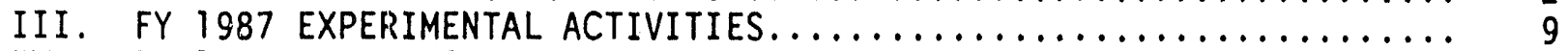

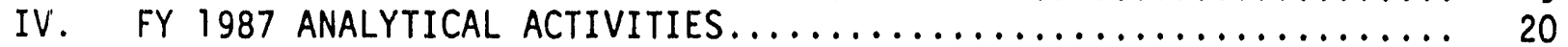

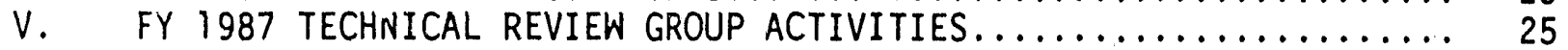

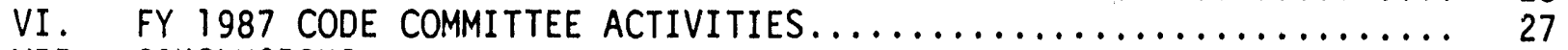

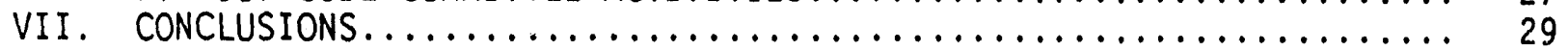

VIII. REFERENCES ................................ 31

APPENDIX A: SUMMARY OF MEASURED STIFFNESS VALUES $\ldots \ldots \ldots \ldots \ldots \ldots \ldots$

A. Review of Previous Static Test Results Obtained In

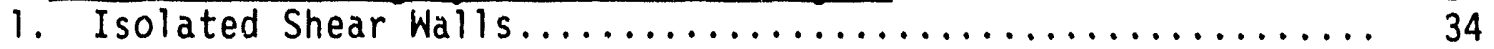

2. 1/30-Scale, Single-.Story, Diesel Generator Buildings........ 37

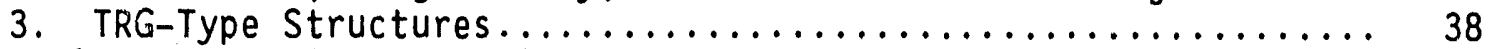

B. Review of Previous Dynamic Test Results Obtained

In the Seismic Category I Structures Program.............. 40

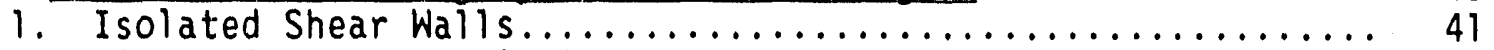

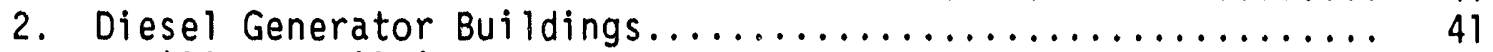

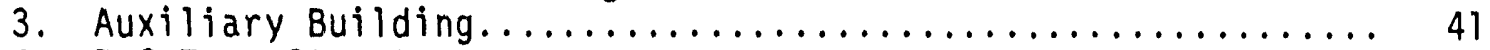

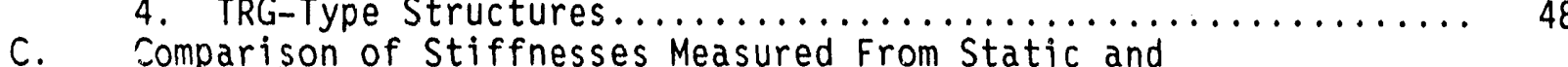

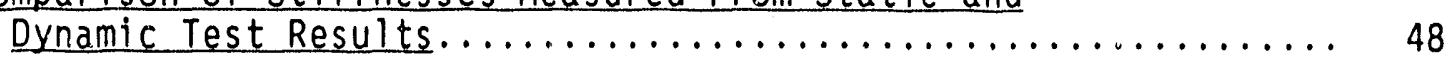

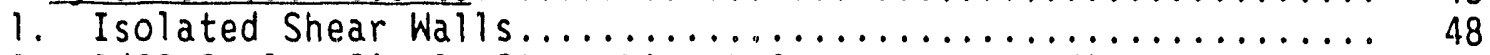

2. 1/30-Scale, Single-Story Diesel Generator Buildings........ 51

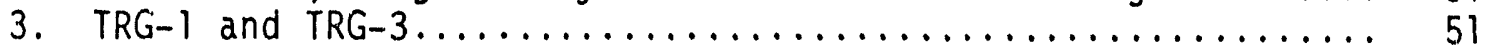

APPENDIX B: THE TECHNICAL REVIEW GROUP'S RESPONSE TO QUESTIONS CONCERNING IN VALIDITY OF THIS PROGRAM'S RESULTS........ 53

\section{LIST OF FIGURES}

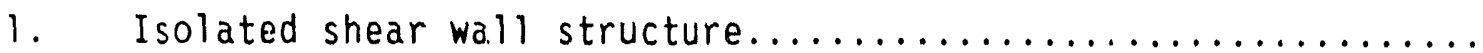

2. Diesel generator building model.

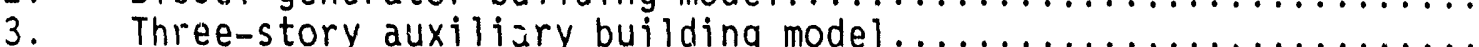

4. TRG-3-4 $(1.0,0.60)$ and TRG-5-4 $(1.0,0.60) \ldots \ldots \ldots \ldots \ldots \ldots \ldots \ldots$

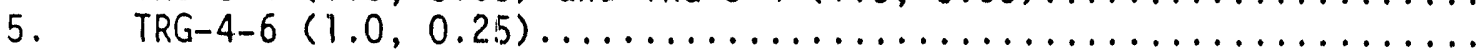

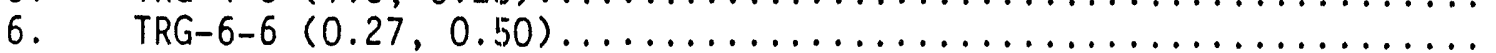

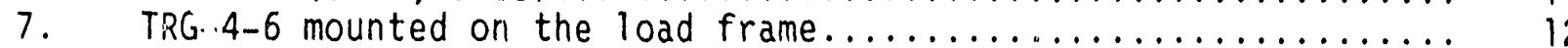

8. TRG-4 mounted on air bearings for experimental modal analysis... 13

9. Electrodynamic shaker used to excite the structures during the experimental modal analysis....................... 14

10. Comparison of a mode shape identified during the experimentai modal analysis with a mode shape determined by finite ele-

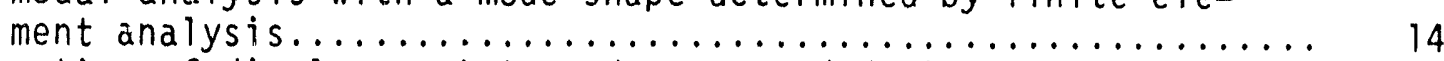

11. Location of displacement transducers used during static

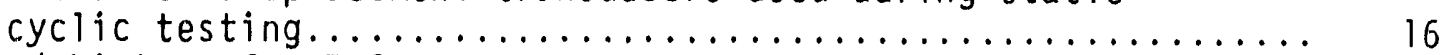

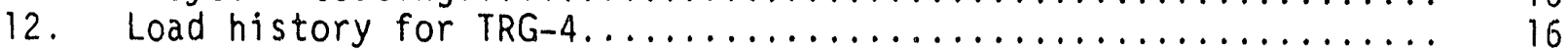

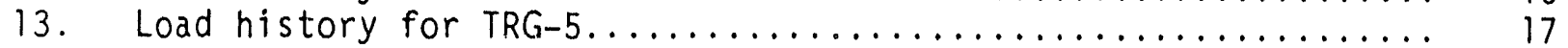

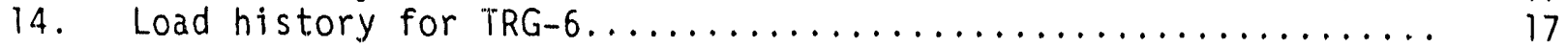


15. Load displacement response of TRG-5................... 18

16. Final crack patterns in TRG-5.......................... 18

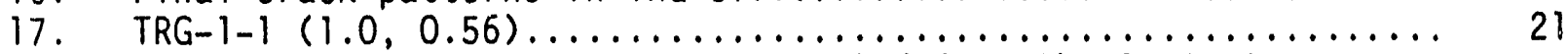

18. Base input response spectrum generated from the $1.88 \mathrm{~g}$ 's peak acceleration seismic input used on the 1/10-scale

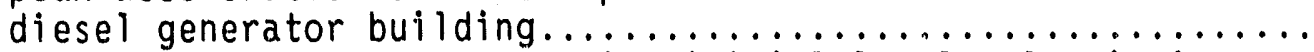

19. Reduced stiffness measured during initial low-level seismic tests of the structures analyzed in the response spectra matching exercise................................... 23

20. Lumped mass model of the 1/10-scale diesel generator building...

21. Comparison of the measured and analytical response spectra for the first floor of the $1 / 10$-scale diesel generator

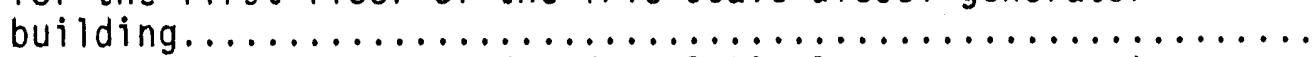

22. Comparison of the measured and analytical response spectra for the second floor of the 1/10-scale diesel generator

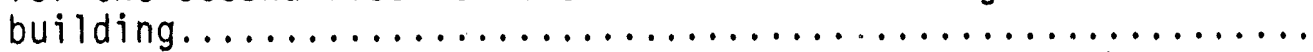

23. Reduction in stiffness as a function of the NBSS for the structures that were quasi-statically cycled...............

\section{LIST OF TABLES}

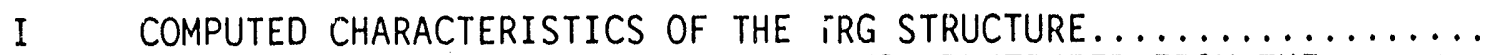

II A COMPARISON OF RESONANT FREQUENCIES IDENTIFIED FROM THE EXPERIMENTAL MODAL ANALYSIS AND RESONANT FREQUENCIES IDENTIFIED FROM THE ANALYTICAL MODAL ANALYSIS FOR LARGE TRG STRUCTURES ............................... 15

II I HYSTERETIC ENERGY LOSSES MEASURED ON TRG $4 \ldots \ldots \ldots \ldots \ldots \ldots \ldots \ldots 19$

IV HYSTERETIC ENERGY LOSSES MEASURED ON TRG $5 \ldots \ldots \ldots \ldots \ldots \ldots \ldots \ldots 19$

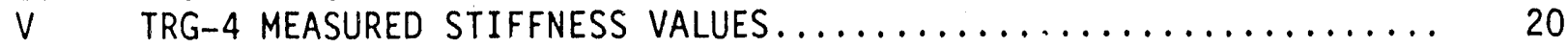

VI ANALYTICAL STIFFNESS VALUES COMPARED WITH MEASURED STIFFNESS VALUES................................. 26

VII RESPONSE OF THE TRG MEMBERS TO QUESTIONS CONCERNING ROGRAM OBJECTIVES ............................... 28

VIII SUMMARY OF LOS ALAMOS TEST STRUCTURE GEOMETRY $\ldots \ldots \ldots \ldots \ldots \ldots . . . \ldots$

IX PREVIOUS STATIC TEST RESULTS ........................... 36

$X$ MEASURED PROPERTIES FOR DYNAMIC TEST SPECIMENS $\ldots \ldots \ldots \ldots \ldots \ldots, 40$

XI RESULTS OF SINE-SWEEP TESTS ON ISOLATED SHEAR WALLS ............ 42

XI I ISOLATED SHEAR WALL MODEL 21 SIMULATED SEISMIC TEST RESULTS..... 43

XIII ISOLATED SHEAR WALL MODEL 23 SIMULATED SEISMIC TEST RESULTS..... 44

XIV ISOLATED SHEAR WALL MODEL 2-2 SIMULATED SEISMIC TEST RESULTS.... 45

XV I/30-SCALE DIESEL GENERATOR BUILDING MODELS DYNAMIC TEST

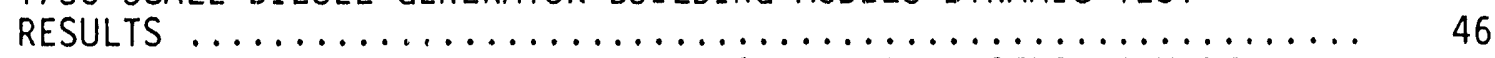

XVI TWO-STORY DIESEL GENERATOR BUILDING SIMULATED SEISMIC TEST RESULTS ......................................... 47

XVII 1/42-SCALE AUXILIARY BUILDING MODEL SIMULATED SEISMIC TEST

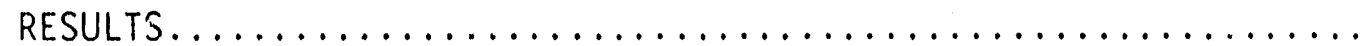

XVIII A COMPARISON OF RESONANT FREQUENCIES IDENTIFIED FROM THE EXPERIMENTAL MODAL ANALYIS AND RESONANT FREQUENCIES IDENTIFIED FROM THE ANALYTICAL MODAL ANALYSIS FOR ALL THE

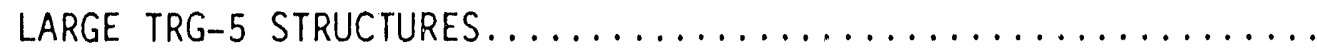




\title{
THE SEISMIC CATEGORY I STRUCTURES PROGRAM \\ RESULTS FOR FY 1987
}

by

\author{
Charles R. Farrar \\ Joel G. Bennett \\ Wade E. Dunwoody \\ and William E. Baker
}

\section{INTRODUCTION}

The Seismic Category I Structures Program is being carried out at the Los Alamos National Laboratory under sponsorship of the U.S. Nuclear Regulatory Commission (NRC), Office of Nuclear Regulatory Research. Its objective is to investigate the dynamic response of Seismic Category I reinforced concrete structures (exclusive of containment) that are subjected to seismic loads beyond their design basis. The program, as originally conceived, is a combined experimental/analytical investigation with heavy emphasis on the experiment component to establish a good data base. A number of meetings and interactions with the NRC staff have led to a set of specific program objectives, which are as follows:

1. Address the seismic response of reinforced concrete Category I structures other than containments;

2. Develop experimental data for determining the sensitivity of structural behavior in the elastic and inelastic response range of Category I structures to variations in configuration, design practices, and earthquake loading;

3. Develop experimental data to enable validation of computer programs used to predict the behavior of Category I structures during earthquake motions that cause elastic and inelastic responses; 
4. Identify floor response spectra changes that occur during earthquake motions that cause elastic and inelastic structural responses; and

5. Develop a method for representing damping in the inelastic range, and demonstrate how damping changes when structural response goes from the elastic to the inelastic ranges.

The prevailing feature of the typical structure under investigation is that shear rather than flexure is dominant, that is the ratio of displacement values calculated from terms identified with shear deformation to the values contributed from bending deformation is one or greater. These buildings are therefore called "shear wall" structures. The background of the program and its status leading to the work reported here will briefly be summarized below.

\section{FY 1980 TO FY 1986 ACTIVITIES}

The Seismic Category I Structures Program began in FY 1980 with an investigation that identified the typical nuclear shear wall structure and its characteristics (stiffnesses, frequencies, etc.) as being the most important and least understood seismic resisting structure. A combined experimentall analytical plan for investigation of the dynamic behavior of these structures was laid out as described in Ref. 1. During the first phase, the program concentrated on investigating isolated shear wall behavior using small models (1/30 scale, 1-in. wall thickness, see Fig. 1) that could be economically constructed and tested both statically and dynamically. This work is reported on in Ref. 2. During this early phase of the program, a Technical Review Group (TRG), consisting of nationally recognized seismic and concrete experts on nuclear civil structures, was established to both review the progress and make recommendations regarding the technical direction of the program. The recommendations of this group have been evaluated in light of the needs of the NRC and, where possible, have been carefully integrated into the program.

Following the isolated shear wall phase, the program began testing and evaluating three-dimensional (3-D) box-like structures that represented ideaiized diesel generator buildings (see Fig. 2). It was recognized from the outset that scale model testing of concrete structures is a controversial issue in the U.S. civil engineering community. Thus, two sizes of structures were tested in an effort to demonstrate scalability of results. This work is reported on in Refs. 3-5. Other variables of interest, especially the effect 


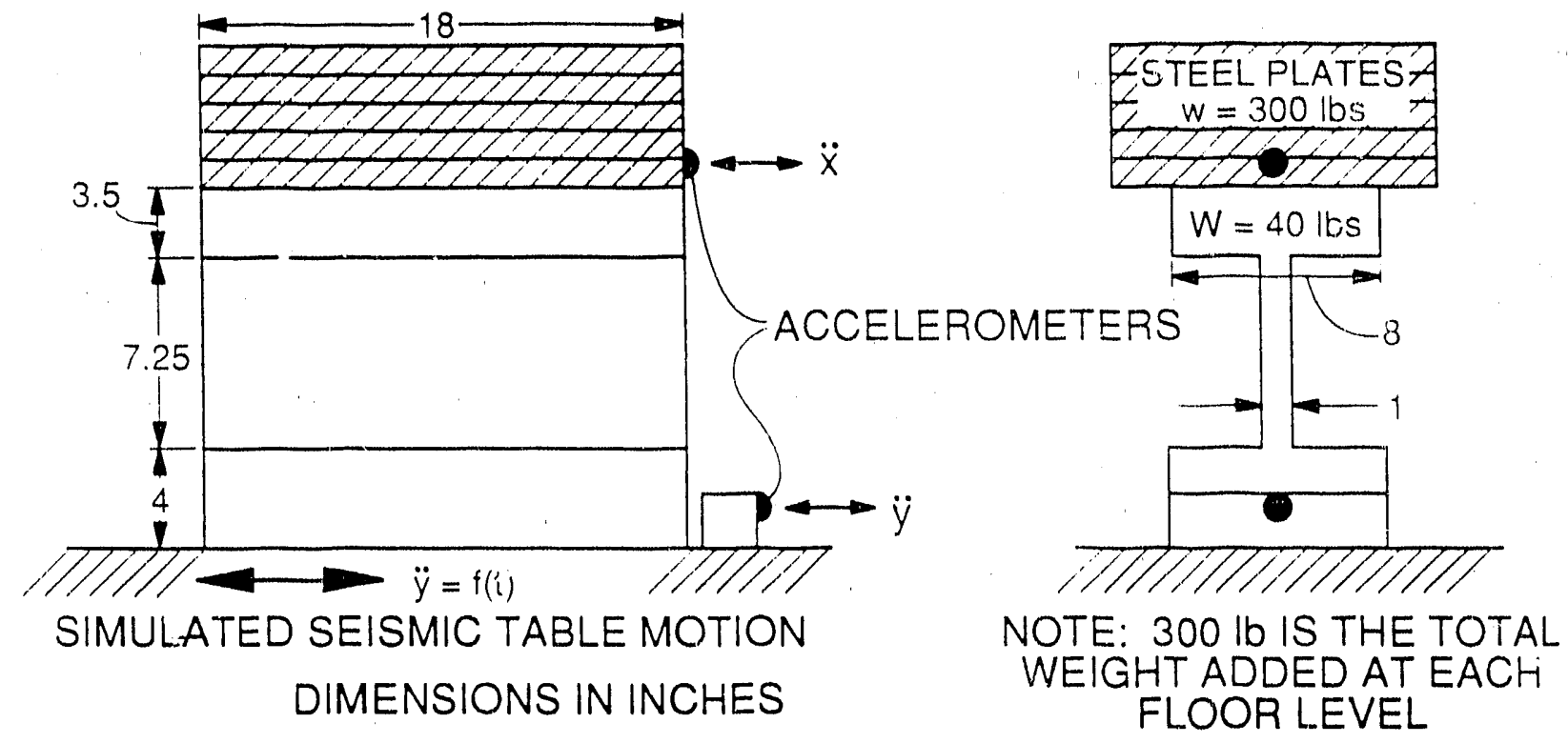

\section{a. ONE-STORY STRUCTURE}

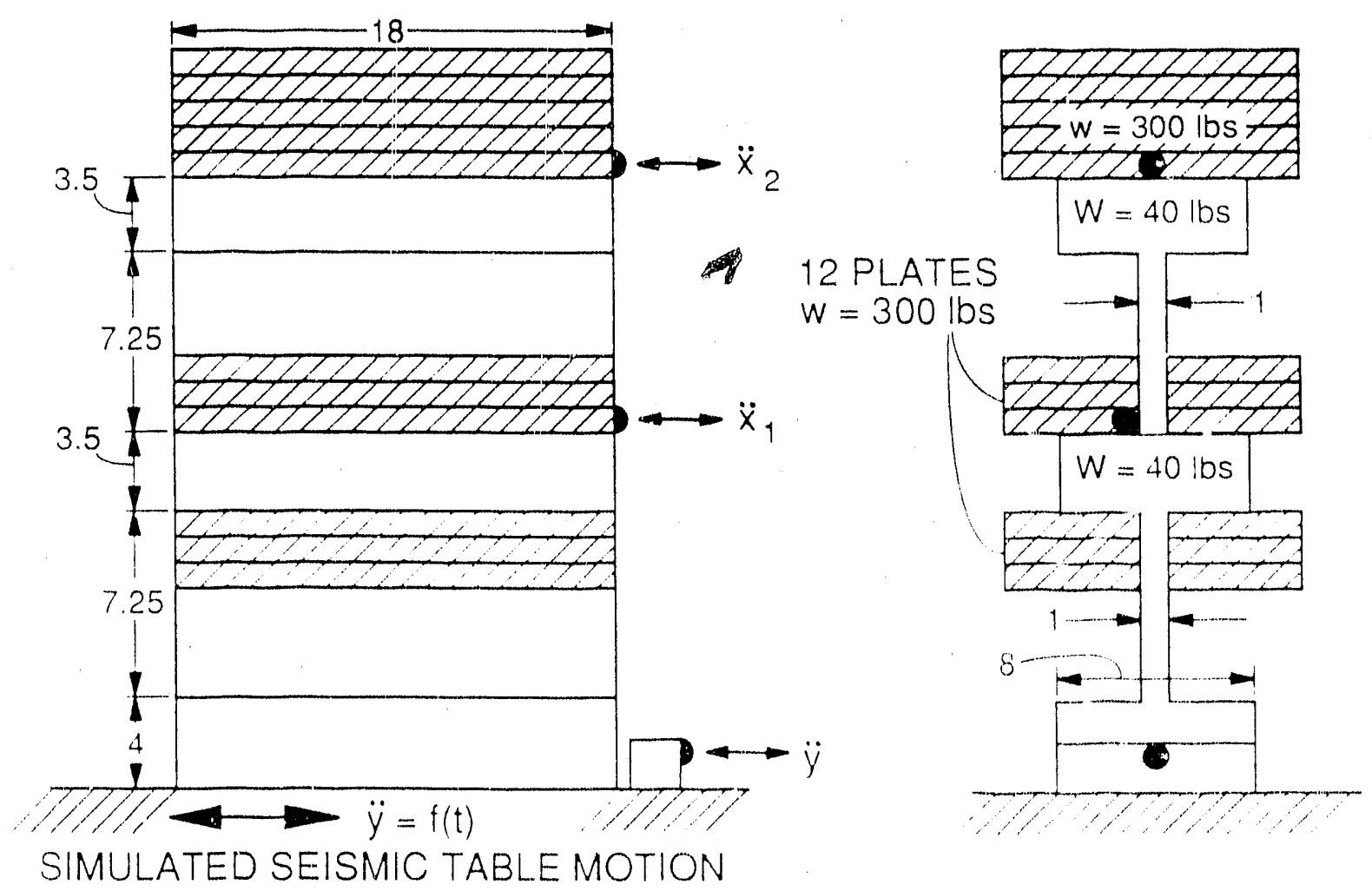

b. TWO-STORY STRUCTURE

Fig. 1. Isolated shear wall structure. 


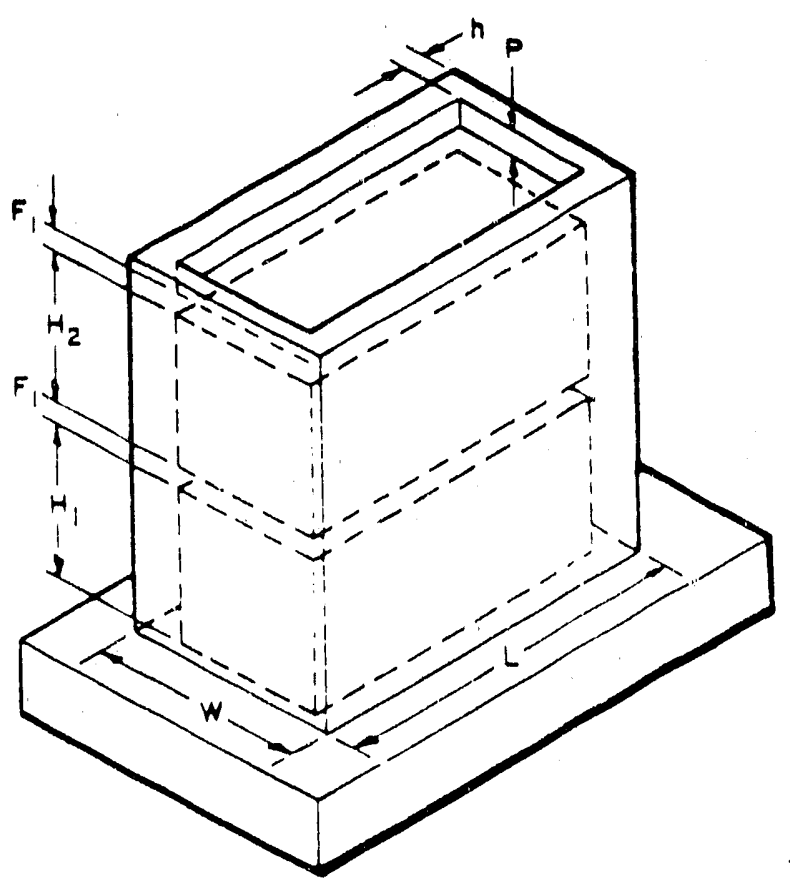

\begin{tabular}{|c|c|c|c|c|c|c|}
\hline & $h_{1} F_{1}, F_{2}$ & $w$ & $L$ & $\mathrm{H}_{1} \& \mathrm{H}_{2}$ & $\mathbf{P}$ & MSTORY"(10) \\
\hline 1/30 SCALE & $1 \mathrm{in.}$ & $10 \mathrm{in.}$ & $18 \mathrm{in.}$ & $7.25 \mathrm{in.}$ & $1 \mathrm{in.}$ & 47.7 \\
\hline 1/10 SCALE & 3 in. & $30 \mathrm{in.}$ & 54 in. & $21.75 \mathrm{in}$ & 3 in. & 1286 \\
\hline PROTOTYPE & $30 \mathrm{in.}$ & $25 \mathrm{ft}$ & $45 \mathrm{ft}$ & $18 \mathrm{ft}, 1.5 \mathrm{in}$. & $30 \mathrm{in.}$ & $1,286,000$ \\
\hline
\end{tabular}

-BASE NOT INCLUDED

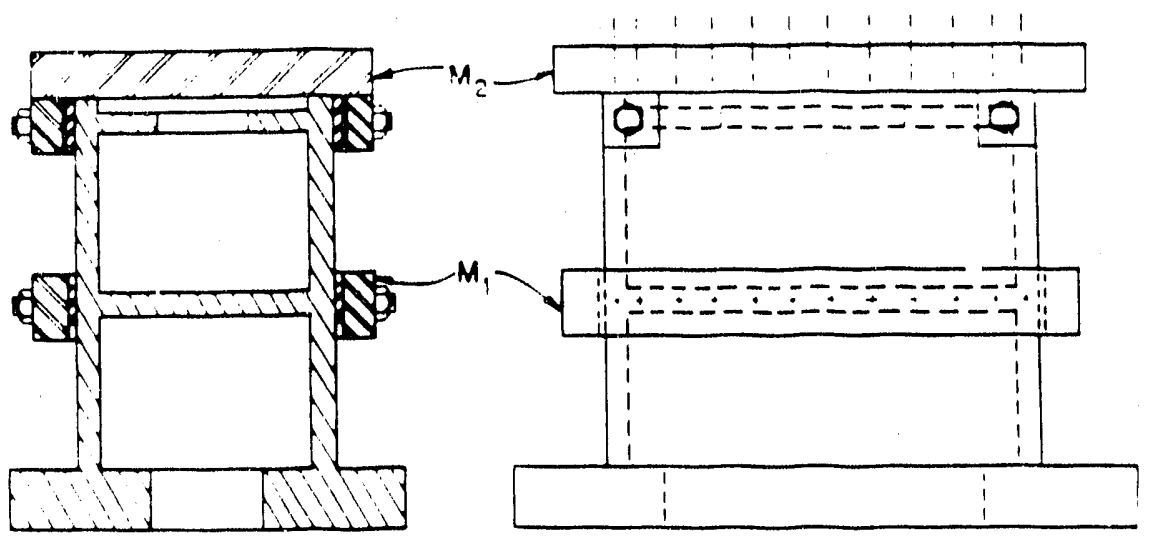

\begin{tabular}{c|c|c|c} 
STRUCTURE & SCALE & $M_{1}$ (lbs) & $M_{2}$ (1bs) \\
\hline $30-10-2$ & $1 / 30$ & 228 & 239 \\
$30-11-2$ & $1 / 30$ & 228 & 231 \\
$30-12-2$ & $1 / 30$ & 236 & 168 \\
CERL 1 & $1 / 10$ & 1285 & 1330 \\
CERL 2 & 1.10 & 1285 & 906
\end{tabular}

Fig. 2. Diesel generator building model. 
of the number of stories, were investigated by constructing, analyzing, and testing small-scale structures representative of a typical three-story auxiliary building shown in Fig. 3. The results obtained from the tests of these structures are given in Ref. 6 .

Although a number of results on items such as aging (cure time), effect of increasing seismic magnitude, etc., have already been ieported, the two most important and consistent conclusions coming out of the data from this program are (1) the scalability of the results between microconcrete models of different sizes was illustrated both in the elastic and inelastic range and (2), the so-called "working load" secant stiffness of the models was lower than the computed uncracked cross-sectional values by a factor of about 4 . The term "working load" is meant as loads that produce stress levels equivalent to at least the operating basis earthquake and up to the safe shutdown earthquake.

During their review of this program, the TRG pointed out the following:

1. Design of prototype nuclear plant structures is normally based on an uncracked cross-section strength-of-materials approach that may or may not use a "stiffness reduction factor" for the concrete, but, if it does, then that factor is never as large as 4.

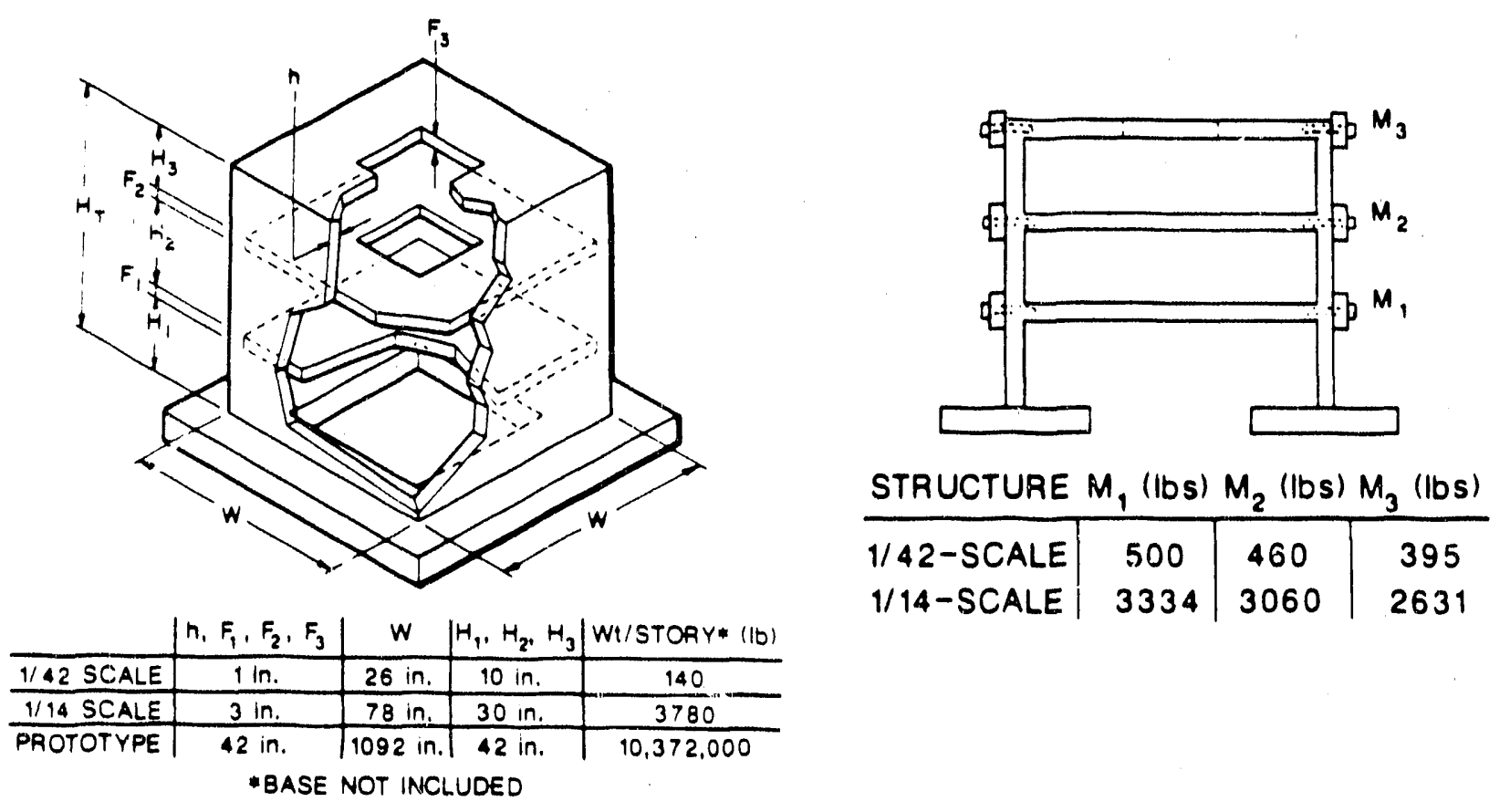

Fig. 3. Three-story auxiliary building model. 
2. Although the structures themselves appear to have adequate reserve margin (even if the stiffness is only $25 \%$ of the theoretical), any piping and attached equipment will have been designed using inappropriate floor response spectra.

3. Given that a nuclear plant structure designed to have a natural response of about $15 \mathrm{~Hz}$ may have a natural frequency of $7.5 \mathrm{~Hz}$ (corresponding to a reduction in stiffness of 4 ), and allowing further that the natural frequency may further decrease because of degrading stiffness, the response of the structure will shift well down into the frequency range for which an earthquake's energy content is the largest. This shifi will result in increased amplification in the floor res;onse spectra at lower frequencies, and this fact potentially has impact on the equipment and piping design response spectra and their margins of safety.

Note that all three points are related to the difference between measured and caiculated stiffnesses of these structures.

Having made these observations, one can think of several questions. Can the previous experimental data taxen on microconcrete models be observed on prototype structures as well? What is the appropriate value of the stiffness that should be used in the design and for component response spectra computations of these structures? Should it be a function of load level? Have the equipment and piping in existing buildings been designed to inappropriate response spectra? What steps shculd be taken to evaluate the reduced stiffness for existing structures?

Thus, starting in FY 1985, the primary Program emphasis was to assure credibility of previous experimental work by beginning to resolve the difference between the analytical and theoretical stiffness that came to be called "stiffness difference" issue. The TRG for this program believed that this important issue should be addressed before other program objectives could be accomplished.

For these stiffness-related concerns, it was agreed that a series of credibility experiments would be carried out using both large- and small-scale structures. For the large-scale structure, the TRG set limitations on the design parameters. Their recommended "ideal" structure characteristics, in order of decreasing priority, were as follows: 
1. Maximum predicted bending and shear mode natural frequency $\leq 30$ itz,

2. minimum wall thickness $=4$ in.,

3. Height-to-depth ratio of shear wall $\leq 1$,

4. Actual No. 3 rebar to be used for reinforcing,

5. Realistic material to be used for aggregate,

6. 0.1 to $1 \%$ steel $(0.3 \%$ each face, each direction ideally) to be used, and

7. Water-blasted construction joints will ensure good aggregate frictional interlock.

The TRG structure shown in Fig. 4 was specifically designed to meet these requirements. The computed characteristics of this structure are given in Table I. However, it was decided that, before constructing this relatively large and expensive (both to build and especially to test) structure, a smaller, 1/4-scale model of the proposed structure should be desicned, constructed, and tested.

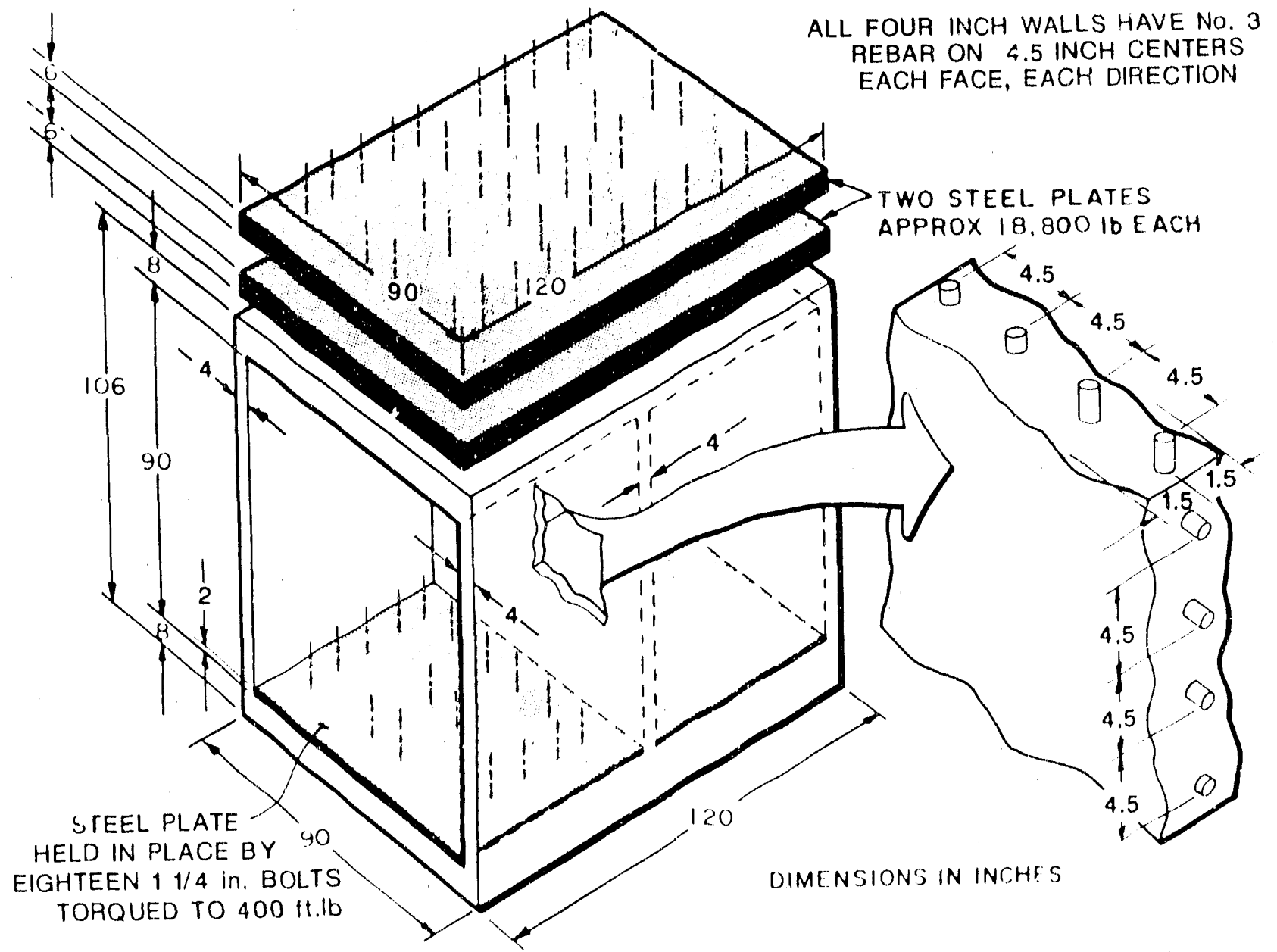

Fig. 4. TRG-3-4 $(1.0,0.60)$ and $T R G-5-4(1.0,0.60)$. 
TABLE I

COMPUTED CHARACTERISTICS OF THE TRG STRUCTURE

$\begin{aligned} \text { Wall thickness } & =4 \mathrm{in.} \\ \text { Cross-section moment of inertia } & =2.06 \times 10^{6} \mathrm{in.} 4 \\ \text { Effective shear area } & =379 \mathrm{in.}^{2} \\ \text { Area total (plan view) } & =1288 \mathrm{in.} \\ \text { Bending stiffness } & =2.5 \times 10^{7} \mathrm{lb} / \mathrm{in} . \\ \text { Shear stiffness } & =5.3 \times 10^{6} \mathrm{ib} / \mathrm{in} . \\ \text { Total stiffness } & =4.2 \times 10^{6} \mathrm{ib} / \mathrm{in} . \\ \text { Max dead weight normal stress } & =42 \mathrm{psi} \\ \text { Total concrete voiume } & =6 \text { cubic yards } \\ \text { Total added weight } & =37,0001 \mathrm{~b} \\ \text { Total weight } & =61,0001 \mathrm{~b}\end{aligned}$

The purposes of this 1/4-scale microconcrete model were as follows: (1) by applying the same principles of analysis and design, and the same construction practices as were used in the previous work, the scalability of the results of a microconcrete model to a protcitype structure of "real" concrete could be investigated; ( $\because$; conclusions (baied on calculations) concerning the model and prototype torsional response, illdividual wall frequencies, out-ofplane bending, and other features that affect the response of the large TRG structure can be confirmed cn a less expensive test structure; and (3), instrumentation and other data acquisition requirements could be worked out before the larger-scale tests. The construction, analysis, testing, (low level static and random base excitation followed by seismic testing to failure) and results from the investigation of the 1/4-scale microconcrete model of the TRG structure are discussed in Ref. 7. Results for the prototype TRG structure using comparable testing procedures are discussed in Ref. 8 . Form these results it tentatively appeared that

1. If either microconcrete or real concrete structures are carefully constructed and tested, their effective initial low-load level stiffness can be in the neighborhood of $50 \%$ of the value predicted by a mechanics of material caiculation using a concrete modulus of $57,000 \sqrt{f}_{c}$. At working loads, the stiffness values can be as $10 \mathrm{w}$ as $25 \%$ of the mechanics of material value.

2. At the low-load level, a microconcrete structure can serve as an adequate model for a real concrete structure.

3. The way in which real concrete structure's stiffness degrades at higher load-levels cannot be established from the tests reported in Ref. 8. 
However, during these tests, the real concrete structure appears to have suffered more stiffness loss than would be predicted by the microconcrete model.

The aithors feel strongly that any further tests to establish the dynamic scalability between "micro" and "real" concrete at higher-load levels should not be conducted using large complete structures because of the inadequacy (in capacity and control) of available dynamic test facllities.

New experimental and analytical activities were initiated in FY 1997 iu further address the reduced stiffness issue and to address program objectives in general. Also, the investigators for this program have worked closely with several code committees in FY 1987 to incorporate the results of this program into current industry standard de-ign and analysis codes. The following sections of this report will summarize these activities. Appendix A sumarizes all the data related to shear wall stiliness that has been obtained " $n$ this program.

\section{FY 1987 EXPERIMENTAL ACTIVITIES}

Because of findings from previous tests and the continued skepticism of certain members of the TRG concerning the reduced stiffness measured during these tests, a new series of tests was suggested by the TRG to further investigate the reduced stiffness issue. This series consisted of quasi-static load cycle tests on structures with a cross-sectional gesmetry similar to the prototype TRG structure previously mentioned. The nomenclature used to distinguish these structures is as follows:

TRG-No.-Wt (AR,\%R), sometimes abbreviated TRG-No.,

where TRG is the designation for the series of structures designed and tested using guidance from the Program's Technical Review Group, a group of nationally recognized nuclear structural experts,

No. is the sequence number in the series,

Wt is the shear wall thickness,

$A R$ is the height-to-length spect ratio of the shear wall, and

$\% R$ is total percentage by area of steel reinforcing in both directions. 
Thus the prototype TRG structure reported in Ref. 8 would be referred to as TRG-3-4 (1.0, 0.6). The test structures for FY 1987 were to be constructed with different aspect ratios and reinforcement percentages so that variations in these parameters that exist in actual category I structures could be taken into account in the experiments, and the sensitivity to these variables could be :dentified. These structures were TRG-4-6 $(1.0,0.25)$, TRG-5-4 $(1.0,0.6)$ and TRG-6-6 $(0.27,0.50)$ and are shown in Figs. 5, 4, 6 respectively. Note that TRG-5 was identical in geometry and reinforcement to TRG-3. A detailed sumirizy of these structures' construction, testing, and results can be found in Ref. 9 and subsequent reports to be issued by Los Alamos.

One of the purposes of these tests was to deturmine if, at equivalent stress levels, a reducion in stiffness occurs during static testing that is similar to that observed during dynamic testing. In addition, the structures

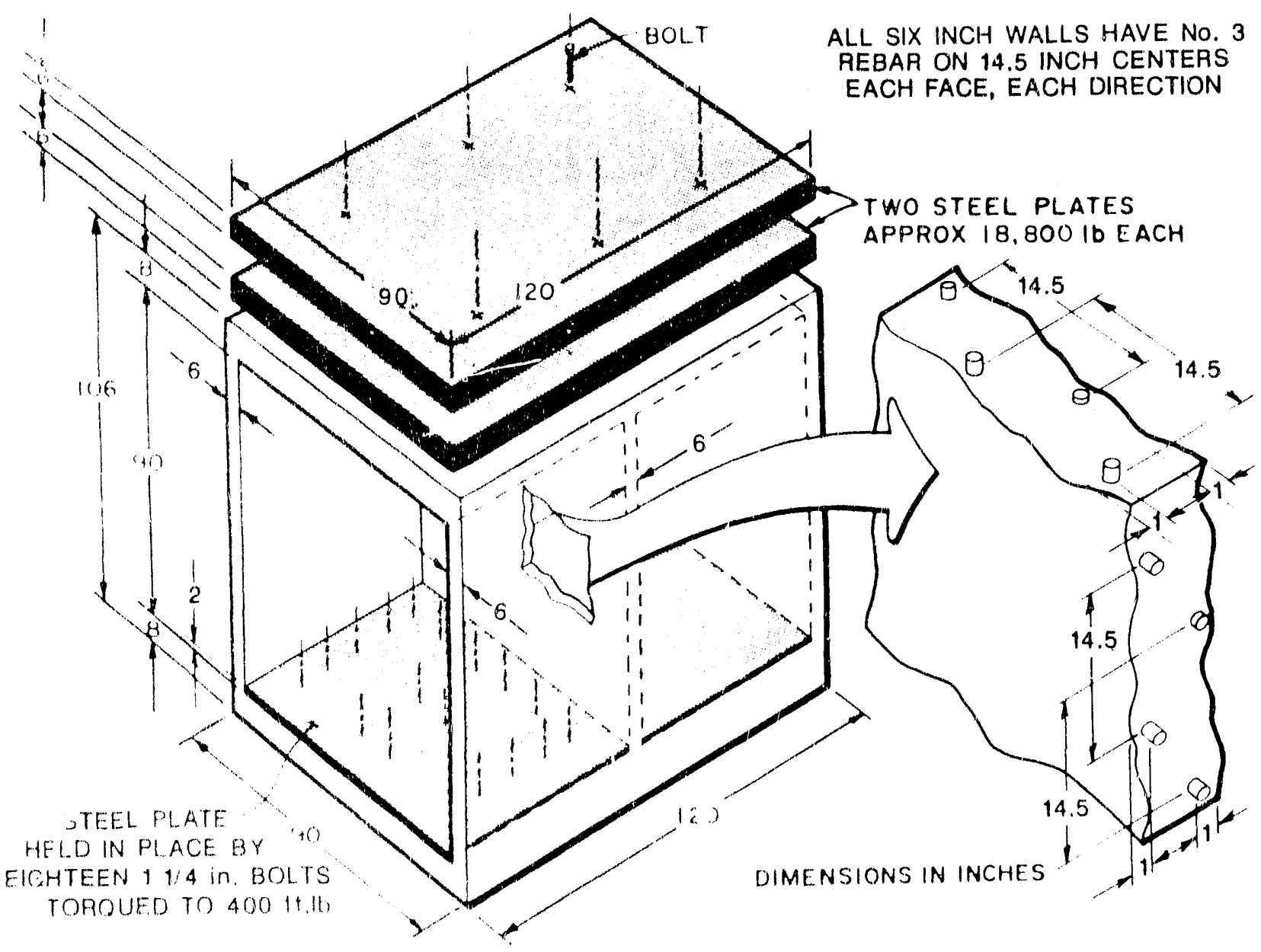




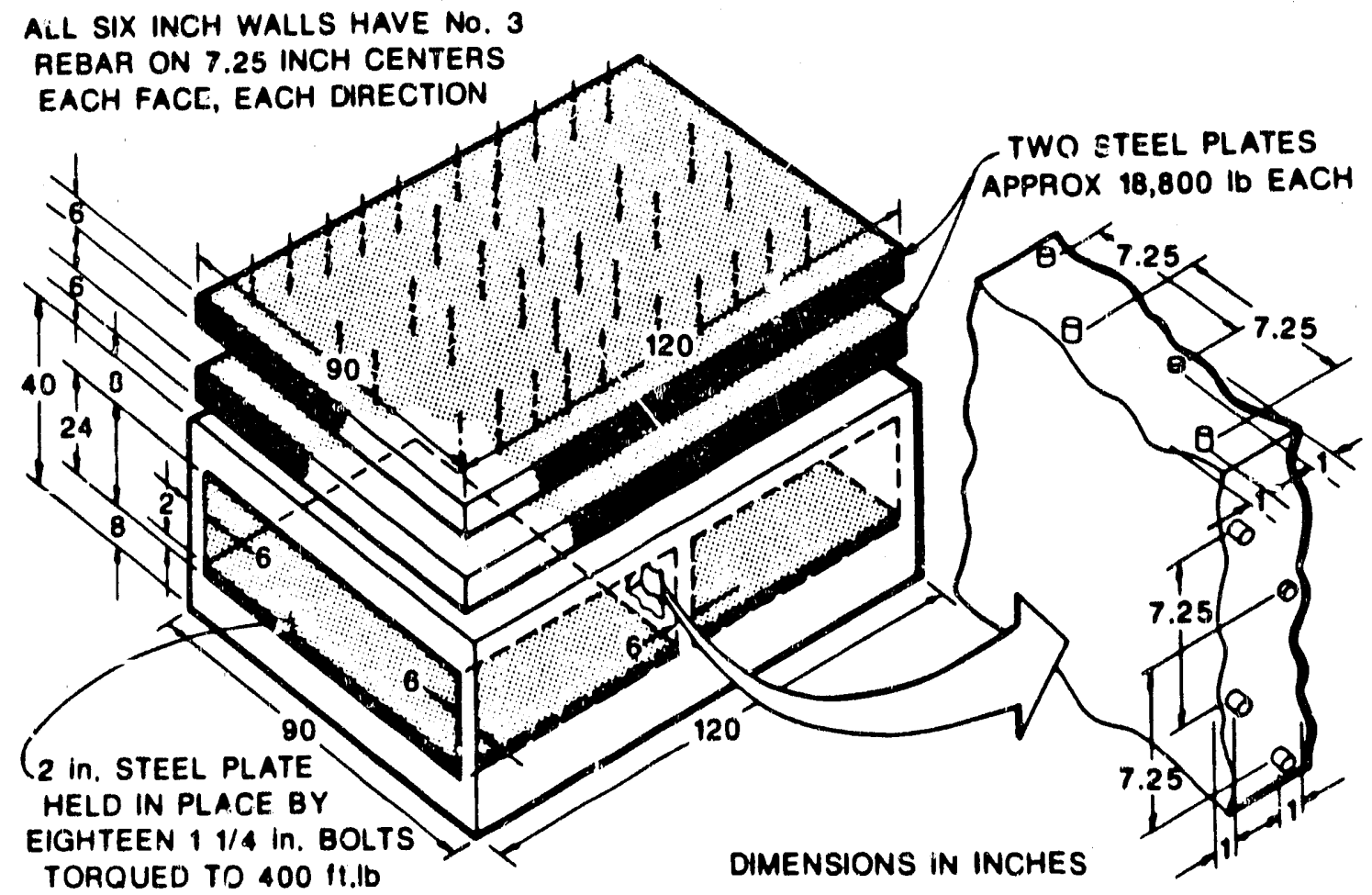

Fig. 6. TRG-6-6 $(0.27,0.50)$.

were to be instrumented so that the contribution to bending stiffness of the flexural boundary elements (shear walls in orthogonal planes) could be assessed. The structures were also instrumented so that the shear and bending contributions to the total stiffness could be measured separately. The separation of shear and bending components of stiffness was intended to provide additional information concerning the mechanism for the reduction in stiffness. Also, these structures were to be constructed and tested in the same facility so that a minimal amount of handling would be required. The minimal handling criteria was to ensure that the reductions in stiffness, if any, were not caused by damage incurred during the shipping process to a remote testing facility.

Before the concrete was placed, weldable strain gages had been attached at various locations on the reinforcement. After the test structures had been placed and had cured for a minimum of 28 days, an ultrasonic inspection was made to determine if voids existed. When voids were found, they wire repaired with a cernent-sand filler. Figure 7 shows the completed TRG-4-6 $(1.0,0.25)$ structure mounted on the load frame. 


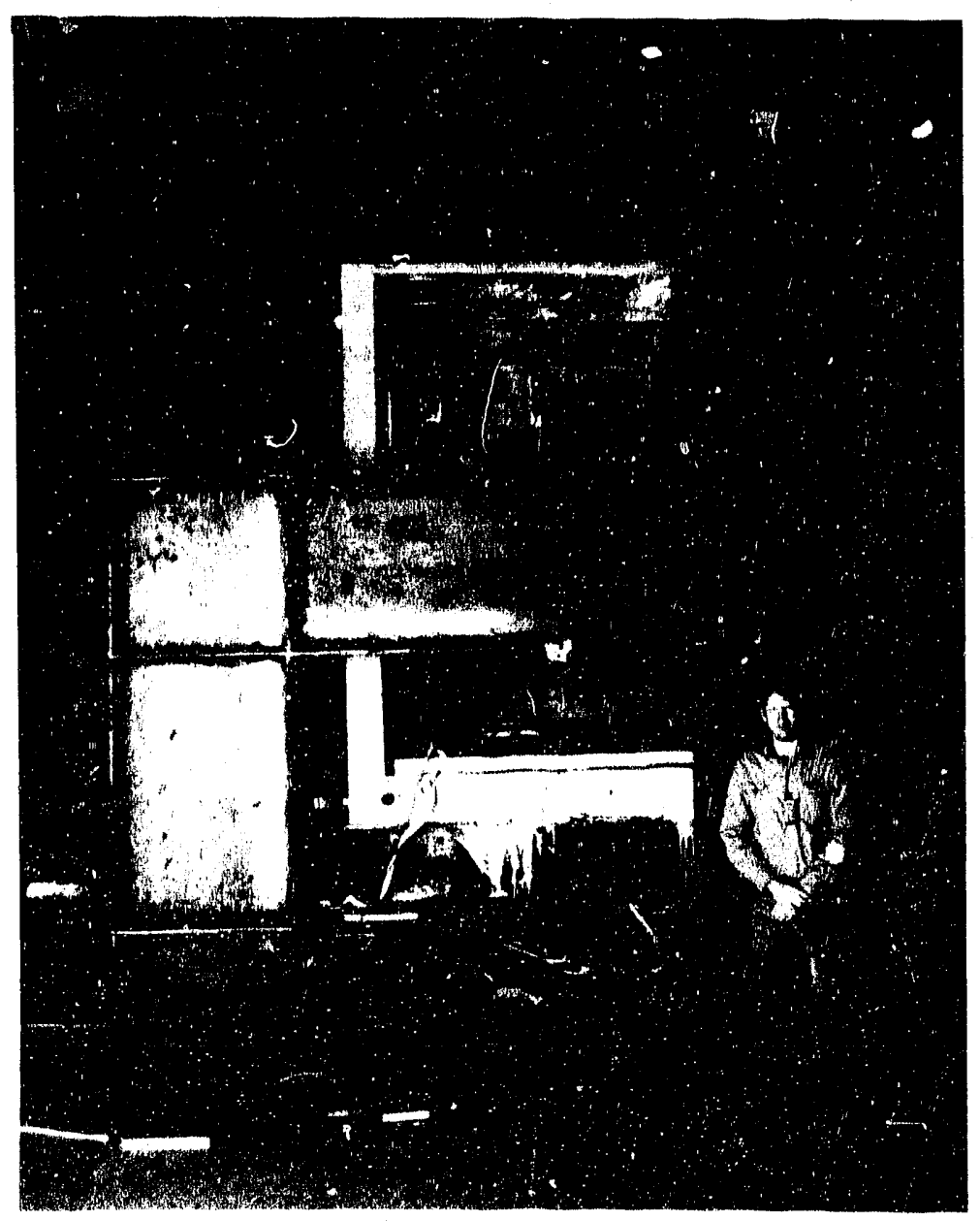

Fig. 7. TRG-4 mounted on the load frame.

Before the quasi-static load cycling was performed, an experimental modal analysis was performed to characterize the dynamic properties (mode shapes, resonant frequencies) of the structures. These properties were then compared with similar properties determined from a linear (uncracked) finite element analysis of the structures. This comparison provided an indirect method to assess the as-built stiffness of the structures while introducing a mirimum amount of damage into the structure. Figures 8 and 9 show a typical mooral test setup. The air bearings used to simulate free-boundary conditions are 


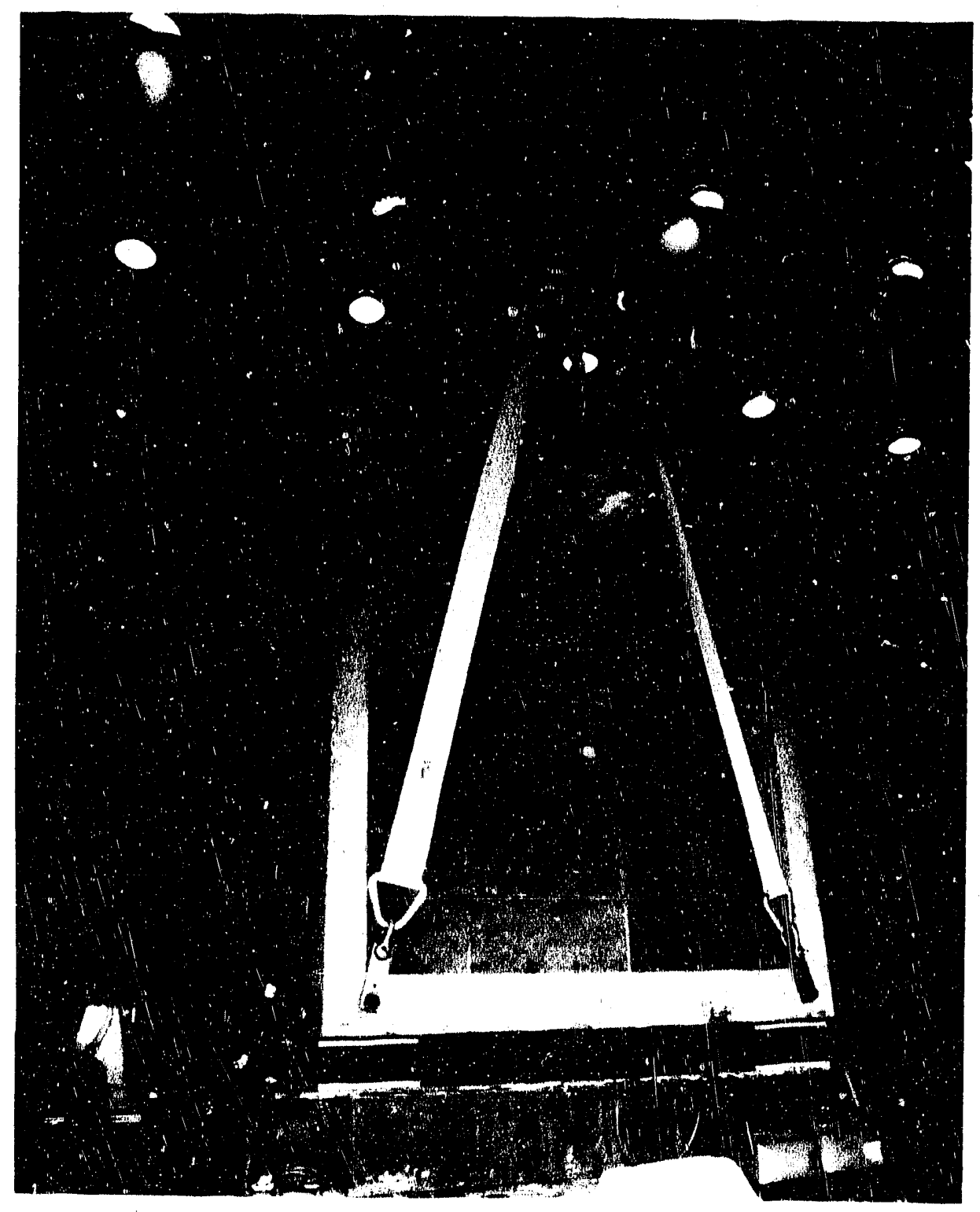

Fig. 8. TRG-4 mounted on air-bearings

for experimental modal analysis.

shown in Fig. 8 and the electrodynamic shaker used to excite the structure is shown in Fig. 9. A typical comparison beiveen an experimentally measured mode shape and the corresponding mode determined by finite element analysis is shown in Fig. 10 for TRG-4-6 (1.0,0.25). Table II compares the measured and analytical resonant frequencies determined for $T R G-4,5$, and 6 . 


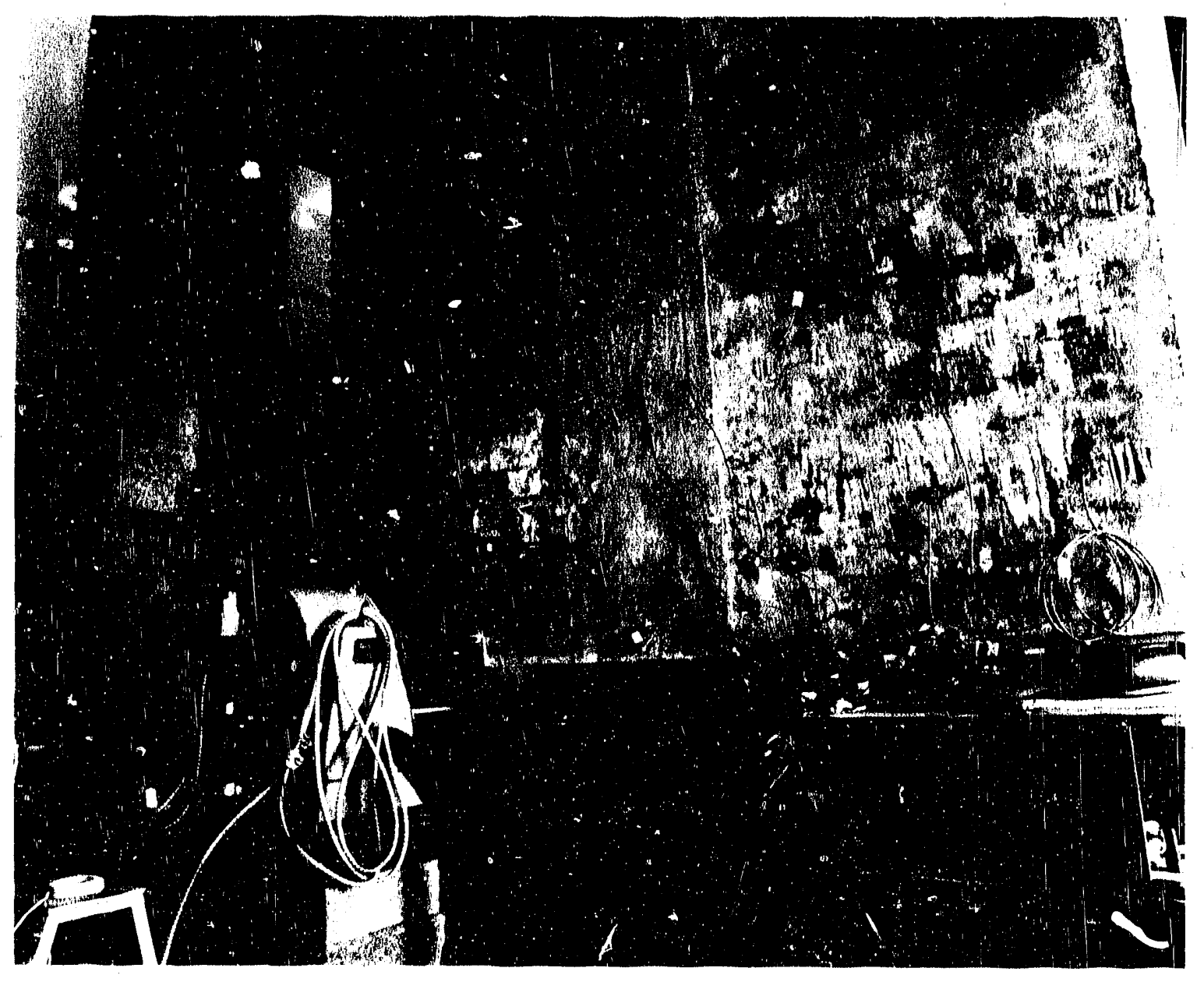

Fig. 9. Electrodynamic shaker used to excite the structures during the experimental modal analysis.

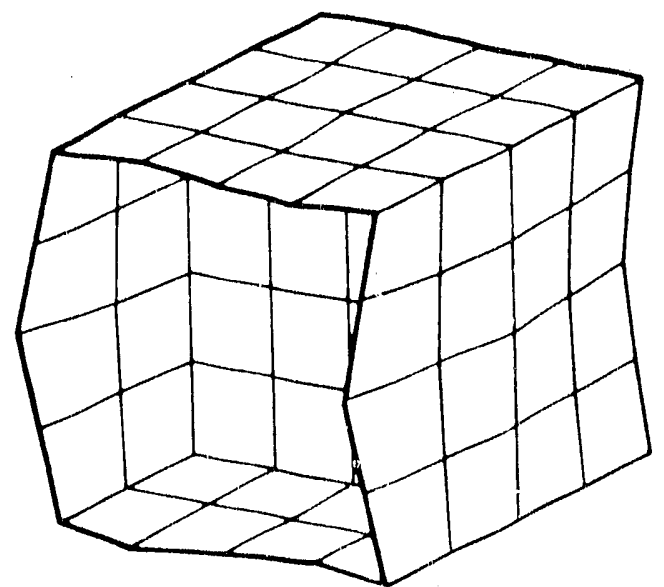

MODE NO. 5

EXPERIMENTALLY DETERMINE[I

$$
\text { Freq }=111 \mathrm{~Hz}
$$

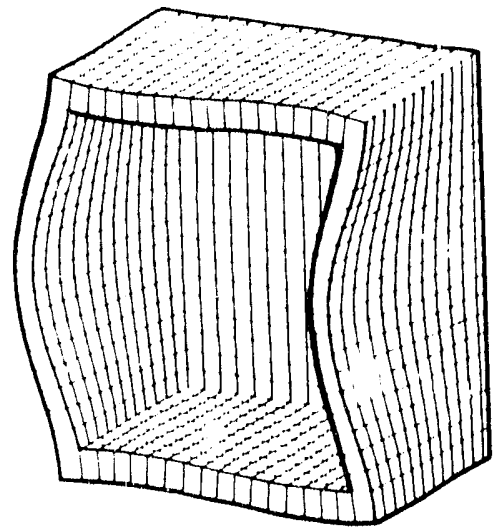

MODE NO. 5

DETERMINED WITH ABAQUS

F.E. PROGRAM

Freq $=111 \mathrm{~Hz}$

Fig. 10. Comparison of a mode shape identified during the experimental modal analysis with a mode shape determined by finite element analysis. 
TABLE II

A COMPARISON OF RESONANT FREQUENCIES IDENTIFIED FROM THE EXPERIMENTAL MODAL ANALYSIS AND THE RESONANT FREQUENCIES IDENTIFIED FROM THE ANALYTICAL MODAL ANALYSIS FOR THE LARGE TRG-STRUCTURES

Mode

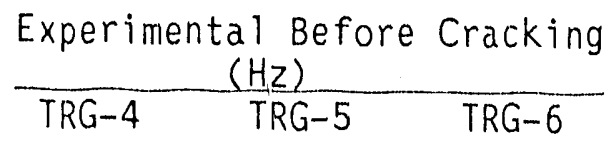

$(\mathrm{Hz})$

$$
37.1
$$

79.2

88.3

100.0

111.0

122.0

141.0

172.0

$\star$

$\star$
31.9

67.0

73.9

77.8

84.4

117.0

126.0

159.0

170.0

198.0

92.9
123.4
136.4
179.2
208.8
$\star$
$\star$
$\star$
$\star$
$\star$
$\star$
$\star$
$\star$

Linear Finite Element Analysis

$(\mathrm{Hz})$

TRG-4 TRG-5 TRG-5

36.3

77.8

86.0

102.0

111.0

120.0

130.0

136.0

143.0

154.0

162.0 $\begin{array}{ll}31.9 & 91.8\end{array}$

72.3

79.7

88.4

95.2

112.0

113.0

129.0

133.0

135.0

152.0

196.0

230.0

125.1

134.9

172.6

196.2

206.1
$-$

$-$

\section{* Not identified.}

The actual quasi-static load cycle testing was similar for each structure. Displacement transducer locations for a typical test are shown in Fig. 11. The load histories for the three structures are shown in Figs. 12-14. As can be seen in Fig. 14, TRG-6-6 $(0.27,0.50)$ was cycled numerous times at different load levels to see if stiffness would reduce with the number of load cycles. A typical load-displacement response curve is shown for $\operatorname{TRG}-5-4(1.0,0.6)$ in Fig. 15 and the final crack patterns for inis structure are shown in Fig. 16. In general, the relative displacement interior gages gave the best results, but on TRG-6-6 $(0.27,0.50)$ the instrumentation system was at its limits because of the low aspect ratio of this structure and its very stiff nature.

Hysteretic energy losses were measured during the static cyclic testing and these losses were used to evaluate equivalent viscous damping ratios. Tables III and IV summarize the damping ratios obtained for TRG-4 and -5 . Because the TRG-6 structure was so stiff, the results from the displacement transducers showed evidence of "lost motion." That is why no hysteresis evaluation was possible for this model. 

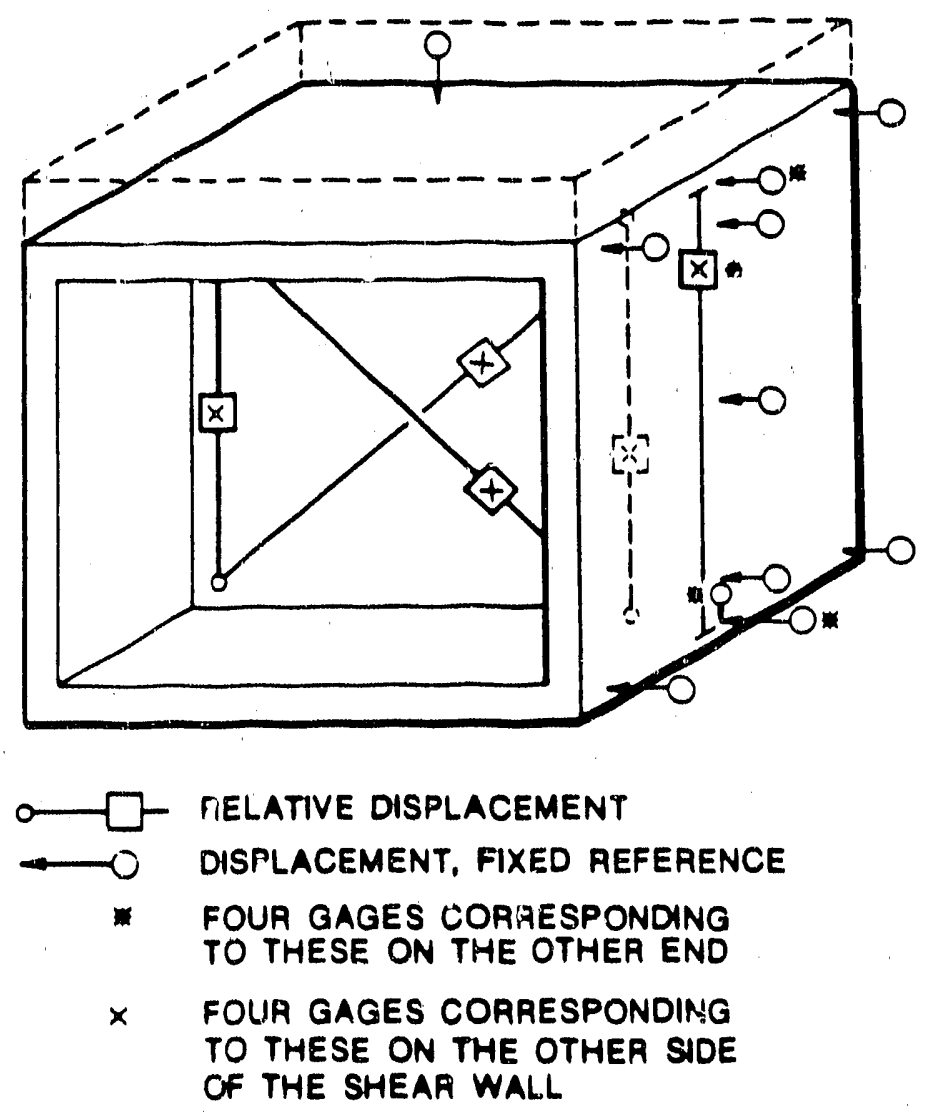

Fig. 11. Location of displacement transducers used during static cyclic testing.

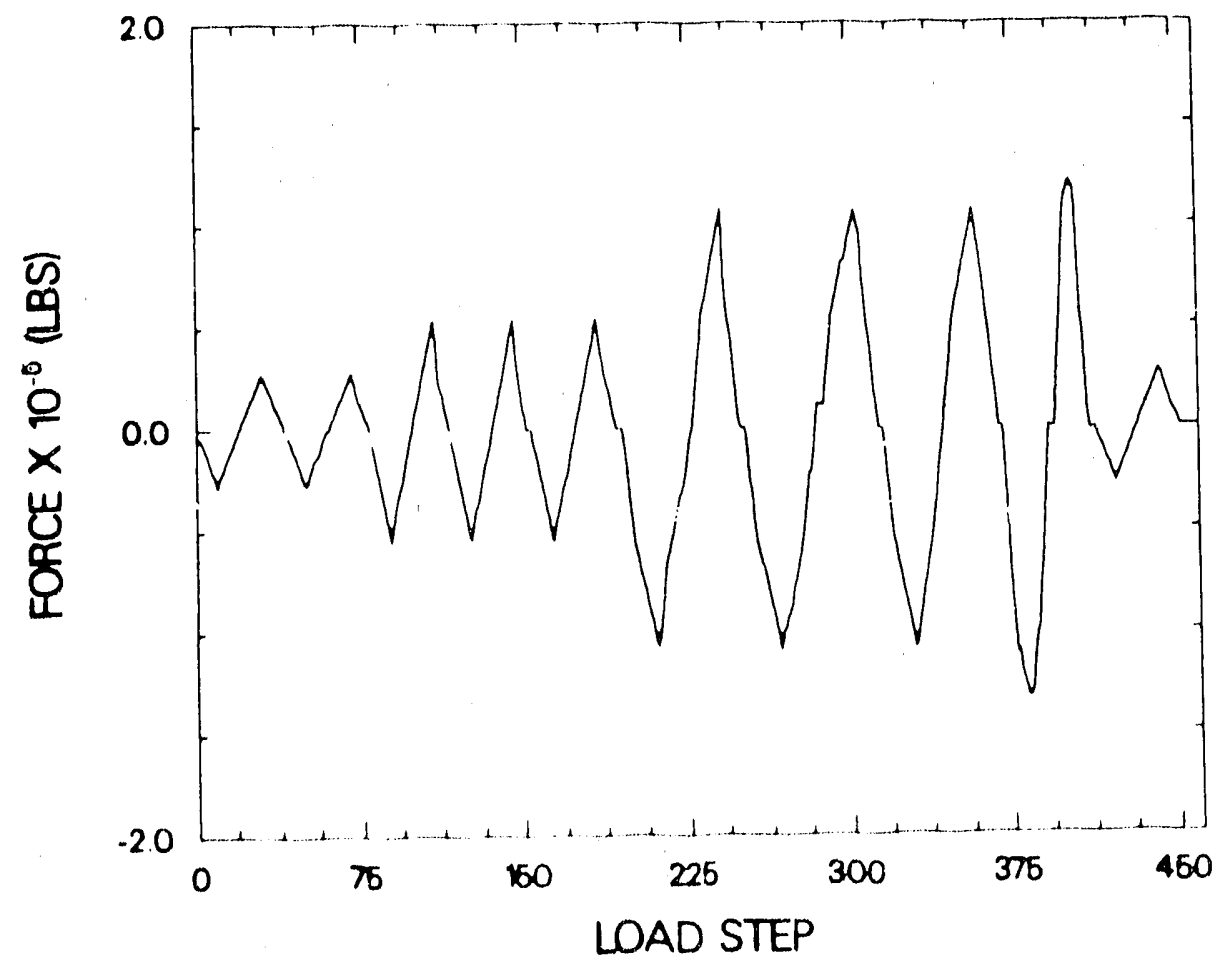

Fig. 12. Load history for RRG-4. 


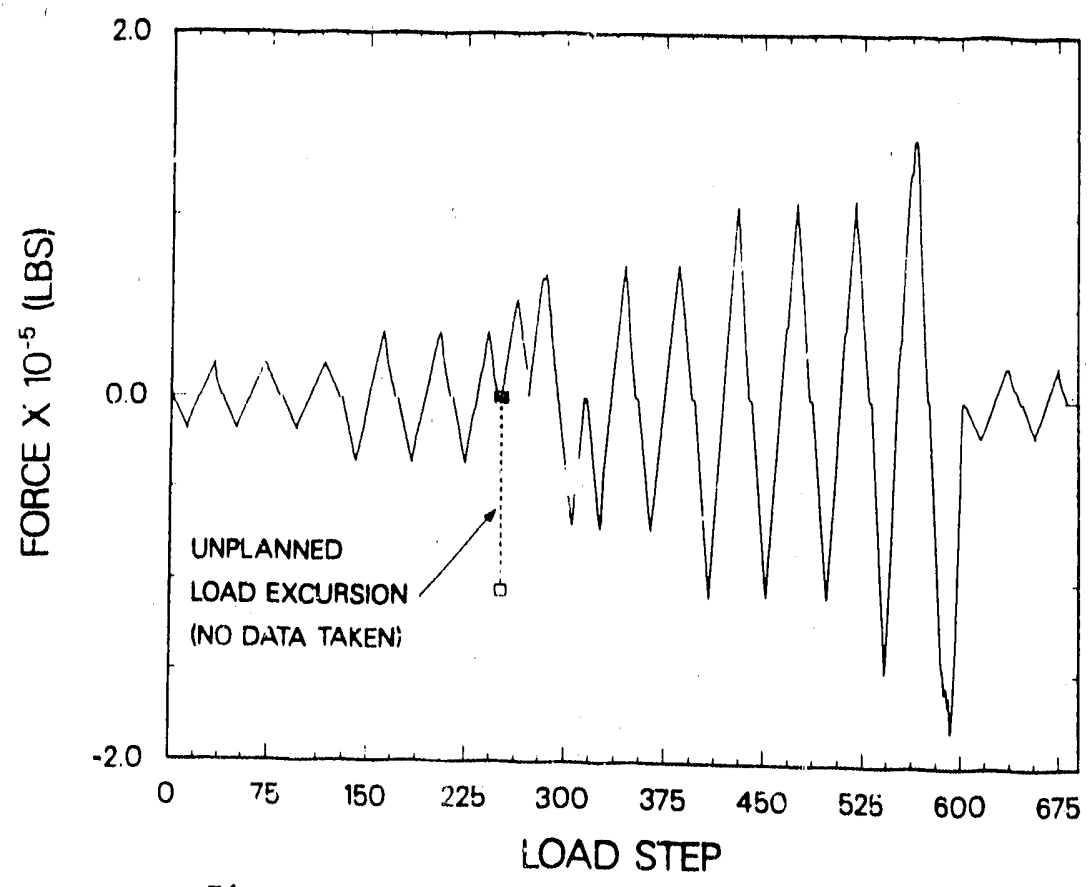

Fig. 13. Load history for TRG -5 .

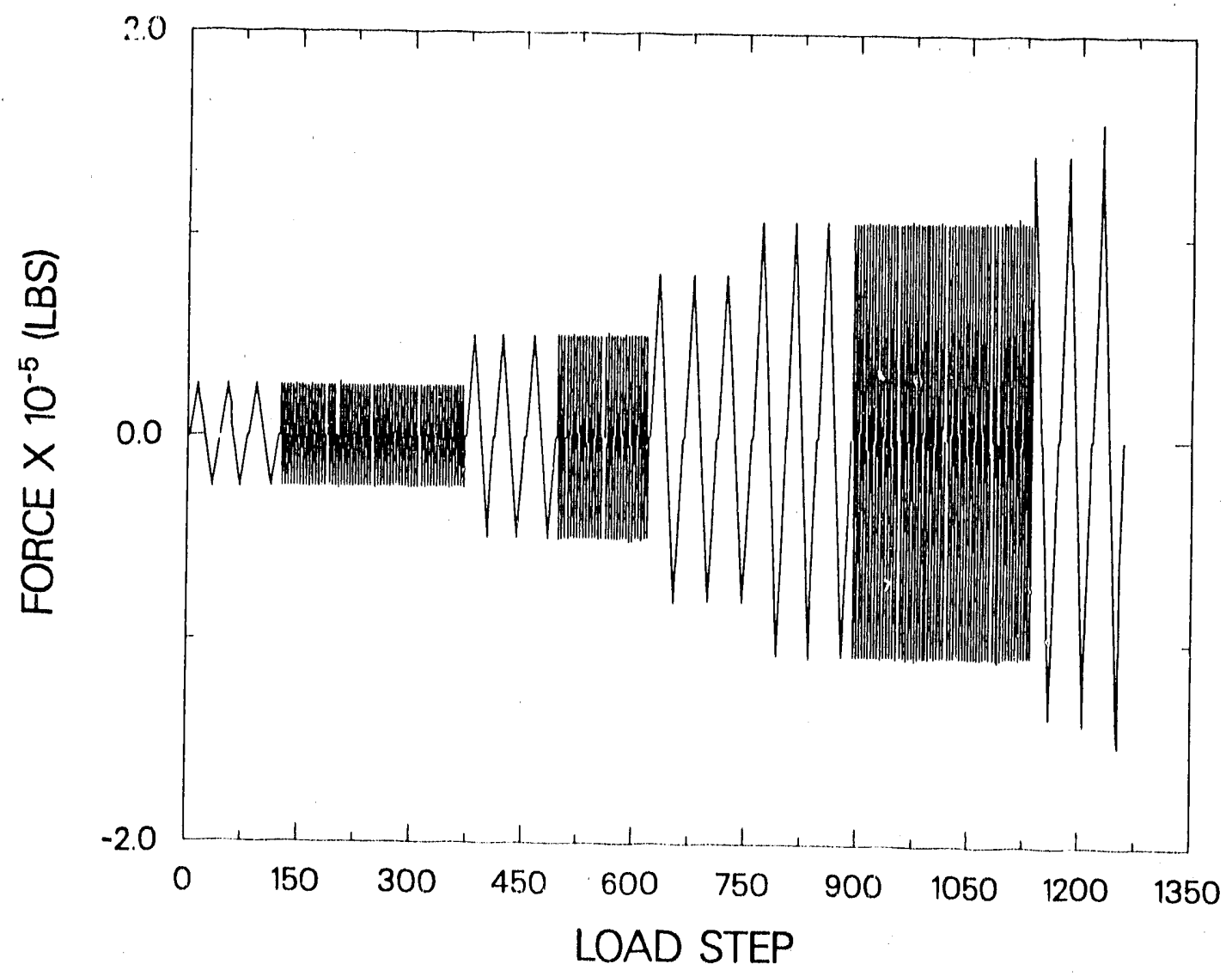

Fig. 14. Load history for TRG-6. 


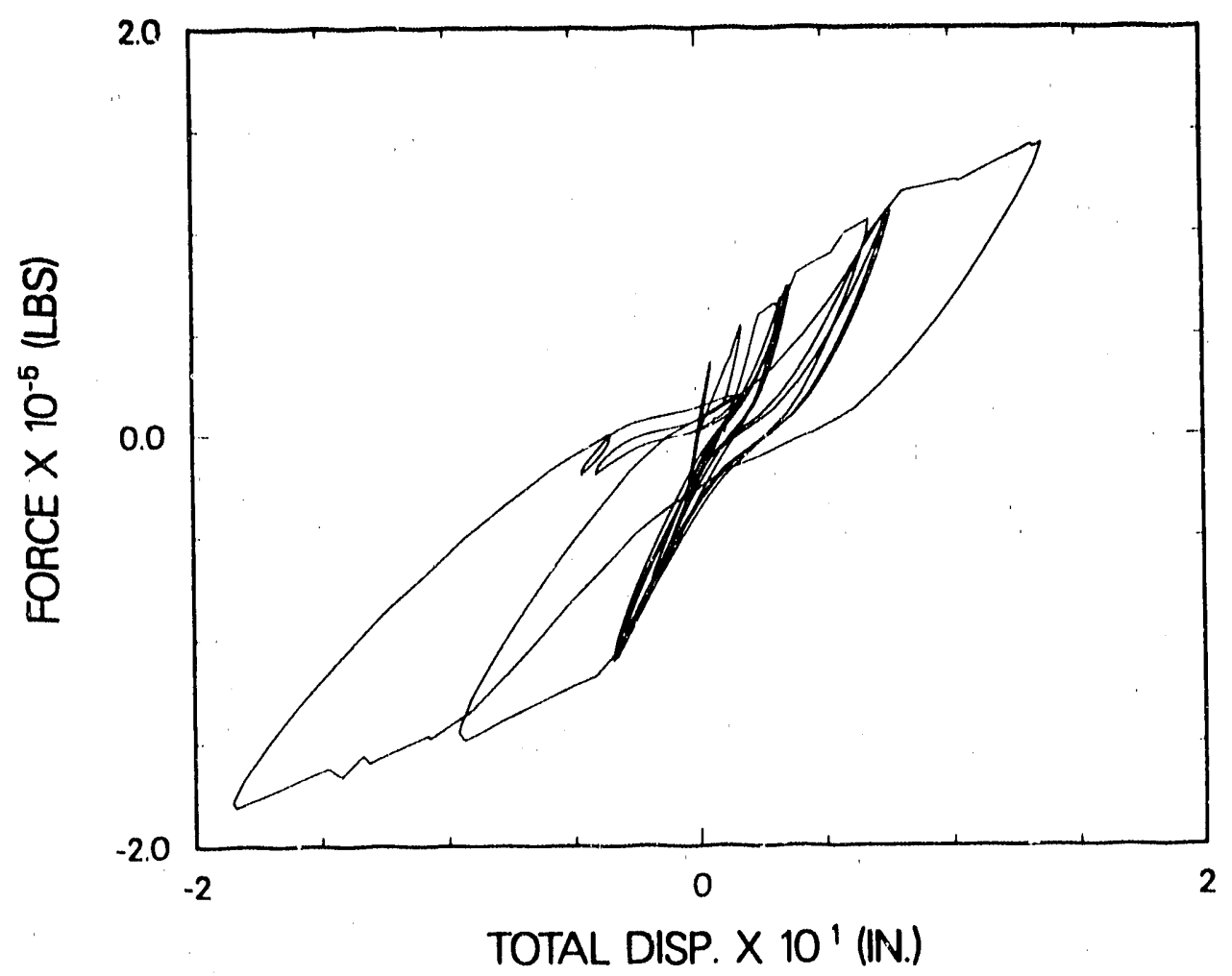

Fig. 15. Load displacement response of TRG-5.

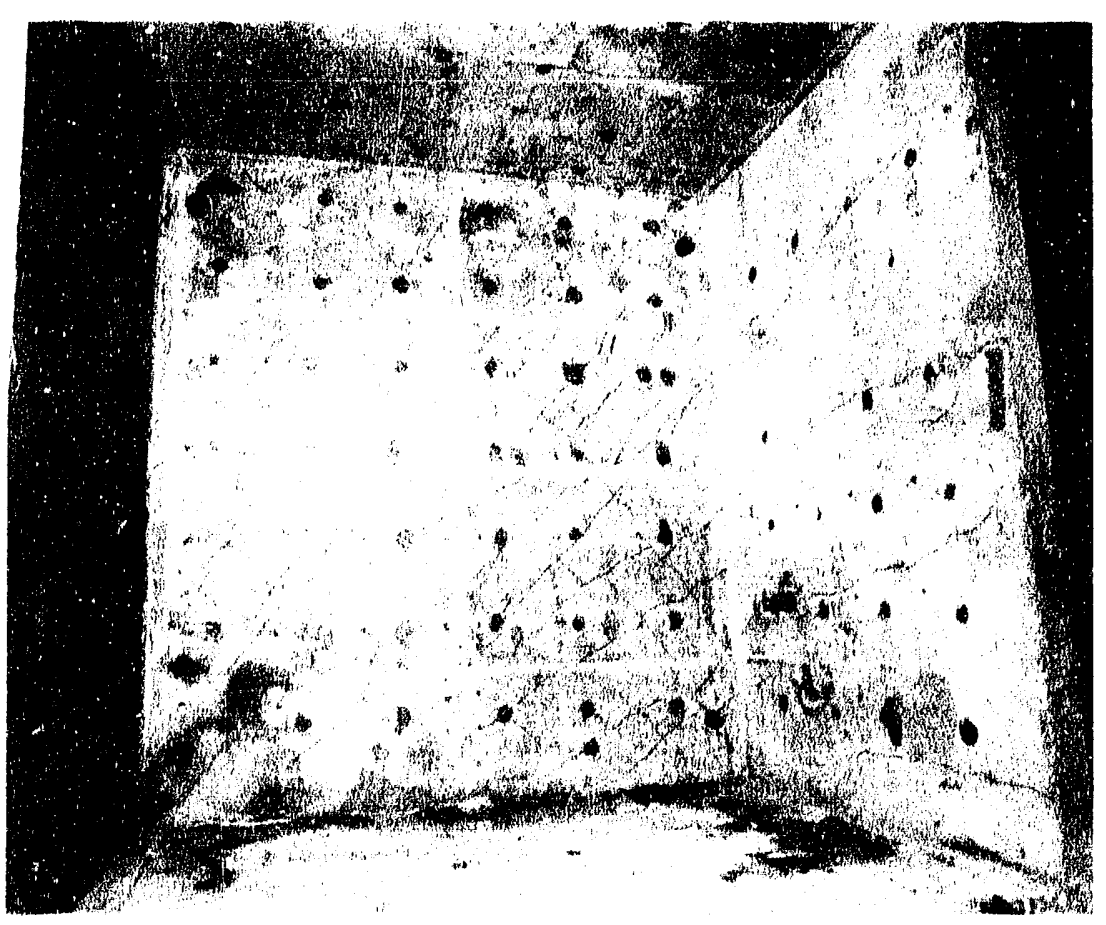

Fig. 16. Final crack patterns in $T R G_{-}-5$. 
TABLE III

HYSTERETIC ENERGY LOSSES MEASURED ON TRG-4

\begin{tabular}{ccccc} 
Load & $\begin{array}{c}\text { Peak Average } \\
\text { Base Shear } \\
\text { Stress } \\
\text { (psi) }\end{array}$ & $\begin{array}{c}\text { Peak } \\
\text { Force } \\
\text { (1bs) }\end{array}$ & $\begin{array}{c}\text { Hysteretic } \\
\text { Energy } \\
\text { Loss } \\
\text { (in. - 1bs) }\end{array}$ & $\begin{array}{c}\text { Equivalent } \\
\text { Viscous } \\
\text { Damping } \\
\text { (pof critical) }\end{array}$ \\
\hline 1 & 50 & 27,000 & 29.5 & 5.9 \\
2 & 50 & 27,000 & 35.4 & 7.0 \\
3 & 100 & 54,000 & 113 & 5.2 \\
4 & 100 & 54,000 & 81.2 & 3.7 \\
5 & 100 & 54,000 & 77.4 & 3.5 \\
6 & 200 & 108,000 & 1560 & 5.7 \\
7 & 200 & 108,000 & 940 & 4.9 \\
8 & 200 & 108,000 & 888 & $*$ \\
9 & 260 & 140,000 & 16400 & 6.3 \\
10 & 50 & 27,000 & 582 &
\end{tabular}

* Cycles that exhibited nonlinear response.

TABLE IV

HYSTERETIC ENERGY LOSSES MEASURED ON TRG-5

\begin{tabular}{|c|c|c|c|c|}
\hline $\begin{array}{l}\text { Load } \\
\text { Cycle }\end{array}$ & $\begin{array}{l}\text { Peak Average } \\
\text { Base Shear } \\
\text { Stress } \\
\text { (psi) } \\
\end{array}$ & $\begin{array}{l}\text { Peak } \\
\text { Force } \\
(1 \mathrm{bs})\end{array}$ & $\begin{array}{l}\text { Hysteretic } \\
\text { Energy Loss } \\
\text { (in.-1b) }\end{array}$ & $\begin{array}{l}\text { Equivalent } \\
\text { Viscous Damping } \\
(\% \text { of Critical) } \\
\end{array}$ \\
\hline $\begin{array}{r}1 \\
2 \\
3 \\
4 \\
5 \\
6 \\
7 \\
8 \\
9 \\
10 \\
11 \\
12 \\
13 \\
14 \\
15 \\
16 \\
17\end{array}$ & $\begin{array}{r}50 \\
50 \\
50 \\
100 \\
100 \\
100 \\
150 \\
200 \\
200 \\
200 \\
300 \\
300 \\
300 \\
400 \\
500 \\
50 \\
50\end{array}$ & $\begin{array}{r}18000 \\
18000 \\
18000 \\
36000 \\
36000 \\
36000 \\
54000 \\
72000 \\
72000 \\
72000 \\
108000 \\
108000 \\
108000 \\
144000 \\
180000 \\
18000 \\
18000\end{array}$ & $\begin{array}{r}10 \\
10 \\
11 \\
39 \\
33 \\
32 \\
156 \\
786 \\
475 \\
449 \\
2630 \\
1690 \\
1300 \\
12000 \\
11300 \\
434 \\
293\end{array}$ & $\begin{array}{l}3.5 \\
3.4 \\
4.0 \\
3.3 \\
2.7 \\
2.8 \\
\star \\
\star \\
3.8 \\
3.5 \\
\star \\
4.6 \\
3.4 \\
\star \\
\star \\
\star \\
8.0\end{array}$ \\
\hline
\end{tabular}

\footnotetext{
*Cycles that exhibited nonlinear response. Stiffness was not well defined during these cycles.
} 
To briefly summarize the results of these tests, it was found that before the structure cracked, the stifiness of the structure had accurately been predicted by strength-of-materials analysis. After the structure had cracked, stiffness was found to be a function of the amount of reinforcement, prior load history, and current load level. Because of the structure's geometry, the entire end walls were effective in resisting bending deformations. No effects from repeated load cycling to a corstant load level were noticed for TRG-6. Shear and bending components of stiffness degraded equally in terms of percentage as can be seen in Table $V$. The reader is reminded that a detailed summary of these tests can be found in Ref. 9 and subsequent reports to be issued by Los Alamos.

IV. FY 1987 ANALYTICAL ACTIVITES

Concurrent with this experimental effort, an analytical investigation was conducted to match floor response spectra (FRS) determined from measured acceleration-time histories during simulated seismic tests (herein referred to as measured FRS) with FRS determined from linear analytical models of the test structures subjected to the same base excitation (herein referred to as analytical FRS).

TABL.E $V$

TRG-4 MEASURED STIFFNESS VALUES

\begin{tabular}{|c|c|c|c|}
\hline $\begin{array}{c}\text { Total } \\
\text { Stiffness } \\
\text { s/in. } \times 10^{-6} \\
\end{array}$ & $\begin{array}{r}\text { Bending } \\
\text { Stiffness } \\
\text { lbs/in. } \times 10^{-6} \\
\end{array}$ & $\begin{array}{l}\text { Shear } \\
\text { Stiffness } \\
\text { lbs/in. } \times 10^{-6} 6 \\
\end{array}$ & $\begin{array}{l}\text { Ratio } \\
\text { Shear Stiffness } \\
\text { Bending Stiffnes }\end{array}$ \\
\hline es) ${ }^{8.5}$ & 52.6 & 10.2 & 0.19 \\
\hline
\end{tabular}

(50 \& 100 psi cycles)
$7-8$
4.05
23.0
4.91
0.21

(200 psi cycles

after 1st cracking)
10
0.54
4.8
0.61
0.13

(post failure

50 psi cycle) 
The response spectra matching was attempted on a variety of test structure geometries including TRG-1-1 $(1.0,0.56)$, TRG-3-4 $(1.0,0.60)$, a two-story $1 / 10$-scale diesel generator building model, and the three-story 1/42-scale auxiliary building. These structures are shown in Figs. 17, 4, 2, and 3 , respectively. Matching was to be accomplished by adjusting the stiffness and damping in the analytical model. The motivation for this investigation was based on the TRG's feeling that more emphasis should be placed on the analysis of data already obtained. In particular, the TRG felt that it was pertinent to determine if the Seismic Category I structures can continue to be analyzed with corrected linear models despite the reductions in stiffness associated with the seismic loading. Also, comparisons of measured and analytical response spectra quantify the differences between the predicted response of these structures based on current design practices and the experimentally observed response as they would actually be used by the engineer in plant and equipment design. A detailed summary of the response spectra matching calculations can be found in Ref. 10 .

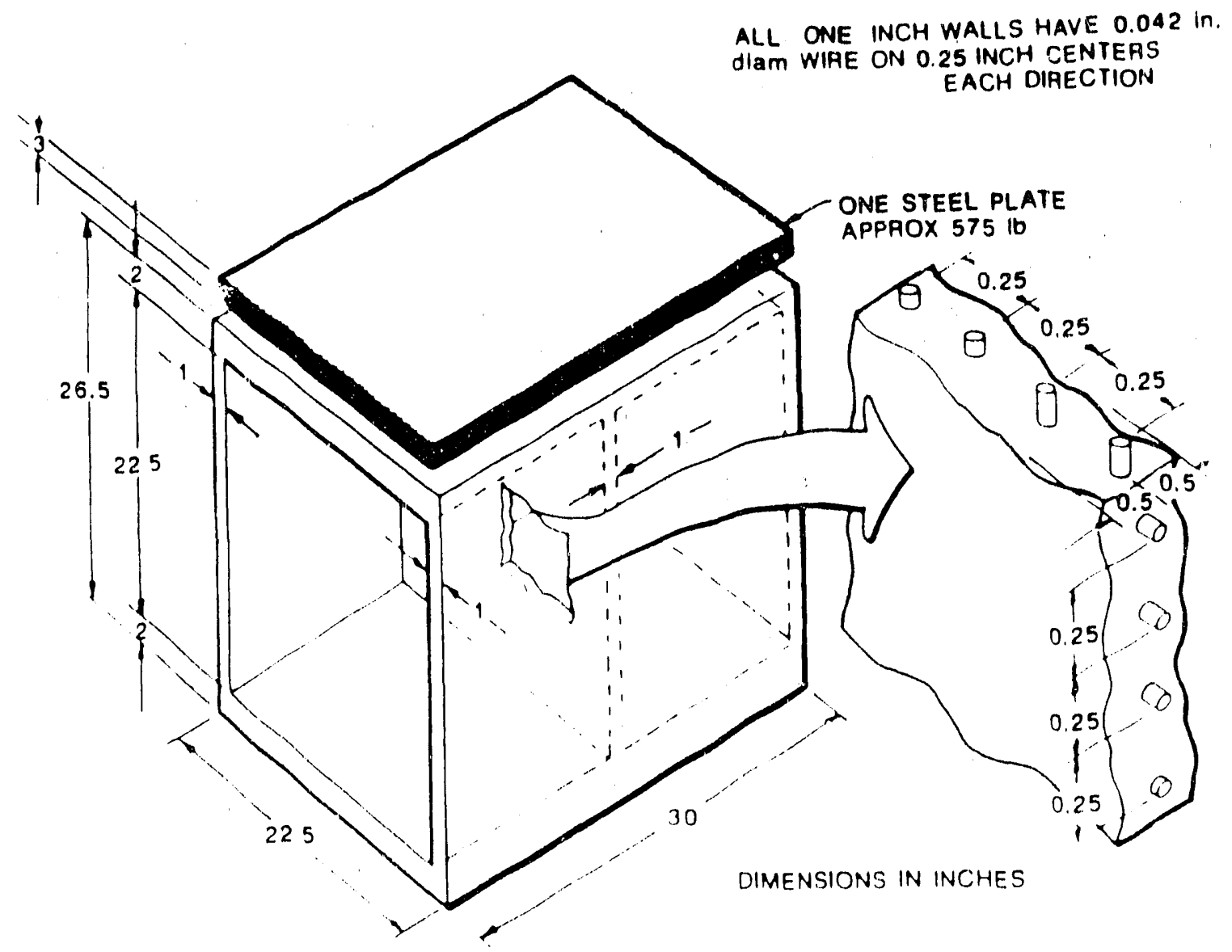

Fig. 17. TRG-1-1 (1.0,0.56). 
For each structure, three different levels of simulated seismic base excitation were analyzed. An example of a base excitation response spectrum is shown in Fig. 18 for the diesel generator building model. This spectrum was generated from a time-scaled version of the North-South component of the 1940 El Centro earthquake normalized to $1.88 \mathrm{~g}$ 's peak acceieration. Two and ten

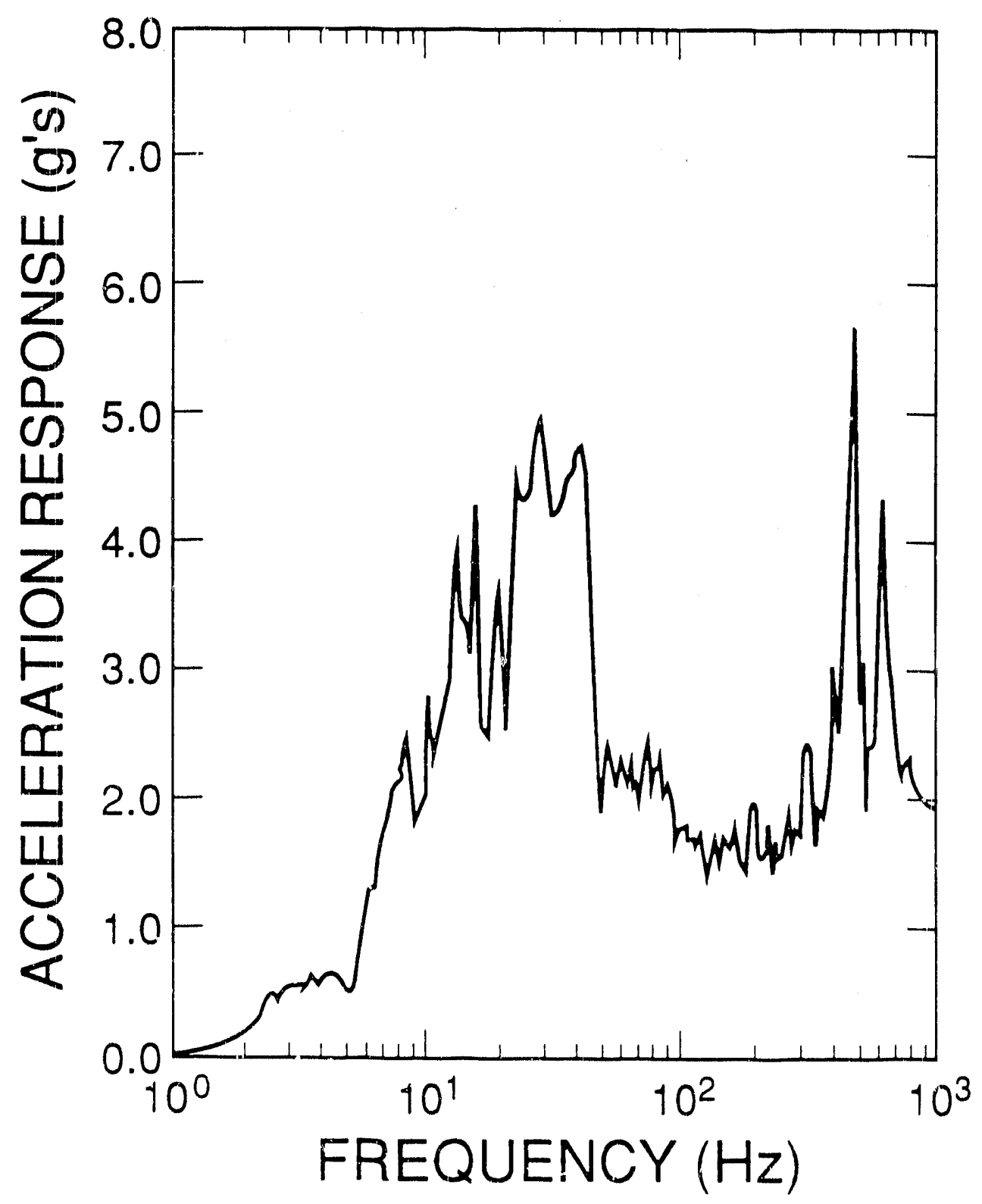

Fig. 18. Base input response spectrum generated from the $1.88 \mathrm{~g}$ 's peak acceleration seismic input used on the 1/10-scale diesel generator building. 
percent equipment damping was used in the FRS calculations. The initial values of stiffness in the allalytical model were taken from the reduced stiffness plot in Fig. 19 and damping was initially estimated at $7 \%$ of critical based on previous test results. Stiffness was adjusted to match the frequency of peaks in the analytical response spectrum while damping was adjusted to match the amplitudes in the spectrum. All damping values refer to viscous damping, percent of critical.

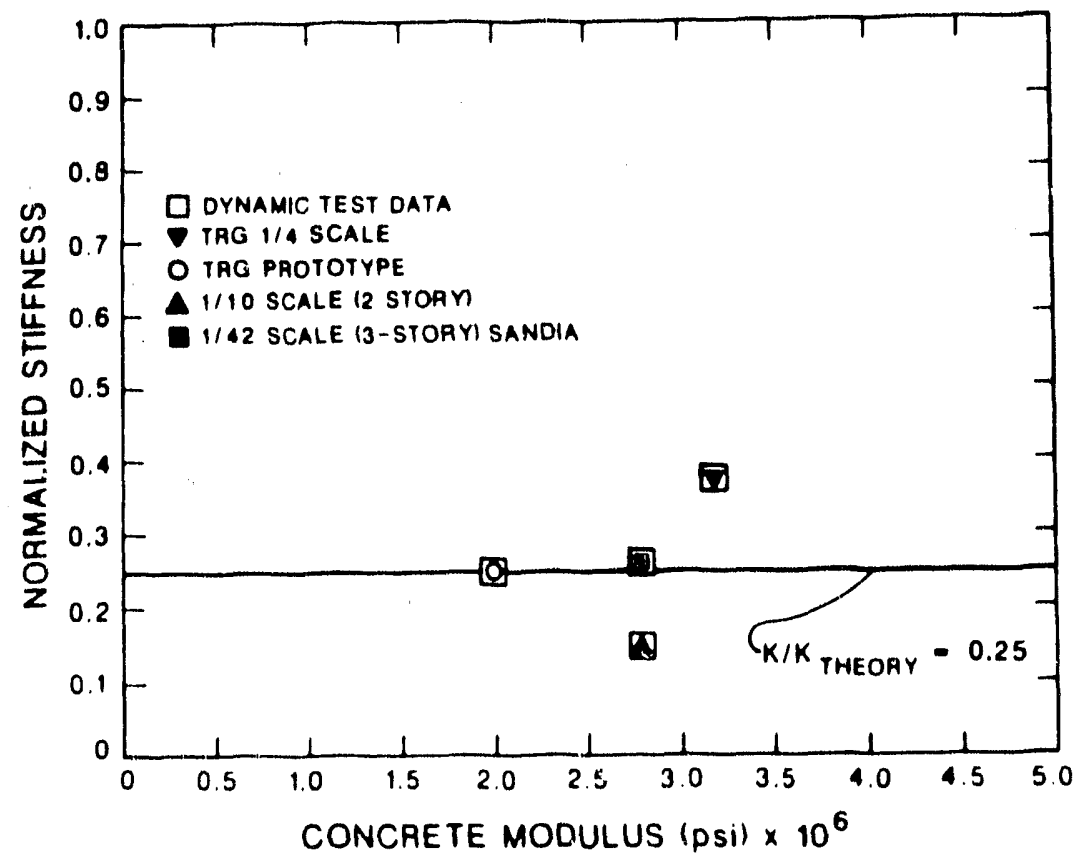

Fig. 19. Reduced stiffness measured during initial lowlevel seismic tests of the structures analyzed in the response spectra matching exercise.

A summary of the steps used to match the response spectra is given below.

1. Calculate base input response spectra using $2 \%$ and $10 \%$ damping, filter the signal for $60 \mathrm{~Hz}$ noise, and baseline correct for dc offset before the calculation.

2. Calculate measured floor response spectra for $2 \%$ equipment damping, filter the signals for $60 \mathrm{~Hz}$ noise, and baseline correct for dc offset before the calculation.

3. Develop a lumped mass model of the test structure and subject it to the measured base input.

4. Calculate floor resporise spectra based on response of model in step 3 for $2 \%$ equipment damping. 
5. Repeat steps 3 and 4 adjusting stiffness in the model to match response specira peaks in terms of frequency (often requiring several iterations).

6. Repeat steps 3 and 4 adjusting damping in the model to match the ampiitude of the peaks in the response spectra (often requiring several iterations).

7. Repeat steps $2-6$ for $10 \%$ equipment damping.

Figure 20 shows the lumped mass model of the 1/10-scale diesel generator building model and figs 21 and 22 compare the measured FRS for each floor of the diesel generator building with the reduced stiffness analytical FRS that best match the measured response for this structure when subjected to the input whose response spectrum is shown in Fig. 18. Also included on this plot is an analytical FRS based on the "current design practice." These plots are typical of the reduced stiffness, linear analytical model's ability to predict the measured reduced stiffness response.

For the 1/42-scale auxiliary building, three additional calculated response spectra were generated. The first referred to as the "current design practice" used a strength-ofmaterials stiffness value assuming the entire end walls contribute to the bending stiffness. The second

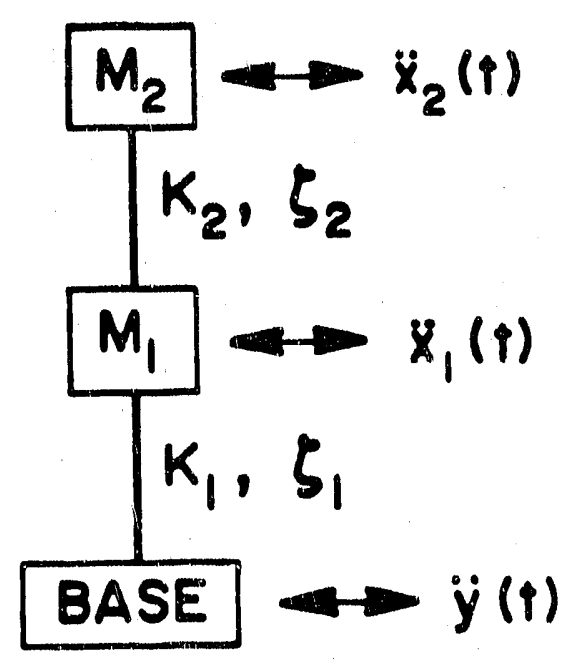

Fig. 20. Lumped mass model of the 1/10-scale diesel generator building.

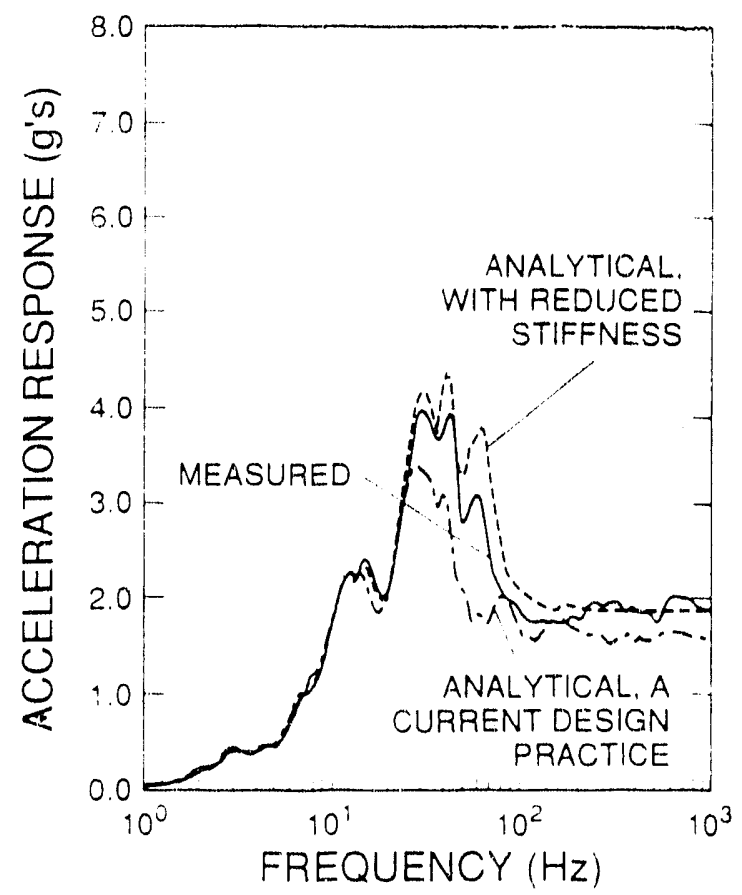

Fig. 21. Comparison of the measured and analytical response spectra for the first floor of the 1/10-scale diesel generator building. 


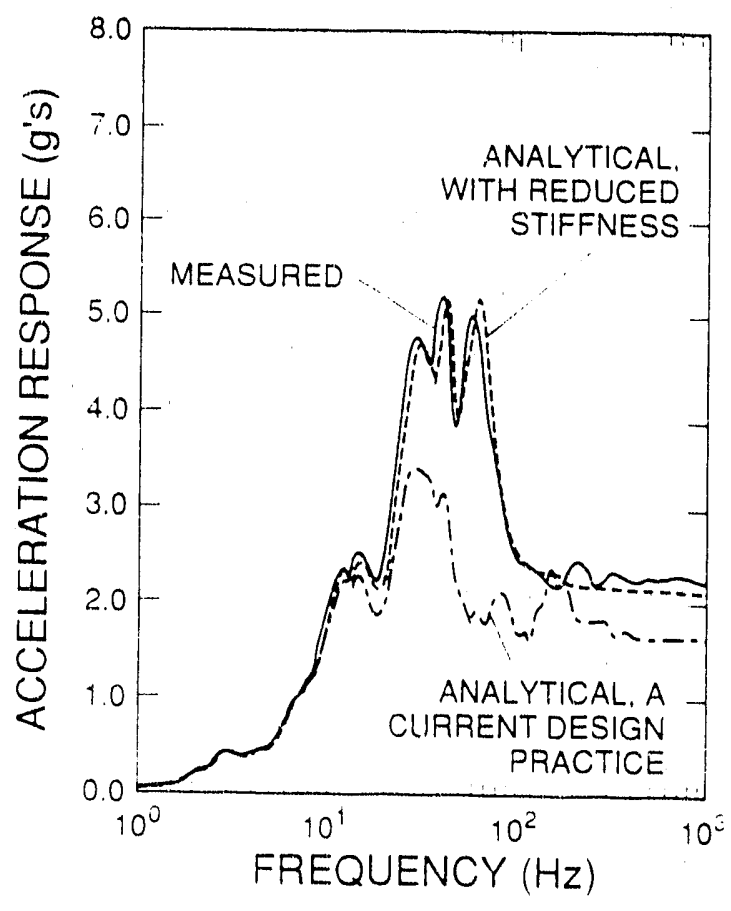

Fig. 22. Comparison of the measured and analytical response spectra for the second floor of the $1 / 10$-scale diesel generator building. used ACI 349-85 (Ref. 11) T-beam criteria to determine the end walls contribution and the third neglected the end walls altogether. These additional response spectra correspond to the alternate stiffness values that were calculated and reported in Ref. 10. Current design practice plots were included in Ref. 10 for the other structures as well. All analytical stiffness values were calculated with measured modulus of elasticity values as opposed to using the empirical formulas in ACI $349-85 .^{11}$

The TRG also requested that the analytical values of stiffness for several different test structure geometries be recomputed using various design assumptions. These alternate values of stiffness were then to be compared with the measured stiffness values. Table VI summarizes the results of these alternate stiffness calculations. These results are discussed in detail in Ref. 10.

\section{FY 1987 TECHNICAL REVIEW GROUP ACTIVITIES}

In addition to providing input with regard to the experimental and analytical efforts for FY 1987, the members of the TRG were requested to respond in writing to a series of questions that addressed the general issue of whether the results obtained for tests in this program were credible and whether these results were addressing the program objectives. Replies to these questions were solicited for the purpose of providing members of the Nuclear Regulatory Research (NRR) Branch of the NRC with all the input possible to 


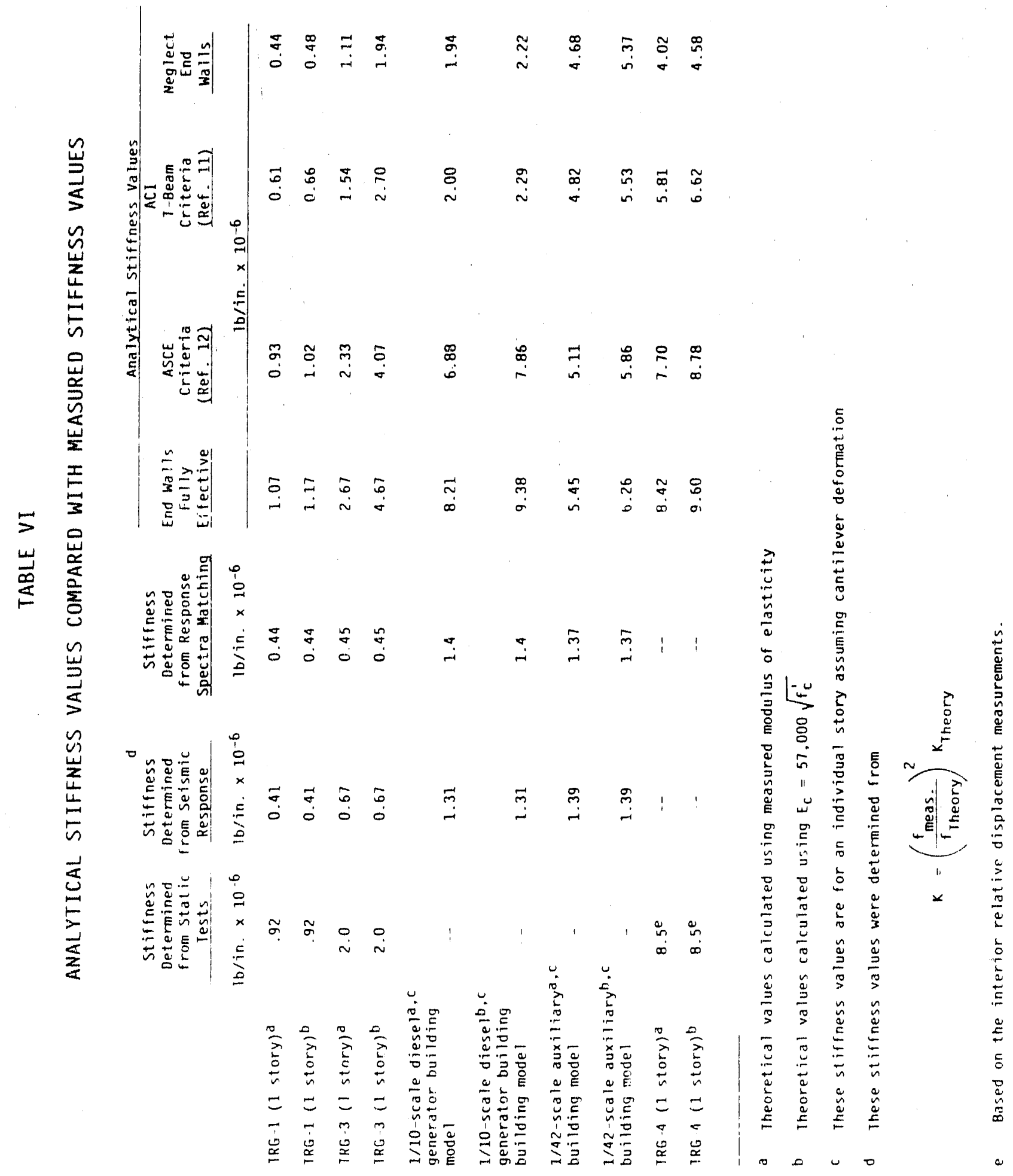


make decisions about both the applicability and regulatory impact of this research program. The questions posed to the TRG were

1. Are the tests in this program valid for addressing the program objectives?

2. In light of the program objectives, are the model test data obtained applicable to nuclear power plant structures?

3. Have the technical issues of scaling, instrumentation, and model fabrication effects been resolved?

4. Should there be another "carefully handled" dyn-mic test to address the possible "dynamic effects" issue? If so, what configuration should be used?

5. Have we obtained enough data and have we tested the correct configurations to meet the program objectives?

6. Would the variability in stiffness observed in the models be observed in real nuclear plant structures at comparable load levels?

The TRG's responses to these questions can be found in Appendix B. A summary of the responses, as interpreted by the authors, is given in Table VII.

\section{FY 1987 CODE COMMITTEE ACTIVITIES}

Finally, results from this program were presented to both American Society of Civil Engineers (ASCE) and American Concrete Institute (ACI) code committees during FY 1987. This in seraction with the code committees has led to investigators from Lus Alamos being added to the committees and the results that have been presented, will, most likely, be reflected in future revisions of these committees' current analysis and design standards.

This program has generated considerable interest among members of national code committees addressing reinforced concrete analysis and design. Presentations of the findings and issues with regard to the reduced stiffness implications on seismic response of equipment and piping were given in November 1986 to an ACI Committee, and the ASCE Dynamic Analysis Committee.

Dr. John Stevenson, a member of the Program's TRG is chairman of the ASCE Nuclear Standards Committee. Dr. Joel Bennett, principal investigator for this program, is a member of the ASCE Nuclear Standards Committee. This committee has just approved an ASCE Standard for the Seismic Analysis of Safety-Related Nuclear Structures. 12 The new standard does not include results from this 


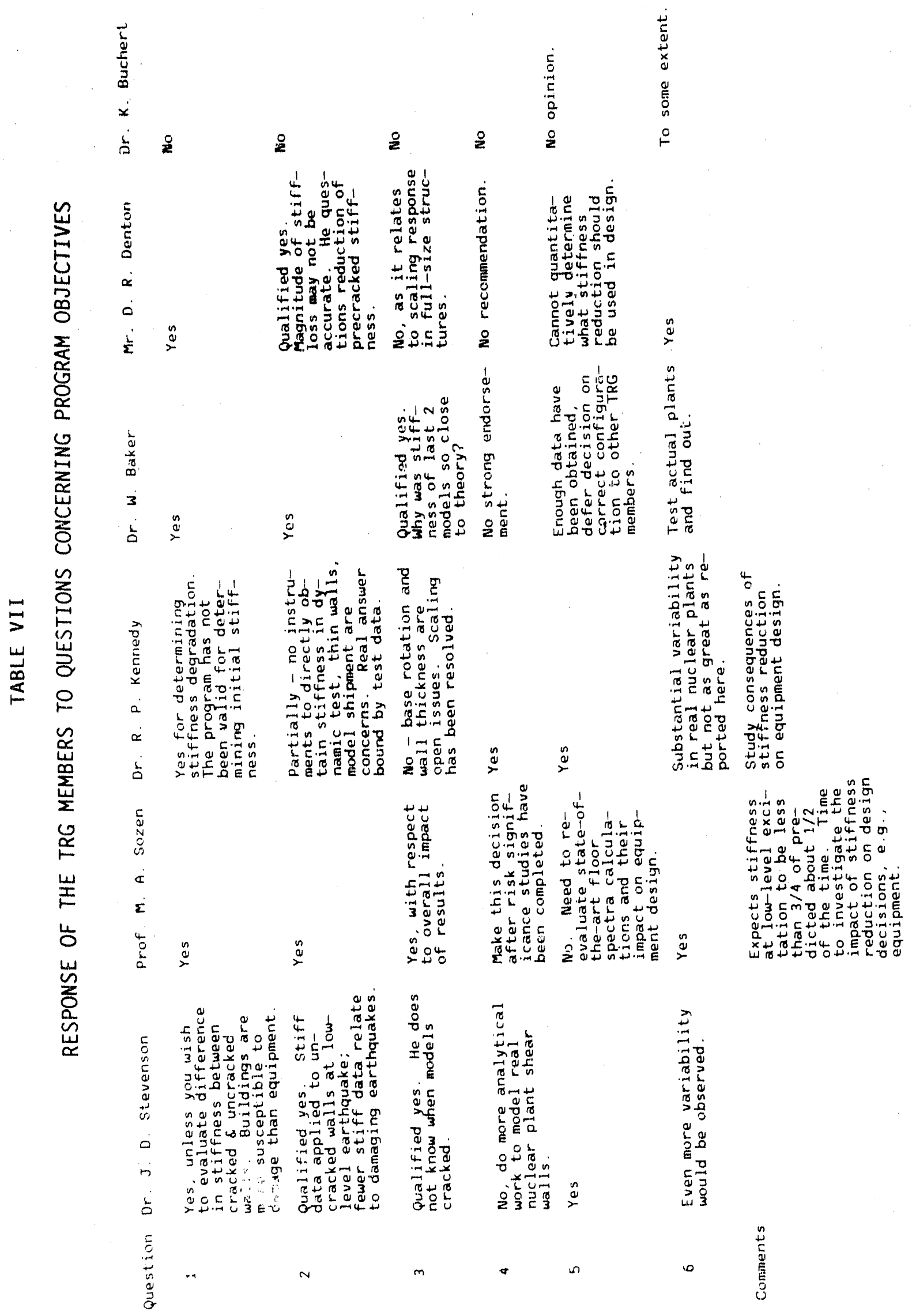


Program. Committee members are aware that a portion of the Standard may have to be revised depending upon the outcome of future tests.

Dr. Robert P. Kennedy, a member of the Program's TRG, is immediate past chairman of the ASCE Dynamic Analysis Committee. Dr. Kennedy's committee was responsible for developing the Standard for Seismic Analysis of Safety-Related Nuclear Structures. Dr. Kennedy has advised the subcommittee of the Seismic Category I Structures Program results, particularly with regard to the reduced stiffness issue and its implication on floor response spectra. Based on program results, Dr. Kennedy has reconstituted the Working Group on Stiffness of Concrete Shear Wall Structures. The Working Group, chaired by Dr. Robert Murray, Lawrence Livermore National Laboratory, will meet biannually.

Dr. Bennett is a member of the working group as is Dr. Charles Farrar. During FY 1987, this Working Group has undertaken the task of writing a position paper on the proper stiffness to be used in calculating the dynamic response of low aspect ratio shear wall structures. The investigators from the Seismic Category I Structures Program have provided the Working Group with a review of previous investigations into the stiffness of low aspect ratio shear walls and detailed information concerning results obtained by this Program. Appendix A contains a summary of the shear wall test data provided to the Working Group.

VII. CONCLUSIONS

One of the primary purposes of the tests performed in FY 1987 was to determine if, during a carefully monitored static load cycle test, a stiffness reduction of 4 would occur at similar load levels as have been observed in dynamic tests. The models tested in FY 1987 were constructed with prototypical materials; with one exception, TRG-3, the previous dynamic test specimens were constructed with microconcrete. During the precracking load cycles and the low-level modal analysis, no stiffness reduction was observed, and in the case of TRG-6, the measurements indicated a stiffness slightly higher than theory would predict. The precracking response of these structures was accurately predicted with currently used linear analysis techniques based on strength of materials theory. These same techniques would not have adequately predicted the dynamic response of structures previously tested in this program, even though 
stress levels during the dynamic tests were well below those predicted to crack the structure.

The boundary elements or end walls were found to be fully effective in resisting bending deformation, but it is felt that the geometry of the test structure constrained these elements to be effective. In terms of percentage, the stiffness components were found to degrade equally implying that the reduction in stiffness is not caused by a loss of one of the stiffness components.

Based upon the quasi-static, cyclic testing of TRG structures 4,5 , and 6 , it is readily apparent that carefully handled structures tested fairly "green" (i.e., unaged), are uncracked, and the stiffness can be accurately predicted by strength-of-materials theory.

The most likely cause of the reduced stiffness that has been measured in this Program is concrete cracking. The source of this cracking has probably been (in our tests), a combination of several causes that include handling and transportation, aging (curing), shrinkage, and other time effects, and the construction imperfections and material variability that exist in all fabricated structures. However, we generally believe that the same cracking effects exist in real reinforced concrete structures because of many of the same reasons (handling and transportation loadings can be replaced by "differential settlement").

The current method of treating these structures, namely, using an uncracked cross-section for determining the structural element parameters and resulting floor response spectra should be re-examined and more realistic guidelines established to cover the effects. Los Alamos is working with the professional society committees in this re-examination.

The following conclusions were made based on the results of the floor response spectra matching for the various structures:

1. Linear response spectra techniques applied to the analytical responses generated with lumped mass models of the structures did an adequate job of predicting the experimentally measured response spectra. These predictions required modifications in the stiffness and damping from currently used design practice. The linear response spectra techniques continued to work well even after the structure was known to have sustained significant damage in previous tests. 
2. The stiffness values that provide the best match are significantly less than current design criteria would predict even if end walls were neglected.

3. At higher input levels, stiffness must be further reduced to obtain an accurate match.

4. In order to obtain an accurate match for these particular tests, damping values must be in the $6 \%$ to $10 \%$ range at the low-level excitations and must be increased to as high as $35 \%$ when the damaged structure receives severe. seismic loading.

5. Damping has a greater effect on peaks in the response spectra because of resonance than it does on peaks caused by a surge in the energy content of the input signal.

6. For multi-degree-of-freedom (MDOF) systems, a good match with the measured response spectra was obtained by progressively increasing the damping in the lower floor. This fact suggests a frictional damping mechanism.

7. For MDOF systems, the damping in the bottom floor plays a major role in controlling the system response. The structures seem relatively insensitive to the damping values associated with the upper floors.

8. For MDOF systems, it is not clear that there is a unique set of damping values that provide the best match to the measured response spectra. In general, the analytical model that gives the best overall match tends to overestimate the bottom floor response and underestimate the top floor response.

\section{VIII, REFERENCES}

1. E. G. Endebrock, R. C. Dove, and C. A. Anderson, "Margins to Failure Category I Structures Program: Backgound and Experimental Plan," Los Alamos National Laboratory report LA-9030--MS, NUREG/CR-2347 (December 1981).

2. E. G. Endebrock, R. C. Dove, and W. E. Dunwoody, "Analys is and Tests on Small Scale Shear Walls - FY 82 Final Report," Los Alamos National Laboratory report LA-10443-MS, NUREG/CR-4274 (September 1985).

3. R. C. Dove, J. G. Bennett, C. R. Farrar, and C. A. Anderson, "Seismic Category I'Structures Program: Final Report, FY 1983-84," Los Alamos National Laboratory report, LA-11013-MS, NUREG/CR-4924 (August 1987). 
4. E. G. Endebrock, R. C. Dove, and C. A. Anderson, "Selsmlc Category I Structures Program," Proceedings of the 12th Water Reactor Safety Information Meeting, National Bureau of Standards, Bethesda, Maryland, NUREG/CR-0058, Vo1. 5 (January 1985).

5. R. C. Dove, E. G. Endebrock, W. E. Dunwoody, and J. G. Bennett, "Selsmic Tests on Models of Reinforced Concrete, Category I Bulldings," 8th International Conference on Structural Mechanics in Reactor Technology, Brussels, Belgium, August.19-23, 1985.

6. J. G. Bennett, R. C. Dove, W. E. Dunwoody, E. G. Endebrock, C. R. Farrar, and P. Goldman, "Simulated Seismic Tests on 1/42- and 1/14-Scale Category I, Auxiliary Building," Los Alamos National Laboratory report LA-11093-MS, NUREG/CR 4987 (July 28, 1987).

7. J. G. Bennett, R. C. Dove, W. E. Dunwoody, C. R. Farrar, and F. Goldman, "The Seismic Category I Structures Program: Results for FY 1985, "Los Alamos National Laboratory report LA-22227-MS, NUREG/CR 4998 (December 1987).

8. J. G. Bennett, R. C. Dove, W. E. Dunwoody, C. R. Farrar, and P. Goldman, "The Seismic Category I Structures Program: Results for FY 1986," Los Alamos National Laboratory report LA-11377-MS, NUREG/CR 5182, (July 1988).

9. C. R. Farrar, J. G. Bennett, W. E. Dunwoody, and W. E. Baker, "Static Load Cycle Testing of a Low-Aspect-Ratio Six-Inch Wall TRG-Type Structure TRG-4-6 (1.0,0.25)," LoS Alamos National Laboratory report LA-11422-MS, NUREG/CR-5222 (June 1989).

10. C. R. Farrar and C. M. Alvord, "Use of Linear Reduced-Stiffness Analytical Models to Predict Seismic Response of Damaged Concrete Structures," Los Alamos National Laboratory report LA-11444-MS, NUREG/CR-5237 (May 1989).

11. ACI Committee 349, Code Requirements for Nuclear Safety Related Concrete Structures and Commentary. (American Concrete Institute, Detroit, 1985).

12. Committee on Nuclear Standards, Seismic Analysis of Safety-Related Nuclear Structures and Commentary on Standard for Seismic Analysis of Safety Related Nuclear Structures, ASCE 4-86, September 1986). 
APPENDIX A

SUMMARY OF MEASURED STIFFNESS VALUES 


\section{APPENDIX A \\ SUMMARY OF MEASURED STIFFNESS VALUES}

Because the experimental effort of FY 1987 was primarily intent upon resolving discrepancies between measured and calculated stiffness values, it is appropriate to review all the experimentally determined stiffness values obtained during this Program. Table VIII summarizes the geometry of all previous test structures.

Initially in this Program, measured stiffness values from static and dynamic tests $2,3,6$ were compared with theoretical values that were determined using a modulus of elasticity calculated from the empirical formula in ACI 349-85. ${ }^{11}$ The empirical formula generally gave a higher value for the concrete's modulus than the values measured from test specimens. It is the opinion of a member of the TRG that this formula does not apply to microconcrete. In addition, theoretical stiffness values were determined using measured moduli from the ASTM standard test. Because this investigation is concerned with determining the proper values of stiffness to be used in the analysis of Seismic Category I Structures, it is felt that the best estimate of actual material properties should be used when experimental results are compared with theory. The comparisons between measured and theoretical stiffnesses that were calculated with the empirical modulus do, however, provide information concerning analytical differences that could occur during the design process, when material properties have yet to be measured. These comparisons have been reported in all subsequent investigations. ${ }^{7-9}$

A. Review of Previous Static Test Results Obtained In the Seismic Category I Structure Program

Table IX summarizes the previous static test results using both the measured and design values for the concrete's modulus. These results are discussed in the following paragraphs.

1. Isolated Shear Walls. The first static tests were performed on single-story isolated shear walls and were reported in Ref. 2 . These walls are shown in Fig. 1. Five walls were tested, two monotonically and three cyclically. These specimens were made with microconcrete and with wire mesh reinforcement. The amount of reinforcement at the shear wall base and shear wall 
TABLE VIII

SUMMARY OF LOS ALAMOS TEST STRUCTURE GEOMETRY

\begin{tabular}{|c|c|c|c|c|c|c|}
\hline $\begin{array}{c}\text { Type of }{ }^{\mathrm{a}} \\
\text { Structure }\end{array}$ & $\begin{array}{l}\text { Wall } \\
\text { Thickness } \\
\text { (in.) }\end{array}$ & $\begin{array}{l}\text { Aspect } \\
\text { Ratio } \\
(h / L) \\
\end{array}$ & $\begin{array}{r}\text { Num } \\
\text { Tes } \\
\text { Static } \\
\end{array}$ & $\begin{array}{l}\text { ber } \\
\text { ted } \\
\text { Dynamic }\end{array}$ & $\begin{array}{l}\text { Reinforcement } \\
\% \text {, each } \\
\text { direction } \\
\end{array}$ & $\begin{array}{l}\text { Maxe } \\
\text { Normal } \\
\text { Stress } \\
\text { (psi) }\end{array}$ \\
\hline $\begin{array}{l}\text { Isolated Shear } \\
\text { Walls, 1-story }\end{array}$ & 1.0 & 0.42 & 5 & 6 & Hardware cloth & $\begin{array}{l}D=19.5 \\
S=0.625\end{array}$ \\
\hline $\begin{array}{l}\text { Isolated Shear } \\
\text { Walls, 2-story }\end{array}$ & 1.0 & 0.42 & 0 & 1 & Hardware cloth & 39.0 \\
\hline $\begin{array}{l}\text { Diesel Generator } \\
\text { Bujlding } 1 \text { instory, } \\
\text { |/30-scale }\end{array}$ & 1.0 & $\begin{array}{l}0.40 \\
0.73\end{array}$ & 11 & 2 & Hardware cloth & 5.3 \\
\hline $\begin{array}{l}\text { Diesel Generator } \\
\text { Bujlding, } 2 \text {-story } \\
1 / 30-\text { scale }\end{array}$ & 1.0 & 0.73 & 0 & 3 & Hardware cloth & 10.6 \\
\hline $\begin{array}{l}\text { Diesel Generator } \\
\text { Buil 1ding, } 2 \text {-story } \\
1 / 10-\text { scale }\end{array}$ & 3.0 & 0.73 & 0 & 2 & Model 0.56 rebar & 10.8 \\
\hline $\begin{array}{l}\text { Auxiliary Bldg. } \\
3 \text { story } \\
1 / 42-\text { scale }\end{array}$ & 1.0 & 0.38 & 0 & 1 & Hardware cloth & 17.6 \\
\hline $\begin{array}{l}\text { Auxiliary Bldg. } \\
\text { 3-story } \\
\text { l/14-scale }\end{array}$ & 3.0 & 0.38 & 0 & 1 & Model 0.56 Rebar & 10.8 \\
\hline TRG-1 & 1.0 & 1 & (c) & 1 & Hardware cloth & 10.4 \\
\hline TRG-3 & 4.0 & 1 & (c) & 1 & $\# 3^{0.61}$ Rebar & 42.3 \\
\hline TRG-4 & 6.0 & 1 & 1 & 0 & $\# 3^{0.25}$ Rebar & 31.0 \\
\hline TRG-5 & 4.0 & 1 & 1 & 0 & \#3 ${ }^{0.61}$ Rebar & 42.3 \\
\hline TRG-6 & 6.0 & 0.27 & 1 & 0 & $\# 3^{0} \dot{R}^{5} \mathrm{ebar}$ & 25.7 \\
\hline
\end{tabular}

\footnotetext{
A 11 structures were made with microconcrete except TRG-3 through TRG-6;
these were made with $3 / 4$-in. aggregate concrete.

b For multi-story structures, the aspect ratio reported is for an individual
floor.

c TRG-1 and TRG-3 were statically tested to low-stress levels before the
dynamic tests.

d Hardware cloth is 0.042 -in. -dia. welded wire fabric; l,odel rebar is deformed model reinforcing rods obtained from the Portland Cement

e With added mass used during dynamic tests. Static testing of the isolated
shear walls wâs performed without added mass.
} 
TABLE IX

PREVIOUS STATIC TEST RESULTS

\begin{tabular}{|c|c|c|c|c|c|c|}
\hline \multirow{2}{*}{$\begin{array}{l}\text { Measured } \\
\text { Stiffness } \\
\text { Before } \\
\text { Cracking } \\
\text { (Ib/in.) } \\
1\end{array}$} & \multirow{2}{*}{$\begin{array}{c}\text { Ultimate } \\
\text { Compressive } \\
\text { Strength } \\
f^{\prime} \\
(k s i)\end{array}$} & \multirow{2}{*}{$\begin{array}{l}\text { Theoretical } \\
\text { Stiffness Using } \\
\text { Measured } \\
\text { Modulus } \\
(1 b / i n .) \\
2\end{array}$} & \multirow{2}{*}{$\begin{array}{l}\text { Theoretical } \\
\text { Using ACI } \\
\text { Empirical } \\
\text { Modulus } \\
\text { (1b/in.) } \\
3\end{array}$} & \multicolumn{3}{|c|}{$\begin{array}{l}\text { The Ratio of } \\
\text { Columns }\end{array}$} \\
\hline & & & & $\frac{2}{1}$ & 1 & $\frac{2}{3}$ \\
\hline
\end{tabular}

Isclated Shear Walls:

$\begin{array}{lllllllll}1 & 0.78 \times 10^{6} & 4.34 & 1.60 \times 10^{6} & 2.33 \times 10^{6} & 2.05 & 2.99 & 0.69 \\ 2 & 0.79 \times 10^{6} & 5.89 & & 2.71 \times 10^{6} & - & 3.43 & - \\ 3 & 1.0 \times 10^{6} & 7.35 & 1.90 \times 10^{6} & 3.03 \times 10^{6} & 1.90 & 3.03 & 0.63 \\ 4 & 1.06 \times 10^{6} & 6.86 & - & 2.92 \times 10^{6} & - & 2.75 & - \\ 5 & 0.87 \times 10^{6} & 6.31 & 1.75 \times 10^{6} & 2.80 \times 10^{6} & 2.02 & 3.22 & 0.63\end{array}$

1/30-scale, 1-story,

Diesel Generator Buildings:

\begin{tabular}{|c|c|c|c|c|c|c|c|c|}
\hline $\begin{array}{l}3 D-2 \\
3 D-4 \\
3 D-7 \\
3 D-8 \\
3 D-9 \\
3 D-10 \\
3 D-11 \\
3 D-12 \\
3 D-13 \\
3 D-19 \\
3 D-20\end{array}$ & $\begin{array}{l}0.76 \times 10^{6} \\
1.74 \times 10^{6} \\
0.92 \times 10^{6} \\
0.80 \times 10^{6} \\
1.67 \times 10^{6} \\
1.14 \times 10^{6} \\
0.92 \times 10^{6} \\
1.23 \times 10^{6} \\
0.88 \times 10^{6} \\
0.80 \times 10^{6} \\
1.08 \times 10^{6}\end{array}$ & $\begin{array}{l}2.70 \\
3.32 \\
2.35 \\
2.30 \\
2.69 \\
3.27 \\
3.09 \\
2.05 \\
2.04 \\
4.70 \\
4.30\end{array}$ & $\begin{array}{l}2.25 \\
4.82 \\
2.45 \\
2.36 \\
4.62\end{array}$ & 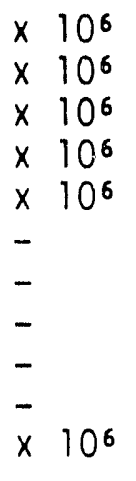 & $\begin{array}{l}2.90 \times 10^{6} \\
6.08 \times 10^{6} \\
2.71 \times 10^{6} \\
2.68 \times 10^{6} \\
5.47 \times 10^{6} \\
3.19 \times 10^{6} \\
3.11 \times 10^{6} \\
2.53 \times 10^{6} \\
2.52 \times 10^{6} \\
3.83 \times 10^{6} \\
3.65 \times 10^{6}\end{array}$ & $\begin{array}{l}2.96 \\
2.77 \\
2.66 \\
2.95 \\
2.77 \\
= \\
= \\
= \\
= \\
= \\
2.98\end{array}$ & $\begin{array}{l}3.82 \\
3.49 \\
2.95 \\
3.35 \\
3.27 \\
2.80 \\
3.38 \\
2.06 \\
2.86 \\
4.79 \\
3.38\end{array}$ & $\begin{array}{l}0.78 \\
0.79 \\
0.90 \\
0.88 \\
0.84 \\
- \\
- \\
- \\
- \\
- \\
0.88\end{array}$ \\
\hline $\begin{array}{l}\text { TRG1 } \\
\text { TRG3 } \\
\text { TRG4 } \\
\text { TRG5 } \\
\text { TRG6 }\end{array}$ & $\begin{array}{r}0.75 \times 10^{6} \\
4.4 \times 10^{6} \\
8.5 \times 10^{6} \\
6.9 \times 10^{6} \\
58.2 \times 10^{6}\end{array}$ & $\begin{array}{l}3.77 \\
3.81 \\
4.15 \\
5.03 \\
4.69\end{array}$ & $\begin{array}{r}1.2 \\
3.0 \\
8.4 \\
6.8 \\
48.5\end{array}$ & $\begin{array}{ll}x & 10^{6} \\
x & 10^{6} \\
x & 10^{6} \\
x & 10^{6} \\
x & 10^{6}\end{array}$ & $\begin{array}{r}1.3 \times 10^{6} \\
5.0 \times 10^{6} \\
9.6 \times 10^{6} \\
7.1 \times 10^{6} \\
54.8 \times 10^{6}\end{array}$ & $\begin{array}{l}1.60 \\
0.68 \\
0.99 \\
0.99 \\
0.83\end{array}$ & $\begin{array}{l}1.73 \\
1.13 \\
1.13 \\
1.03 \\
0.94\end{array}$ & $\begin{array}{l}0.92 \\
0.60 \\
0.88 \\
0.96 \\
0.89\end{array}$ \\
\hline
\end{tabular}

*The empirical modulus, $E_{C}$. is $57,000 \sqrt{f_{C}^{\prime}}$, and the measured modulus, $E_{C_{m}}$, can be computed by the following formula:

$$
E_{C_{m}}=57,000 \sqrt{f_{c}^{\prime}}\left\{\frac{\text { Stiffness Col. 2 }}{\text { Stiffness Col. 3 }}\right\} \text {. }
$$

** Based on the gross section. 
top plate interface was varied along with the amount of moment reinforcement in the form of threaded steel rods located at the ends of the shear wall.

All specimens remained essentially linear up to a load producing a nominalbase shear stress (NBSS) of 200 psi and a principal tensile stress (PTS) of 600 psi or more. The load at first cracking, as predicted from a strength-ofmaterials approach, agreed very well with the measured cracking strength of the wall's and the average split-cylinder tensile strength of 670 psi. Also, when the walls were subjected to repeated load cycles below the first-cracking load, there was no evidence of stiffness degradation or increase in the area of the hysteresis loop for a given load level. Above the first-cracking load, stiffness degraded and the area of the hysteresis loop increased with increased load and increased cycles at a constant load. The ultimate strength of the walls exceeds the provisions for shear capacity, as determined by ACI 349-85, 11.10. The measured stiffnesses in the linear region were down by a factor of 1.90 to 2.05 from the calculated uncracked cross-section stiffness using a measured modulus.

2. 1/30-Scale, Single-Story. Diesel Generator Buildings. Eleven 1/30scale, single-story, diesel generator buildings were statically tested to failure and are reported in Ref. 3. These structures had a geometry identical to that of the second floor of the 1/30-scale, two-story diesel generator buildings (Fig. 2). Nine models were tested monotonically, eight in the transverse direction and one in the longitudinal direction. Two models were tested cyclically, one each in the transverse and longitudinal directions. All these specimens were made with microconcrete and with wire mesh reinforcement. Other than the direction of applied load, the only parameters that were varied in these tests were the amount of cure time each model experienced before testing and the embedment length of the reinforcement into the base of the structure.

As with the isolated shear walls, all specimens remained linear up to the load that produced cracking. This load produced an NBSS on the order of 200 psi and a PTS on the order of 340 psi, assuming the end walls were fully effective in bending. At a given load level below the first-cracking load, the area under the hysteresis 1000 remained constant when the load was cycled and the stiffness remained constant. Above the cracking load, stiffness again was observed to degrade and the area of the hysteresis loop increased with either increases in load level or increases in the number of load cycles. The load at 
first cracking was in good agreement with the value predicted from strength-ofmaterials analysis and the measured tensile stress of the concrete. Provisions for the shear capacity of the walls from ACI 349-85 were exceeded. Stiffness based on a secant from the origin to half the ultimate load were down by factors ranging from 2.7 to 3.0 , when compared with the calculated stiffness based on an uncracked cross section and measured modulus.

It should be noted that the moment of inertia used in the calculated stiffness value and principal stress calculations considered the entire end wall to contribute to the flexural stiffness of the shear wall, and the modulus of elasticity was based on the measured values. No effect from cure time or embedment length was observed.

3. TRG-Type Structures. TRG-3 and the two 1/4-scale models of it, TRG-1 and -2 , were tested statically and monotonically at low-load levels that produced a NBSS of $28 \mathrm{psi}$ and a PTS of $40 \mathrm{psi}$ on TRG-3 and a NBSS of $53 \mathrm{psi}$ and a PTS of 80 psi on TRG-1 and TRG-2. TRG-1 and -2 are shown in Fig. 17 and TRG-3 is shown in Fig. 4.

These tests were repeated several times and were intended to identify the initial stiffness conditior of each model while introducing a minimum amount of damage into the test structure. TRG-3 was constructed with conventional concrete and No. 3 rebar, and TRG-1 and -2 were made with microconcrete and wire mesh reinforcement.

During these low-level tests, TRG-3 showed a measured stiffness up by a factor of 1.47 from the uncracked cross-section stiffness, and TRG-1 showed a reduction of 1.60 from the theoretical stiffness. In both cases, the theoretical stiffness was computed with a measured value of $E_{c}$ and the end walls were considered fully effective in bending. However, the measured modulus for TRG-3 was considerably less than the empirical modulus $\left(2.1 \times 10^{6}\right.$ psi compared to $3.5 \times 10^{6} \mathrm{psi}$ ). TRG-2 was found to have significant shrinkage cracks; results from this model were not considered to be accurate. When properly scaled, the static stiffness values for the two models were in good agreement, showing that stiffness can be scaled from microconcrete to conventional concrete in this low-load level region.

TRG-4 and TRG-5 were tested statically to failure in a cyclic manner and TRG-6 was tested statically to first cracking. TRG-4 is shown in Fig. 5, TRG-5 was identical to TRG-3, and TRG-6 is shown in Fig. 6. TRG-4 and TRG-5 exhibited repeatable linear response with stiffnesses that were almost identical to theory 
until first cracking. TRG-6 exhibited stiffness values that were $20 \%$ above theory until first cracking. This increased stiffness was assumed to result from errors in the deformation readings caused by limitations in the resolution of the instrumentation. For TRG-4, first cracking occurred when a NBSS of 131 psi and a PTS of 171 psi were reached. For TRG-5, this occurred approximately at a NBSS of $167 \mathrm{psi}$ and a PTS of $227 \mathrm{psi}$. For TRG-6, first cracking occurred at a NBSS of $150 \mathrm{psi}$ and a PTS of $169 \mathrm{psi}$. "Approximately" is used with the TRG-5 value because an unplanned load excursion prevented the actual value from being recorded. For TRG-4 and TRG-5, the components of stiffness caused by shear and bending were separated, and these components also agreed with their respective theoretical values. Because of the low aspect ratio of TRG-6, bending deformations could not be accurately measured and, hence, the individual components of stiffness could not be assessed. After cracking, the structures behaved once again in a linear manner when loaded to levels that did not exceed the peak load during the first-cracking cycle. During these cycles, the stiffness in TRG-4 and TRG-5 was down by a factor of 2, with the loss occurring equally in each component of the stiffness. The stiffness in TRG-6 did not degrade as much after cracking as it did with TRG-4 and TRG-5. Only a $25 \%$ reduction in stiffness was observed in TRG-6 after cracking. Figure 23 shows the degradation in stiffness as a function of the NBSS caused by the applied load.

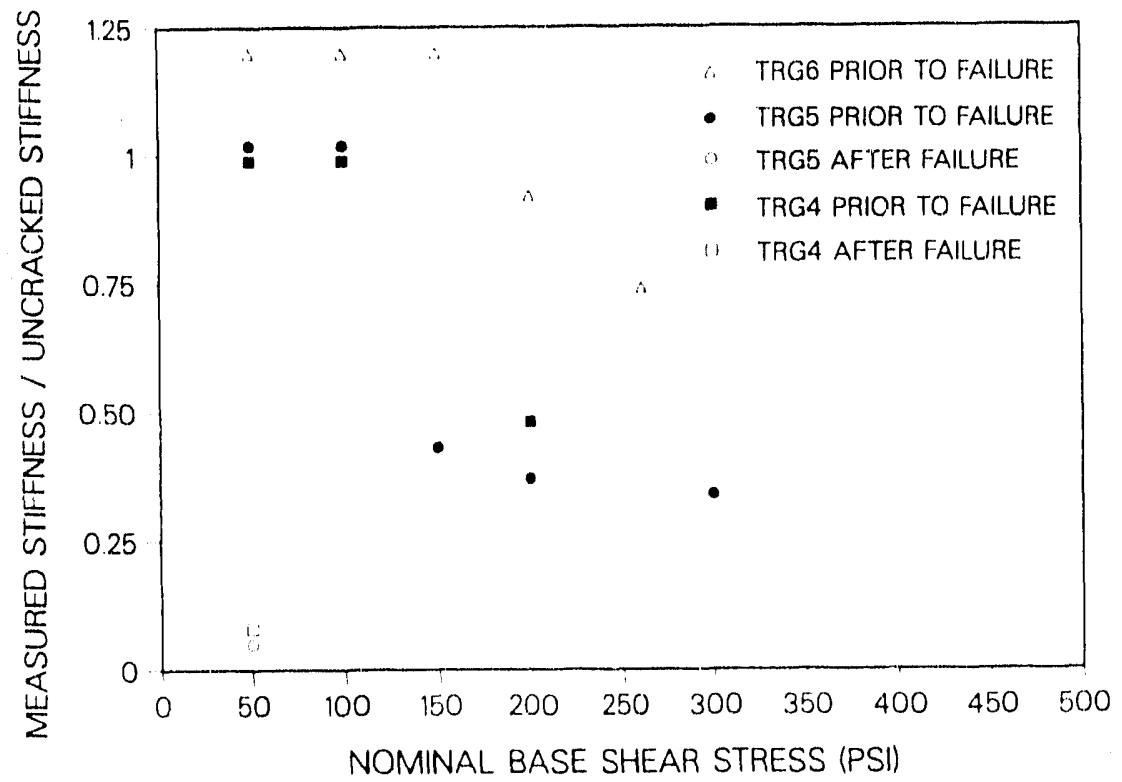

Fig. 23. Reduction in stiffness as a function of the NBSS for the structures that were quasi-statically cycled. 
The testing of TRG-1 is discussed in detail in Ref. 7. TRG-3 testing is discussed in Ref. 8, and the tests on TRG-4 through -6 are reported in Ref. 9 and subsequent reports to be issued by Los Alamos.

B. Review of Previous Dynamic Test Results Obtained in the Seismic Category I Structures Program

Table $X$ summarizes the measured material properties for all the dynamic test specimens except TRG-1 and TRG-3. The properties for TRG-1 and TRG-3 can be found in Table IX.

TABLE $X$

MEASURED PROPERTIES FOR DYNAMIC TEST SPECIMENS

Isolated

Shear Walls

10

11

12

13

21

23

2-2

$1 / 30^{-S c a l e}$,

Single-Story

Diesel Generator

Building

$$
3 \mathrm{D}-5
$$

$3 D-6$

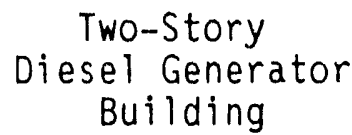

3D-10-2 (1/30-Scale)

$3 D-11-2(1 / 30-S c a l e)$

3D-12-2 (1/30-Scale)

CERL 1 (1/10-Scale)

CERL 2 (1/10-Scale)

Three-Story

Auxiliary

Building

1/42-Scale

1/14-Scale $f_{c}^{\prime}$

(ksi)

7.48

6.27

5.74

6.85

7.18

5.32

7.45

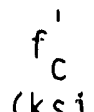

(ksi)

2.62

2.50

$f_{c}^{\prime}$

(ksi)

2.60

2.89

2.78

3.18

3.33

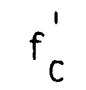

(ksi)

2.90

3.32

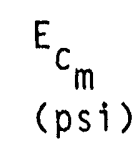

$3.5 \times 10^{6}$

$3.4 \times 10^{6}$

$3.0 \times 10^{6}$

$3.4 \times 10^{6}$

$3.9 \times 10^{6}$

$3.1 \times 10^{6}$

$3.1 \times 10^{6}$

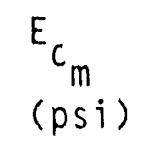

$2.4 \times 10^{6}$
$2.4 \times 10^{6}$

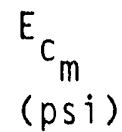

$2.5 \times 10^{6}$

$2.8 \times 10^{6}$

$2.8 \times 10^{6}$

$2.6 \times 10^{6}$

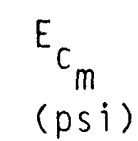

$2.7 \times 10^{6}$

$2.8 \times 10^{6}$
$57,000 \sqrt{f_{c}^{\prime}}$ (psi)

$4.93 \times 10^{6}$

$4.51 \times 10^{6}$

$4.32 \times 10^{6}$

$4.72 \times 1.0^{6}$

$4.83 \times 10^{6}$

$4.16 \times 10^{6}$

$4.92 \times 10^{6}$

$57,000 \sqrt{f_{c}^{\prime}}$ (psi)

$2.92 \times 10^{6}$

$2.85 \times 10^{6}$

$57,000 \sqrt{f_{c}^{\prime}}$
$(p s i)$

$2.91 \times 10^{6}$

$3.06 \times 10^{6}$

$3.01 \times 10^{6}$

$3.21 \times 10^{6}$

$3.29 \times 10^{6}$

$57,000 \sqrt{f^{\prime}}$ (psi)

$3.07 \times 10^{6}$

$3.28 \times 10^{6}$ 
1. Isolated Shear Walls. Four single-story, isolated shear wall structures were subjected to sine-sweep vibration tests. During these tests, the structures had added mass attached, as shown in Fig. 1. The results from these tests are summarized in Table XI. For all dynamic testing, the equivalent stiffness was determined indirectly from the resonant frequency measurements. Initially, these stiffness values were between a factor of 3.6 to 14.3 below the theoretical values, using the measured modulus, and between a factor of 5.0 and 18.1 below the theoretical values, using the ACI empirical modulus.

Two additional tests were performed on single-story isolated shear walls using simulated seismic inputs and raridom inputs. The results from these tests are summarized in Tables XII and XIII. Initially, stiffnesses were down by factors ranging from 4.2 to 5.7 , when the measured modulus was used in the theoretical stiffness calculation; the stiffnesses were down by a factor ranging from 5.7 to 7.1 , when the ACI empirical modulus was used.

Finally, a two-story isolated shear wall structure was tested with simulated seismic and random inputs. The results from this test are summarized in Table XIV. During all the dynamic tests, reductions in the resonant frequencies occurred before there were any visible signs of damage in the structures, and the reductions were greater during the sine-sweep testing than during the simulated-seismic or random testing. A detailed discussion of this testing can be found in Ref. 2 .

2. Diesel Generator Buildings. Two 1/30-scale, single-story diesel generator building models were tested with random inputs. The results of these tests are summarized in Table XV. This table shows the indirectly determined stiffness compared with the theoretical stiffness obtained with an empirical modulus that assumes the entire end wall to be effective in resisting bending.

Five two-story diesel generator models (three 1/30-scale and two 1/10scale), shown in Fig. 2, were tested with simulated seismic and random inputs. The results of these tests are summarized in Table XVI. These tests demonstrated scalability among different-size microconcrete models. Again, the measured resonant frequencies were down by a factor of 1.74 or more; tinis result suggests that stiffnesses were down by a factor of 3.0 or more. The details of all the diesel generator building tests are summarized in Ref. 3 .

3. Auxiliary Building. Two different scale models (1/14- and 1/42-scale) of an auxiliary building were tested with both simulated seismic and random inputs. These structures are shown in Fig. 3 and the results from the i/42- 


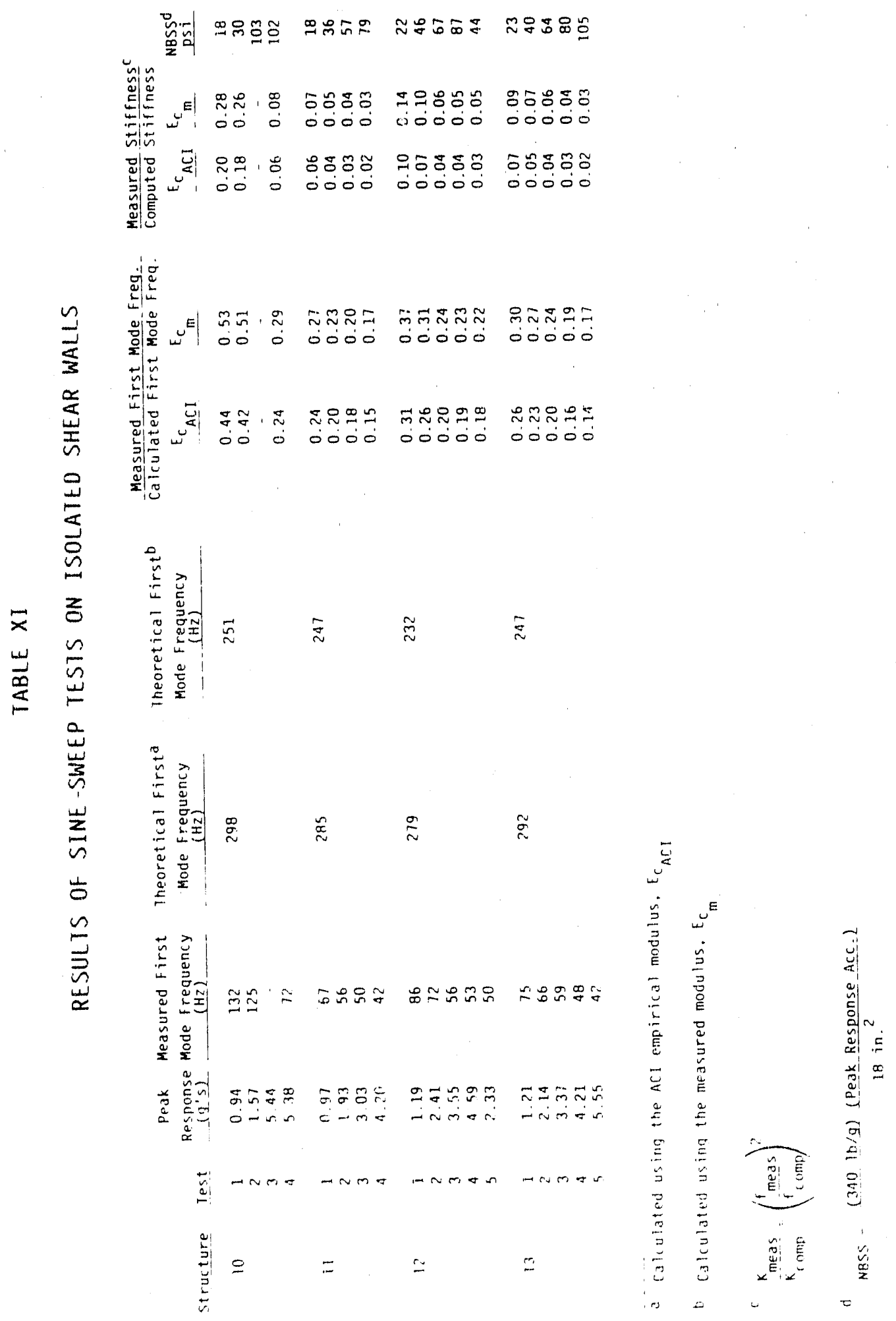




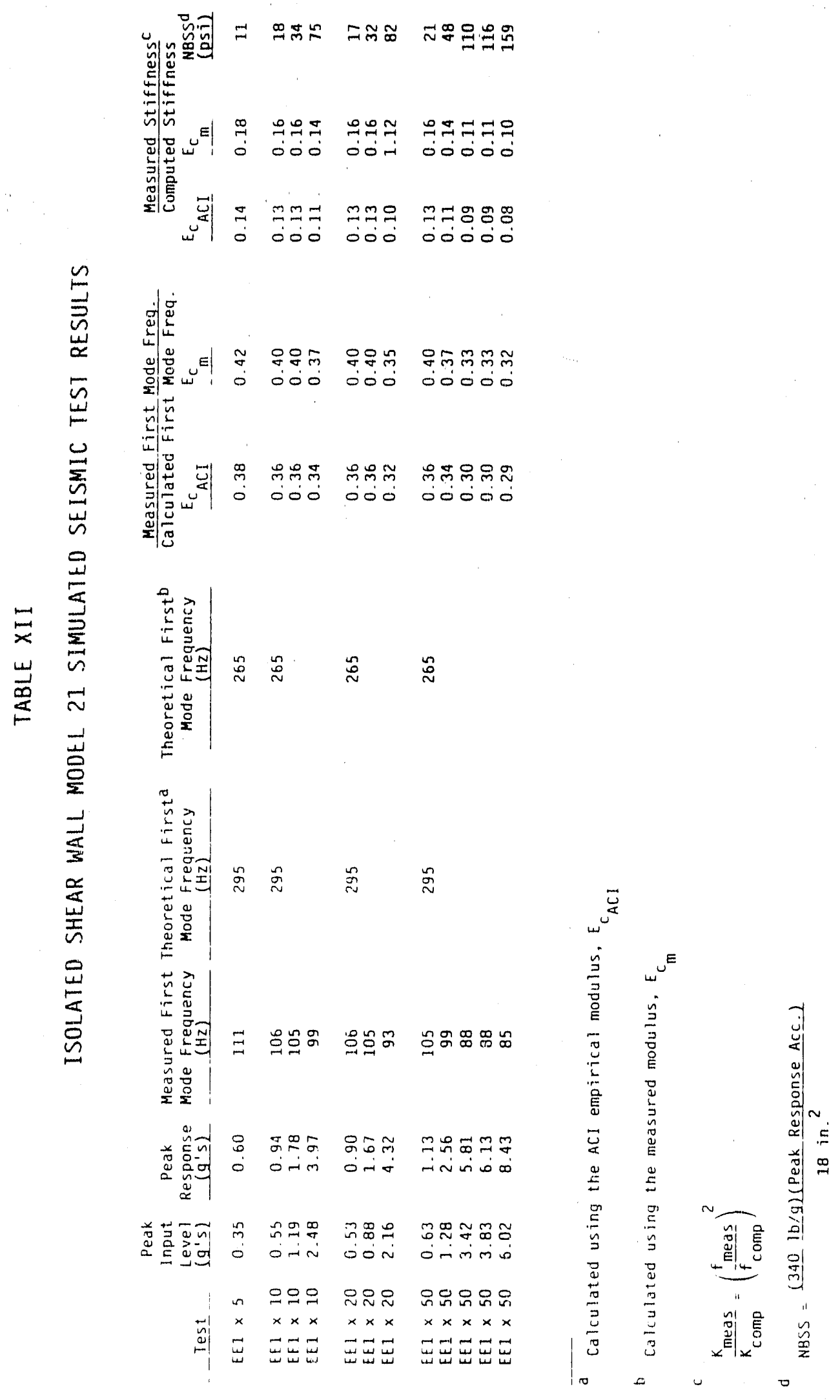



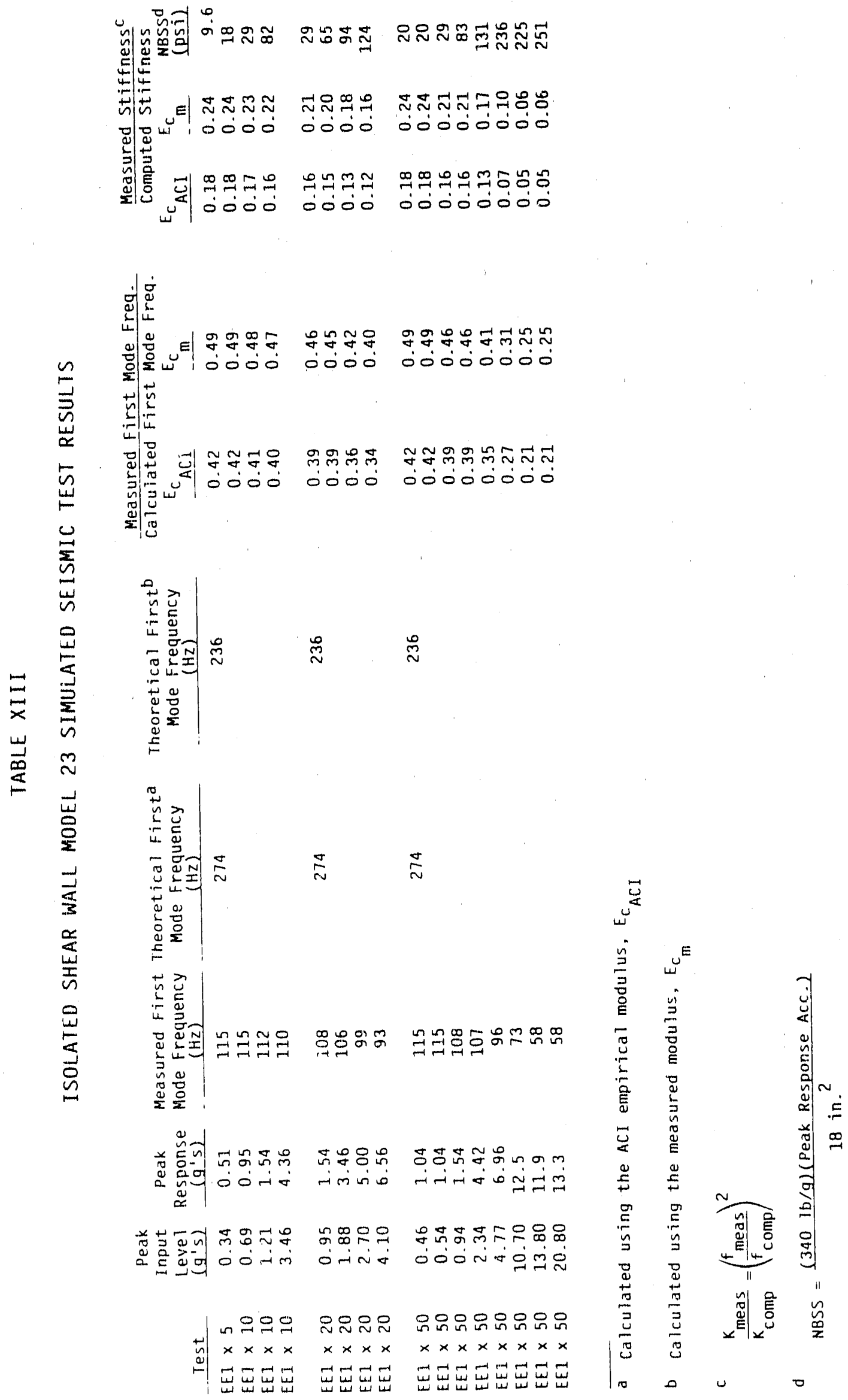


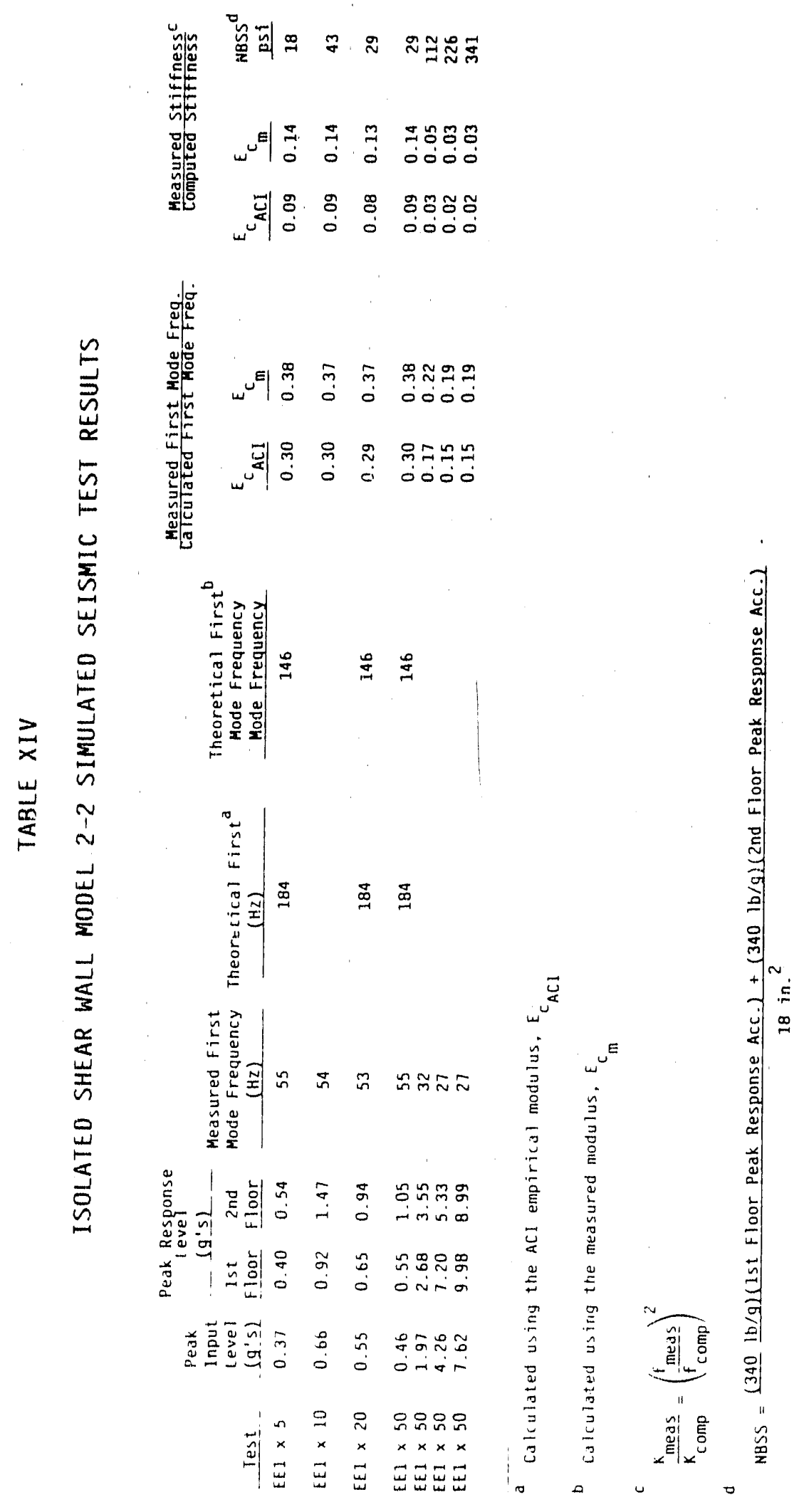




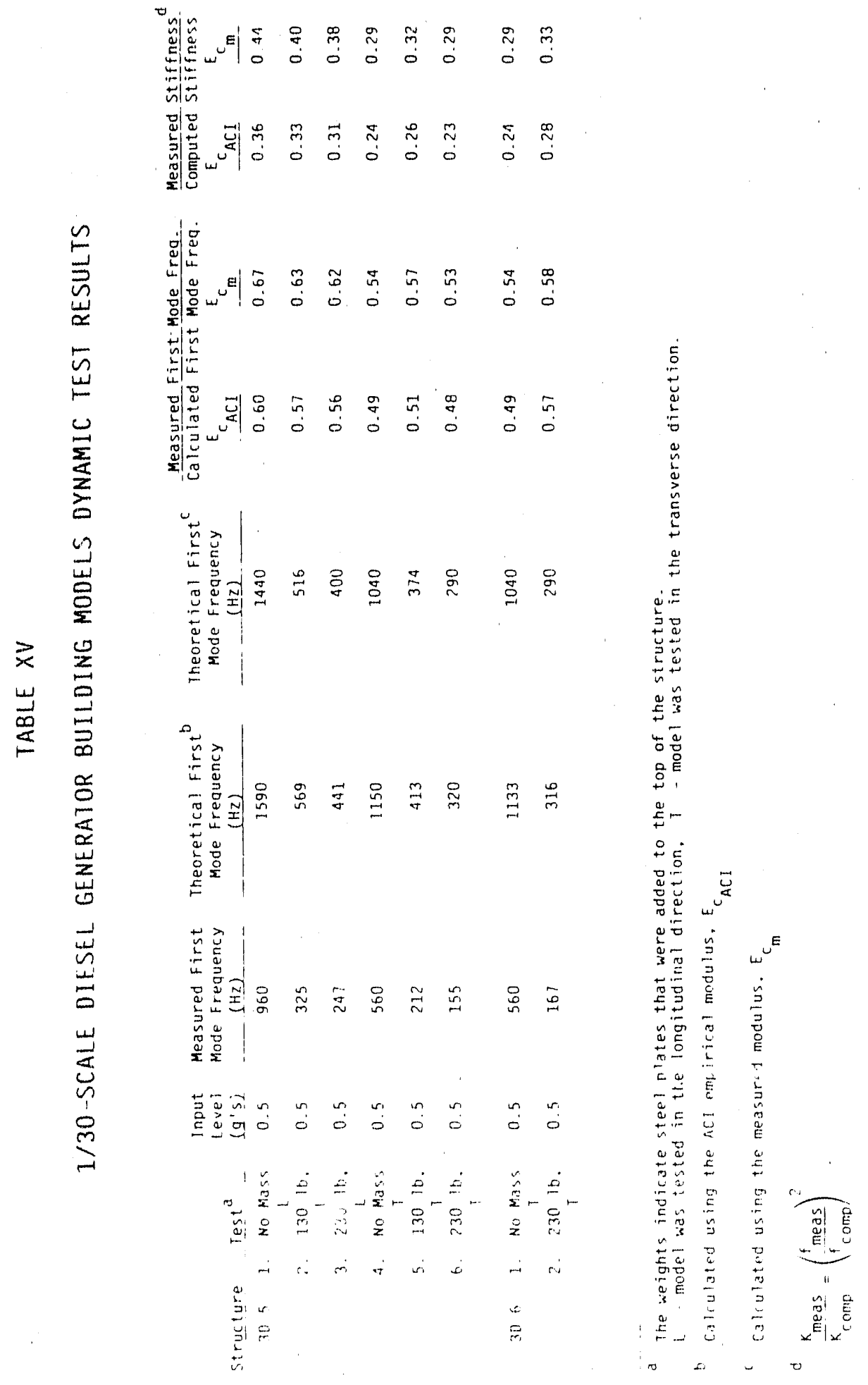



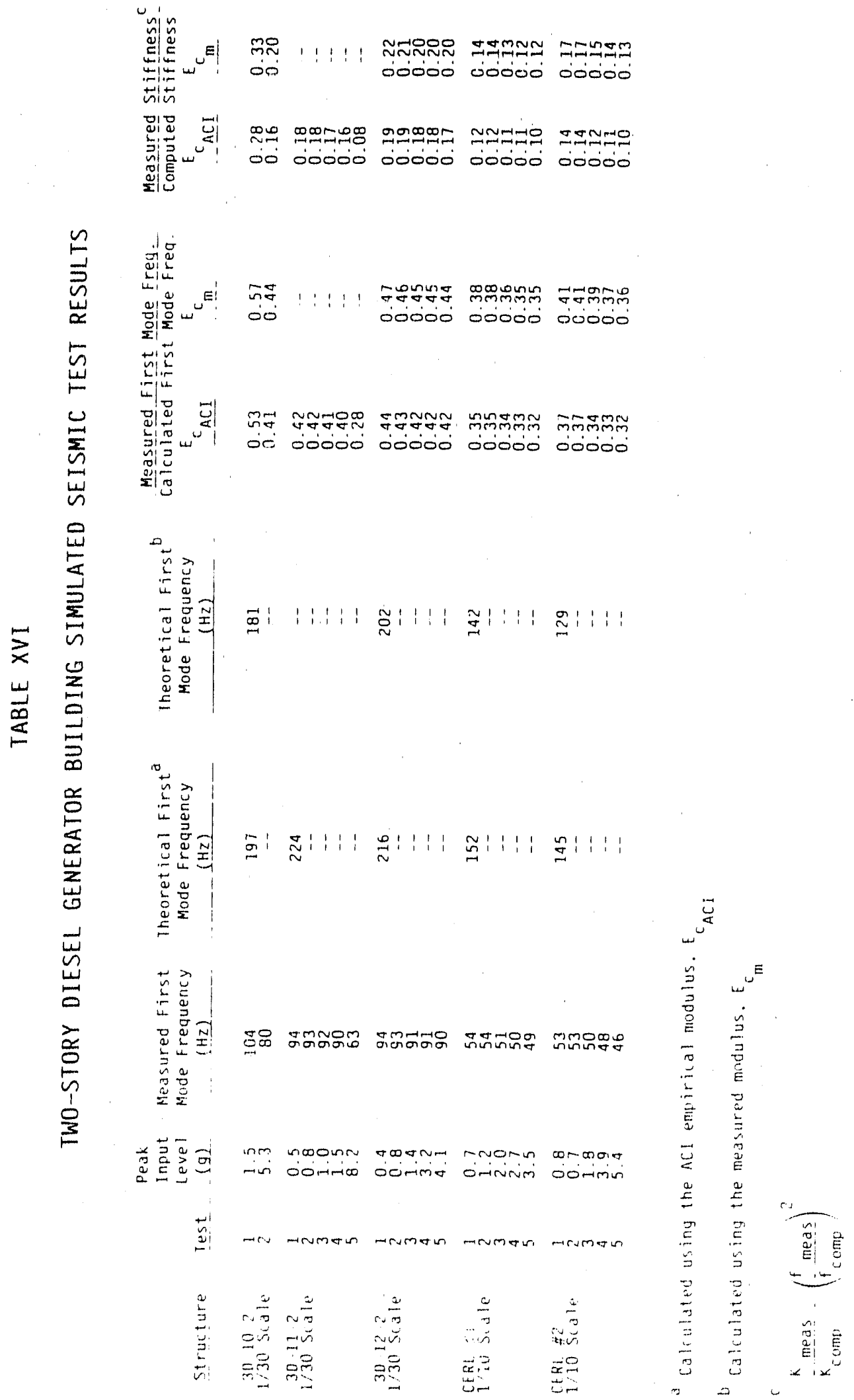
scale models are summarized in Table XVII. The reductions in stiffness shown in Table XVII are consistent with the reductions observed in the two-story diesel generator buildings. An unplanned load excursion occurred while the 1/14-scale model was on the shake table and it produced visible cracking into the structure. Therefore, no data were obtained on this structure in its initial condition. The details of these tests are summarized in Ref. 6 .

4. TRG-Type Structures. TRG-1 and -3 were both tested with simulated seismic inputs. In addition, random inputs were applied to TRG-1 and haversine pulses were applied to TRG-3. Again, stiffnesses determined indirectly from resonant frequency measurements were found to be a factor of 2.6 to 4.0 below the theoretical stiffness values using the measured modulus and assuming the entire end walls were effective in their contribution to the bending stiffness.

When TRG-1 was subjected to a $0.5-g$ peak acceleration random input, it responded with a stiffness that was down by a factor of 2.6 from theory (as inferred from a resonant frequency that was a factor of 1.6 below theory), even though this excitation produced only 16.3 psi NBSS and 16.6 PTS. Similar stiffness values were obtained during a $0.5-g$ seismic test. TRG-3 responded to a 0.73 -g seismic test with a stiffness that was down by a factor of 4.0 from theory at an NBSS of 91 psi and a PTS of 92 psi.

Experimental modal analyses were performed on all the TRG type structures. During these tests, free boundary conditions were simulated by supporting the structures on air-bearings or, in the case of TRG-1, a foam pad. Results of these tests were compared to the results from finite element modal analyses of the structures. In general, the experimental and analytical modal analyses agreed implying that when the structures were subjected to the low level random excitations used during experimental tests, they responded with a stiffness that finite element analyses would have predicted. Table XVIII summarizes the experimental modal analysis results. Dyriamic tests and results for TRG-1 are discussed in Ref. 7. TRG-3 results are discussed in Ref. 8. TRG-4 modal analysis results are discussed in Ref. 9 and modal analysis results for TRG-5 and -6 will appear in subsequent Los Alamos reports.

\section{Comparison of Stiffnesses Measured From Static and Dyanmic Test Results}

1. Isolated Shear Walls. When normalized to a common modulus of elasticity, the static stiffness values can be compared with those measured 


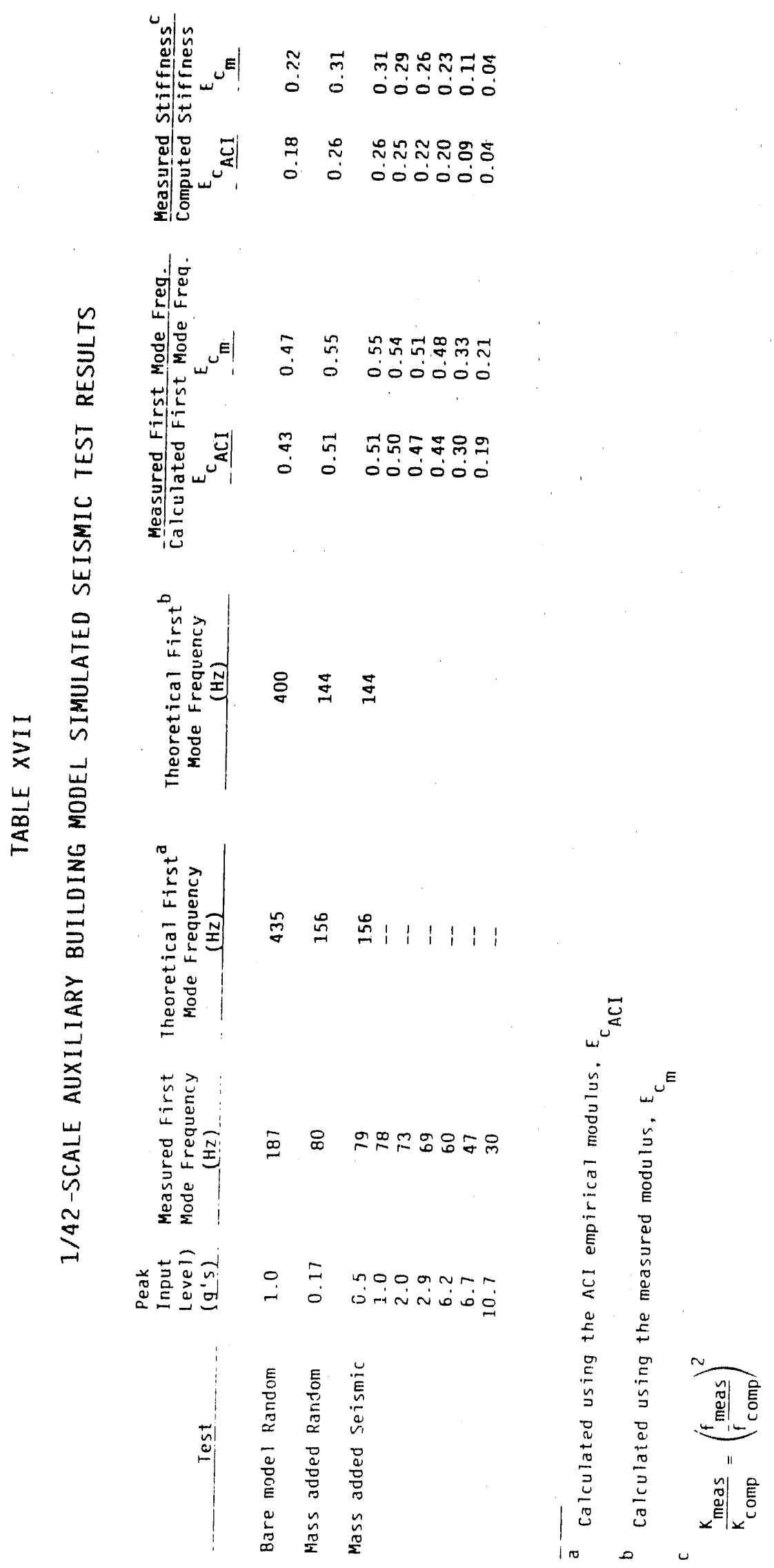




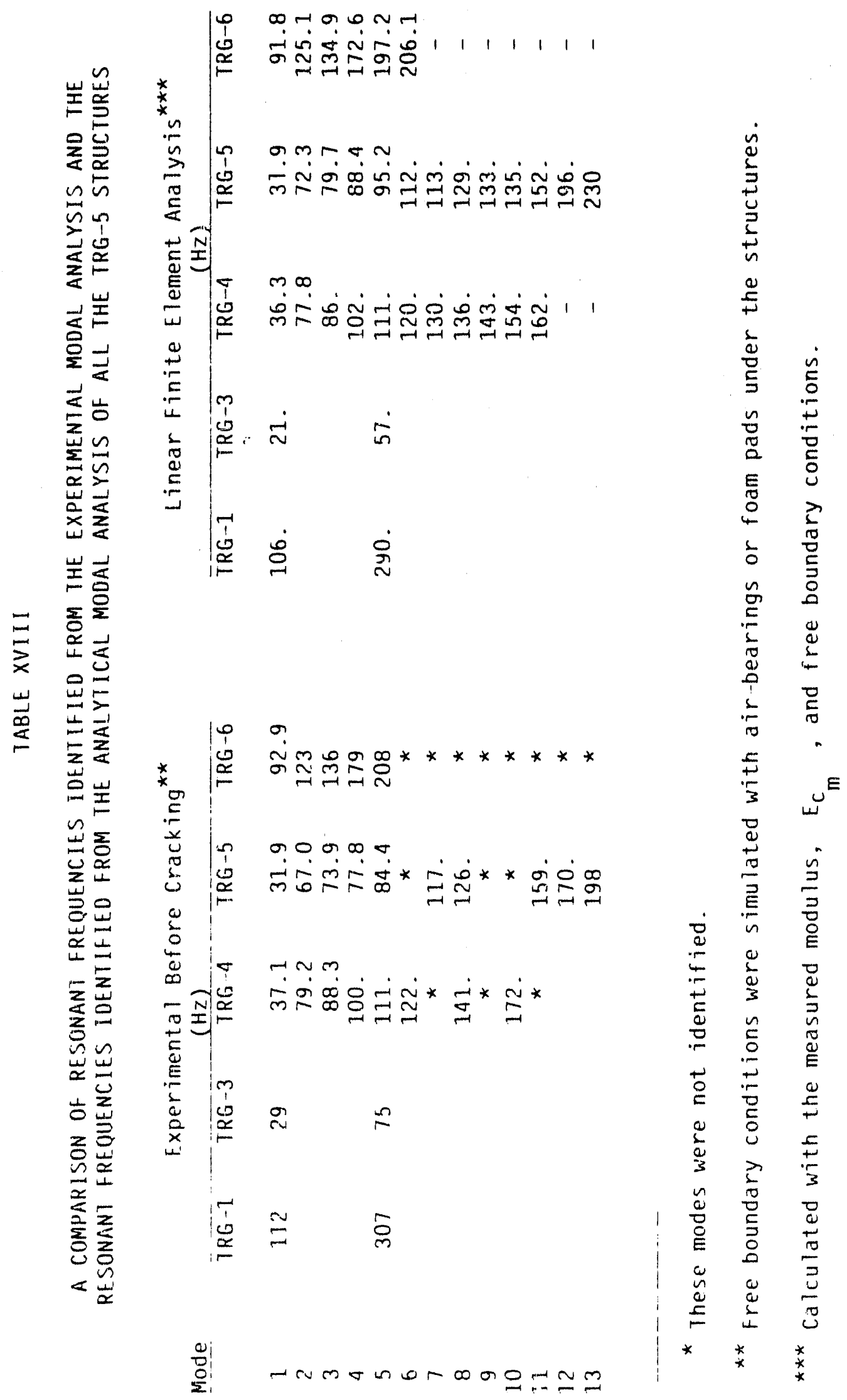


After TRG-3 had been shipped to the shake table facility in Champaign, IL, cracks became visible in the base of the structure; this suggested that the model had been damaged in shipping. 
dynamically during sine-sweep and with simulated seismic tests of similar isolated shear wall models. At force levels that were $10 \%$ of the load required to produce first crackina (200 psi NBSS, 600 psi PTS) in the static test, stiffnesses measured during the sine-sweep and simulated seismic tests were considerably lower than those obtained during static tests. They were even lower than those calculated by using an uncracked cross-section stiffness value with a measured modulus. The sine-sweep and seismic resonant frequency values were down, on the average, by a factor of 2.6 and 2.2 from the calculated uncracked value, respectively. This result suggests that stiffness values were down by an average factor of 6.7 and 4.8 from the calculated uncracked value. In turn, the calculated uncracked values are down by an average factor of 2.9 and 1.9 from the average measured static value.

2. 1/30-Scale, Single-Story Diesel Generator Buildings. When these models were tested dynamically with a $0.5-\mathrm{g}$ 's is peak acceleration random input producing an NBSS of $6.3 \mathrm{psi}$ and a PTS of $10.6 \mathrm{psi}$, the models indicated resonant frequencies that were a factor of 1.7 to 1.95 below theory, suggesting that stiffnesses were down by a factor of 2.9 to 3.8 from the strength-ofmaterials prediction using a measured modulus. These results can be compared with the static results that showed reductions in stiffness between 2.7 and 3.0 from the strength-of-materials prediction using a measured modulus. When normalized to a common modulus of elasticity, the dynamic stiffnesses were, on the average, down by a factor of 1.15 from the static stiffness values. It should be reiterated that the static stiffnesses were determined by a secant from the origin to half the ultimate load, when the NBSS was on the order of $200 \mathrm{psi}$ and the PTS was on the order of $300 \mathrm{psi}$. These stress levels are significantly higher than the ones induced by the dynamic excitations.

3. TRG-1 and TRG-3. TRG-4 exhibited a stiffness that was a factor of 1.60 below theory when tested to a maximum NBSS of $53 \mathrm{psi}$ and a maximum PTS of $28 \mathrm{psi}$. During the first $0.5-\mathrm{g}$ 's peak acceleration random input, the stiffness was down by a factor of 2.6 at excitation levels that produced an NBSS of 16.3 psi and a PTS of 16.3 psi.

TRG-3's static stiffness was a factor of 1.47 above theory when the loads produced a maximum NBSS of $28 \mathrm{psi}$ and a maximum PTS of $40 \mathrm{psi}$. When TRG-3 waS subjected to a $0.73-\mathrm{g}^{\prime} \mathrm{s}$ seismic test that produced an NBSS of 91 psi and a PTS of 92 psi, the stiffness was down by a factor of 4.0 . 
APPENDIX B

THE TECHNICAL REVIEW GROUP'S RESPONSE

TO QUESTIONS CONCERNING THE VALIDITY OF THIS PROGRAM'S RESULTS 
January 4,1988

REVIEW OF TESTS ON MODEL SHEAR WALLS

\begin{abstract}
Appendix I through Appendix XVII give details of a brief review of the literature on tests on shear walls and information on aggregate used on nuclear power plants in the US.

Based upon these and other tests and on the writer's "hands on" experience on the design and field construction of many plants around the world, it is recommended that the results of the Los Alamos tests not be used on the analysis of us nuclear power plants:
\end{abstract}

ken Buchert

\title{
NOTE FROM THE AUTHORS
}

Ken Buchert did not respond directly to the questions that were posed to the TRG. Instead, he sent the above note and appendices. When asked to specifically address the questions over the phone he gave the following answers:

1. Are the tests in this program valid for addressing the program objectives? Ken Buchert's response: No

2. In the light of the program objectives, are the model test data obtained applicable to nuclear power plant structures?

Ken Buchert's response: No

3. Have the technical issues of scaling, instrumentation, and model fabrication effects been resolved?

Ken Buchert's response: No

4. Should there be another "carefully handled" dynamic test to address the possible "dynamic effects" issue? If so, what configuration?

Ken Buchert's response: No

5. Have we obtained enough data and have we tested the correct configurations to meet the program objectives?

Ken Buchert's response: No opinion

6. Would the variability in stiffness observed in the models be observed in real nuclear plant structures at comparable load levels?

Ken Buchert's response: To some extent

In the interest of brevity only a list of the appendices that Ken Buchert sent

to Los Alamos is supplied. 


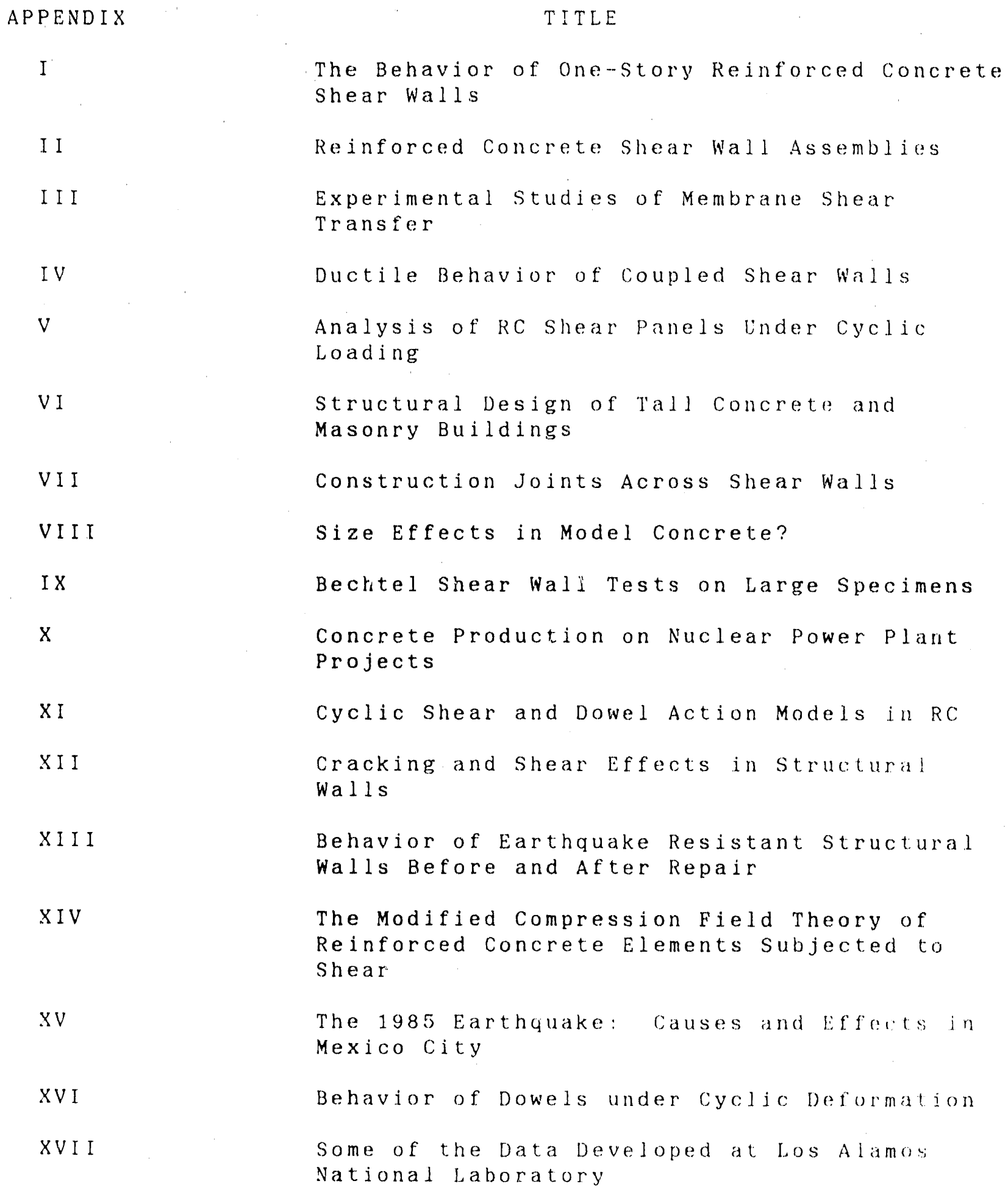




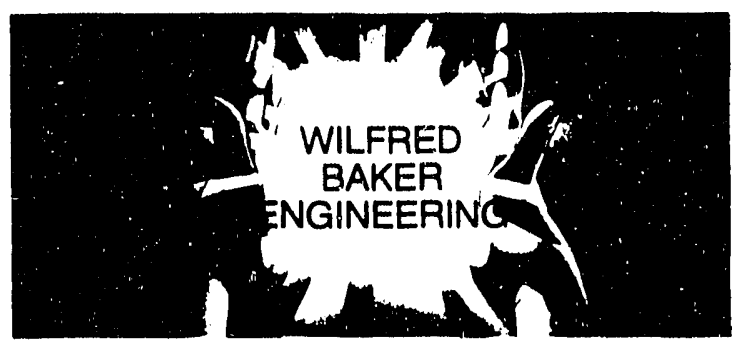

8103 Broadway, Suite 102 • P.O. Box $6477 \bullet$ San Antonio, Texas 78209

(512) $824-5960$

December 30,1987

Mr. Joel G. Bennett

Mail Stop 3576

Los Alamos National Laboratory

Los Alamos, NM 87545

Dear Joel:

I have read (or reread) the reports and papers you sent with your letter of November 16, and have thought at some length about the questions you pose in your letter. Sorry that I couldn't respond in writing before now, but we seem to be having a pre-Christmas rush in our small business. I will now try to follow up my earlier phone call with this written response. I will take your questions in order:

1. Are the tests in this program valid for addressing the program objectives?

I feel that the tests in this program are indeed valid for addressing the program objectives (if not, then we all ought to turn in our union cards).

2. In light of the program objectives, are the model test data obtained applicable to nuclear power plant structures?

I believe that the model test data most certainly should apply to the classes of nuclear power plant structures they were intended to represent. I probably have fewer reservations on the applicability of model test data to larger structures than many of the TRG.

3. Have the technical issues of scaling, instrumentation and model fabrication effects been resolved?

The model analysis has been done carefully and correctly. Instrumentation has, in my opinion, been excellent to superior throughout the parts of the program I have followed in detail. I also believe that model fabrication effects have been largely resolved, and that the issue Ken Buchert raises regarding lack of very detailed testing or characterization of the aggregate for the latest models is a minor issue, havirig little effect on test results. But, one key issue certainly appears to be unresolved. That is, "Why are the stiffnesses of the last two TRG models the only measured stiffiesses in the entire program which reach the full ralues calculated using streng th of materials me thods for uncracked concrete?" 
irr. Joel G. Bennett

Los Alamos National Laboratory

December 30, 1987

Page 2

\section{Should there be another "carefully handled" dynamic test to address the possible "dynamic effects" issue? If so, what configuration?}

It is possible that another dynamic test or tests on carefully handled models could address this issue. I will defer to other TRG members in choosing a configuration, but the size and configuration must be well within the testing capabilities of the test facility.

5. Have we obtained enough data and have we tested the correct configurations to meet the program objectives?

I feel that you certainly have enough data on the configurations tested. As to whether the current configurations are the correct ones, I will defer to other members of the TRG.

6. Would the variability in stiffness observed in the models be observed in real nuclear plant structures at comparable load levels?

In response to this question, I have a reply which the NRC and other inembers of the TRG may feel is impractical. My reply is, "Why don't you find out?" At least, find out what the stiffnesses are for shear walls in existing plant structures by "thumping" them and measuring their response frequencies toge ther with as-built drawings. This should allow stiffness calculations to be easily made. The "thumper" could be an air impulser, of a type developed primarily by SwRI to impulse-load a large submarine hull model. It utilizes a compressed gas bottle with an expansion nozzle, opened rapidly by a rupture disc at the nozzle throat. A very fast rising reaction force occurs, with exponential decay as the vessel exhausts.

In-service buildings could be tested with no damage, or out-of-service buildings could perhaps be subjected to larger impulses.

Perhaps this idea is unreasonable or too expensive to field, but I feel it would perhaps give us more useful information than building and dynamically testing one or more new structural inodels.

Joel, I hope that this letter and my suggestions are of some use to you and Roger Keanneally.

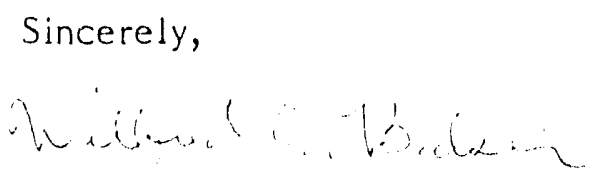

Dr. Wilfred E. Baker

President

/ trne 
December 11,1987

Dr. Joel G. Bennett

Mail Stop 3576

Advanced Engineering Technology

LOS ALAMOS NATIONAL LABORATORY

LOS Alamos, NM 87545

\section{RE: STIFFNESS OF CONCRETE LOW-RISE SHEAR WALL STRUCTURES TEST PROGRAM}

Dear Joel:

This letter is being written in response to your request for written comments from the Technical Review Group (TRG) on the subject test program.

\section{Background Comments}

In 1982, a whole series of small-scale shear wall structures were tested both cyclic statically and dynamically, using a simulated seismic time history. These test structures were made of microconcrete and model rebar. Such model test structures contained both 1 " thick walls (called 1/30- and 1/42-scale tests) and 3" thick walls (called 1/10- and 1/14-scale tests). One of the purposes of these tests was to better understand the stiffness of concrete low-rise shear wall structures under SSE and lesser levels of seismic shaking. Another purpose was to better understand the influence of stiffness degradation at higher levels of shaking on in-structure (floor) spectra to which equipment are subjected.

It is my understanding that all of these tests (both cyclic static and dynamic) exhibited substantial reduction in overall stiffness or natural frequency below values computed using uncracked-strength-of-materials approaches at low input load levels (less than 100 psi average shear stress). The reduction of stiffness below that computed from uncracked-strength-ofmaterials approaches tended to average about a factor of 4 at shear stress levels corresponding to about OBE seismic input. At higher shaking levels, the stiffness continued to degrade to factors substantially greater than 4 below the computed uncracked stiffness.

Frankly, I was very surprised at the fairly consistent reduction of stiffness of about a factor of 4 below the computed uncracked stiffness at input levels resulting in average shear stresses less than $100 \mathrm{psi}$ and sometimes even less than $50 \mathrm{psi}$. The further reduction of stiffness at higher stress levels beyond concrete-cracking stress levels was expected and is consistent with

theoretical models. Because of several open issues concerning these tests of 
Dr. Joel G. Bennett

LOS ALAMOS NATIONAL LABORATORY

December 11,1987

2

microconcrete models, I could not fully support that these tests demonstrated that real concrete low-rise shear wall structures were likely to have reduced stiffness of about a factor of 4 below the computed uncracked stiffness when at low average shear stress levels of less than about $100 \mathrm{psi}$. I judged that these tests exaggerated the effect, but that they did demonstrate that significant reduction at low stress levels was certainly possible. The open issues with these tests were all related to the small scale of the models and the use of microconcrete. Because of the small scale, about anything could reduce stiffness.

In my judgment:

1. Trivial amounts of base rotation or base attachment flexibility could easily account for a factor of 4 stiffness reduction in these small models.

2. Thin walls (1" and $3^{\prime \prime}$ thick walls) can more easily be cracked by shrinkage, aging, and handling effects than could actual walls which are generally $12^{\prime \prime}$ and greater thickness. Furthermore, any existing non-visible cracks of such small-scale models could have more influence on their stiffness than could small, only slightly visible or non-visible cracks on real-scale prototype walls.

3. There is likely to be less aggregate interlock in small-scale models with microconcrete than in full-scale walls. With less aggregate interlock, cracks could result in a greater reduction of stiffness. Thus, small-scale models of microconcrete with cracks could seriously underestimate the stiffness of full-scale models with cracks.

4. Normal stresses were very low in these small-scale models (generally less than 20 psi, if I recall correctly). Normal stresses should help to hold cracks closed and, together with aggregate interlock, should help to lessen the reduction of stiffness at low shear stress levels.

Because of these open issues, the TRG (including myself) recommended testing of a larger-scale structure. This structure was to be of normal concrete with actual rebar. Wall thickness was to be at least 4", and the uncracked natural frequency was to be less than $30 \mathrm{~Hz}$. Substantial top mass was to be added by steel plates to lower the natural frequency and to provide a more realistic and higher normal stress of about 40 psi, which unfortunately is still low compared to most prototype structures. To meet these requirements, TRG-3 was constructed and tested dynamically by simulated seismic shaking on a shake table. Stiffnesses back-calculated from the natural frequency of this test structure at low shaking levels (less than 50 psi average shear stress) also 
Dr. Joel G. Bennett

LOS ALAMOS NATIONAL LABORATORY

December 11, 1987

3

showed about a factor of 4 reduction from the computed uncracked stiffness. Thus, this dynamic testing of TRG-3 seemed to support the tentative conclusions drawn from the small-scale testing.

Unfortunately, TRG-3 seems to contain most of the same open issues as listed previously for the smaller-scale tests, but to a lesser extent. These issues cloud the results of TRG-3:

1. No direct measurements of structure relative deformation were made. Therefore, estimates of stiffness had to be back-calculated from natural frequencies. These natural frequencies could be heavily influenced by base rotation; and such rotations, if present, would cloud the estimates of stiffness. From the limited data I have seen, it still seems probable to me that substantial base rotation effects did occur. For example, the results shown in Figures 16 and 17 of the FY 1986 Rough Draft Final Report for TRG-3 subjected to a haversine pulse are completely consistent with this assumption of substantial base rotation effects. The base $s 1 a b$ and the top of the structure are both oscillating at about $8 \mathrm{~Hz}$, as seen in Figure 16. This result, together with the transfer function of Figure 17, indicates to me a predominant base rotational mode at $8 \mathrm{~Hz}$ rotating about a point located below the base slab.

2. The walls are still thin and the normal stresses are still somewhat low relative to a prototype full-scale structure. These two conditions might result in more cracking and might result in greater reduction in stiffness due to cracking than would occur in a fullscale structure.

3. TRG-3 was built at LOS Alamos and shipped to the shake table at CERL in Illinois. This handling and transportation could have resulted in more cracking of TRG-3 prior to the low-level shake-tabTe test than would exist in an aged prototype structure. However, visible cracking did not appear to be present prior to testing.

Because of concern over issues 1 and 3 , two additional tests (TRG-4 and TRG-5) were performed. Both structures were constructed of normal concrete with actual rebar. TRG-4 had 6" thick walls, and TRG-5 had 4" thick walls. Both models were subjected to cyclic static tests, and both models were handled very carefully prior to being tested to low shear stress levels so that they represented "virgin" uncracked concrete models to the greatest extent practical prior to testing. An internal relative deformation instrumentation system was used so that direct measurements of relative deformations could be taken. This enabled shear and bending deformations to be separately estimated. Also any deformations due to base rotation or base flexibility effects were not included in these measurements, so that base effects could not "cloud" the 
Dr. Joel G. Bennett

LOS ALAMOS NATIONAL LABORATORY

December 11,1987

4

data. Because of the impracticality of adding additional top weight, normal stresses were still low (about 20 psi for TRG-4 and 40 psi for TRG-5, I believe).

Low-level cyclic static tests on these "virgin" uncracked concrete models produced relative deformations in "essentially exact" agreement with those predicted by uncracked concrete stiffness models. Thus, these two tests produced results contradictory to those obtained from all previous tests within this program. The results were exactly as I would expect for "virgin" uncracked concrete models. As the cyclic average shear stress levels were increased to beyond the cracking stress level, stiffness of these models did degrade as one would expect. Prior to reaching their ultimate cyclic loadcarrying capacity (at roughly expected levels), the secant stiffness of these models appears to have degraded to less than $10 \%$ of their uncracked stiffness. I can fully support all test results which I have seen for these wellinstrumented, carefully handled TRG-4 and TRG-5 "virgin" uncracked concrete models. These results will be very useful in defining stiffness degradation of uncracked concrete structures when subjected to high average shear stress cyclic loading from seismic input. Although these tests were cyclic static tests, the measured hysteretic behavior with stiffness degradation can be used analytically to study the effect in floor spectra from increased seismic shaking levels.

However, the results of TRG-4 and TRG-5 tests cannot be used to conclusively demonstrate that uncracked stiffness estimates can be used for estimating the stiffness of actual structures at low cyclic shaking stress levels less than about $100 \mathrm{psi}$. These test models were so carefully handled that they are not likely to be representative of actual structures after 20 or more years of Tife. Actual concrete shear walls crack due to shrinkage, aging, thermal loadings, vibration loadings, and soil settlement over time. Such cracking will undoubtedly be greater than that contained in TRG-4 and TRG-5 prior to testing.

Observations

This test program has rot provided conclusive results concerning the stiffness of low-rise concrete shear wall structures at lower OBE-type stress levels. A number of issues "cloud" all of the smaller-scale test results, as well as the results of TRG-3. Severe doubt can likely be cast on results of all of these tests which show a substantial reduction (about a factor of 4 ) in stiffness below the computed uncracked stiffness at low shear stress levels, because of these "clouding" issues by those who do not believe these results. The results of TRG-4 and TRG-5, which were better-instrumented and better-handled, can be used to support these doubts. However, real structures are likely to be cracked to some extent, and the use of uncracked stiffness estimates may 
Or. Joel G. Bennett

LOS ALAMOS NATIONAL LABORATORY

December 11, 1987

5

not be appropriate for such structures, even though uncracked stiffness estimates worked well for the "virgin" uncracked TRG-4 and TRG-5 models. In my opinion, the results of this test program have simply added "fuel" to the controversy rather than resolving the issue. This conclusion is not meant as a criticism of the test program; I am not sure any model structure test program could resolve this controversy. Certainly this test program provided a substantial quantity of very interesting data.

In my opinion, the stiffness of low-rise concrete shear wall structures at low shear stress levels is highly uncertain at this time. I suspect it is unlikely that real structures with substantial normal stress (40 to 100 psi) on the shear walls have stiffnesses at low shear stress levels (50 to 100 psi) reduced by as much as a factor of 4 below those estimated from uncracked models. On the other hand, I suspect that a substantial number of such structures, after time, have stiffnesses well below their uncracked stiffness, even at low shear stress levels. Because of this strong possibility, I believe we should be studying the consequences of such stiffness reduction for equipment mounted in structures which are currently estimated to have stiffnesses estimated to exceed about $3 \mathrm{~Hz}$ using uncracked stiffness models. Design earthquakes tend to have their power concentrated at frequencies below about $7 \mathrm{~Hz}$, so that structure models with frequencies in excess of about $9 \mathrm{~Hz}$ tend to escape this power; thus the input to equipment is likely to be increased if the actual stiffness is substantialiy less than that used in the structure analysis.

This test program has done an excellent job of demonstrating the stiffness degradation that occurs at higher shear stress levels between the cracking stress and the ultimate strength. All of the tests (both the small models and TRG-4 and TRG-5) demonstrate this reduction, and it seems to be reasonably consistent from test to test. I believe that each of the tests showed at least a factor of 10 reduction in stiffress below the uncracked stiffness before the ultimate cyclic capacity was reached. Particularly, TRG-4 and TRG-5 provide excellent data on the cyclic hysteretic behavior with stiffness degradation of these low-rise shear walls because of the excellent instrumentation available on these tests.

This test program has also provided excellent data on how floor spectra shift as shaking levels are increased. This shift in fToor spectra is observed in the dynamic small-scale tests and can be studied analytically from the TRG-4 and TRG-5 hysteretic data. This test data is also available for studying the necessary characteristics of simplified mathematical models used to estimate floor spectra. For instance, preliminary investigations have indicated that even with substantial frequency shift, pseudo-linear-elastic models with reduced frequency and damping in the 7\% to $10 \%$ range and sometimes higher can be used to estimate the measured floor spectra at high shaking levels. 
Dr. Joel G. Bennett

LOS ALAMOS NATIONAL LABORATORY

December 11, 1987

6

Thus, although this test program has not conclusively resolved the question of low-rise concrete shear wall stiffness at low shear stress levels, it has conclusively demoristrated the further reduction of these stiffnesses to values miuch below the uncracked stiffness as shear stress levels are increased to values approaching the shear wall capacity. This test program has provided the necessary data to study the effects of such stiffness shifts on floor spectra.

\section{Recommendations for Additional Testing}

I believe it would be very useful to conduct one larger-scale dynamic shake table test on a carefully handled, well-instrumented "virgin" uncracked model made of normal concrete and actual rebar. To date we have no such test in this program. This model could look very much like TRG-3. However, it should be built at the shake table site and carefully handled so as to avoid the handling and transportation questions associated with TRG-3. Normal stresses should be at least 40 psi. This model should have instrumentation capable of reliably measuring internal relative deformations during dynamic shaking simi... 1 ar to the measurements taken on TRG-4 and TRG-5. This instrumentation is absolutely necessary so as to directly obtain dynamic stiffness information "unclouded" by base rotation or base flexibility effects. It is not clear to me whether such measurements can be reliably made during a dynamic shake lable test. Inless such measurements can be reliably obtained, I see viry litilo purpose to this test.

I expect that a carefully handled, well.. instrumented "virgin" uncracked TRG 3 model subjected to a dynamic shake table test will produce stiffiness reculi: in agreement with TRG-4 and TRG-5; in other words, that an uncracked st if m. model adequately models its stiffness at low stress lovels. If this povi. i: be the case, then this test can produce data for several comparison atui.....

1. Is the degradation of stiffness during the dyamic test at highei shaking levels, similar to that observed in the cyclic statio tost. of TRG-4 and TRG-5?

2. Can floor spectra measured at the top of this structure during dynamic tests be adequately estimated using the hysteretic ard degrading stiffness properties observed during the cyclic satio tests?

These studies are very important to confirm our ability to predict. dyman. behavior from mathematic models based on cyclic static test data.

If the unexpected occurs and the carefully handled, well insirumentad "viring" uncracked TRG-3 model during low-level dynamic tests exhibits abstantiall: 
Dr. Joel G. Bennett

LOS ALAMOS NATIONAL LABORATORY

December 11, 1987

7

less than the uncracked stiffness, this result would indicate a serious difference between the dynamic and the cyclic static behavior of TRG-4 and TRG-5. This result would provide more credence to the small-scale test results and the current TRG-3 results. Either way, this test should provide important additional data, so long as the model is a large-scale "virgin" uncracked model and internal relative deformations are reliably measured.

However, this test will not resolve the question of the stiffness of low-rise concrete shear wall structures under OBE and SSE shaking levels. After time, real structures are likely to be cracked. This new model should be a "virgin" uncracked mode?, and in this regard it is like?y to underestimate the stiffness reduction below the uncracked stiffness at low shaking levels. Furthermore, the model wall is still thin (4" or 6") relative to actual walls, and thus might overestimate the stiffness reduction due to cracking for actual thicker walls. Lastiy, the normal stress on the model wall will still be low (probably cannot get much above $40 \mathrm{psi}$ ) because of the difficulty of adding sufficient top weight or vertical preload. Thus, the model wall might overestimate the stiffness reduction of cracked actual walls because of the Tesser normal stress. Therefore, no matter what this test produces, I do not expect it to resolve the question of the stiffness of low-rise concrete shear wall structures at low average shear stress levels.

The most convincing (but very costly) way to resolve the question of the stiffness of actual low-rise concrete shear wall structures is to test several structures. Ideally, such tests should use a very large eccentric mass oscillatory, such as that used on the HDR structure in Germany. Furthermore, internal relative deformations need to be measured to avoid "clouding" the results with base flexibility effects. Short of these tests, I am not sure the issue of stiffness of actual structures will be resolved.

Some people have suggested using the large-scale reactor building test structure built by Niagara Mohawk and EPRI at Nine-Mile Point. However, being a model, this structure will not have adequate normal stress to be representative of actual walls, and there will be base rotation effects, again necessitating the measurement of internal relative deformations during dynamic testing. I think tests of this structure would be useful, but not conclusive.

Summary Responses to Specific Questions

Although I believe that I have provided my response to each of your questions in the preceding write-up, to be sure I am responsive I will summarize my response to each question: 
Or. Joel G. Bennett

December 11, 1987

8

1. Are the tests in this program valid for addressing the program objectives?

These tests are valid for addressing the question of stiffness degradation with increasing levels of shaking input and the influence of this degradation on floor spectra and equipment input. The test program has not been particularly valid or conclusive for addressing the stiffness of low-rise concrete shear wall structures at low shear stress levels (less than about $100 \mathrm{psi}$ ). The important issues are: How cracked are actual structures; and how much do these cracks reduce the stiffness of these structures? The small model test results probably overemphasize these issues and TRG-4 and TRG-5 being "virgin" uncracked models should underestimate the influence of cracking.

2. In light of the program objectives, are the model test data obtained applicable to nuclear power plant structures?

Open issues discussed in the Background Comments and Observations sections "cloud" each of the sets of test data. Therefore, none of the test data is totally applicable to nuclear power plant structures. However, the stiffness degradation below the uncracked stiffness of nuclear power plant structures is likely to be bounded between the small scale model and TRG-3 results on one side and TRG-4 and TRG-5 results on the other. This comment is expanded upon in my observations section.

3. Have the technical issues of scaling, instrumentation, and model fabrication effects been resclved?

The technical issue of scaling has been resolved. However, the open issues of base flexibility and rotation effects, and the influence of wali thickness, normal stress, and aggregate interlock on cracking and stiffness reduction has not been resolved. Except for the above, model fabrication effects have been resolved, in my opinion. TRG-4 and TRG-5 had adequate instrumentation. The other tests either did not have adequate instrumentation or else the data has not been adequately processed to fully resolve the issue of base rotation and flexibility effects, at least in my mind.

4. Should there be another "carefully handled" dynamic test to address the possible "dynamic effects" issue? If so, what configuration?

Yes. My recommendations for this test are contained in the Recommendations for Additional Testing section. 
Dr. Joel G. Bennett

December 11, 1987

9

5. Have we obtained enough data and have we tested the correct configurations to meet the program objectives?

With one more dynamic test as discussed in my Recommendations for Additional Testing section, I believe we have obtained the data we are going to obtain from model testing, and have tested correct and sufficient configurations. I cannot recommend any more such test.s beyond one more dynamic test.

6. Would the variability in stiffness observed in the models be observed in real nuclear plant structures at comparable load levels?

I doubt that the variability in stiffness relative to the uncracked stiffness in real nuclear power plants will be as great as that observed in the full range of these model tests, including TRG-4 and TRG-5. However, I expect the variability in real nuclear plant stiffnesses will be substantial, and stiffnesses significantly less than the uncracked stiffness should be considered possible. My comments on this question are expanded upon in the observations section.

Very truly yours,

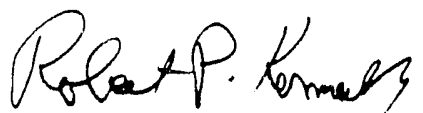

Robert $P$. Kennedy

RPK : Ims 


\section{Tennessee Valley Authority}

KNOXVILLE. TENNESSEE 37902

400 West Sumit Hill Drive, W9 D191

Los Alamos National Laboratory

Los Alamos, New Mexico 87545

Attention: Mr. Joel G. Bennett

Gentlemen:

REVIEW OF OBJECTIVES AND PROGRESS OF THE SEISMIC CATEGORY I STRUCTURES PROGRAM

Reference: Your letter to me dated November 16, 1987, MEE-13:87:567

I have reviewed the materials cited in the referenced letter with the purpose of answering the six questions that were asked of the Technical Review Group. I have given below my "bottom line" answers to the six questions without, for the most part, the basis or rationale for the answers.

1. Yes. The progression of the models used (one-story shear walls, two-story shear walls, box structure and TGR structure), tests performed (static tests, cyclic tests, dynamic tests) and analysis is a logical and purposeful approach.

2. Yes, with this qualification--the model tests clearly show that the stiffness of reinforced concrete structures are degraded by cyclic loadings, and consequently, the stiffness of nuclear power plant structures will be degraded under repeated cycles of strong motion earthquake. The model tests probably do not predict accurately the magnitude of the loss of stiffness. Furthermore, it is not clear that the reduction of the precracked stiffness shown by the model tests, based on strength of materials (SOM) analysis, are true indications.

3. No, as it relates to scaling of the responses to full size nuclear power plant structures.

4. I do not have a recommendation at this time. I would wailt to study the previous tests results some more.

5. Yes and no. Simply stated that tests performed answer a basic question that the response of nuclear power plant structures when subjected to several cycles of strong earthquake ground motion will not be as predicted by linear, SOM analyses based on gross section properties.

The test available to date, in my opinion, is not sufficient to answer, quantitively, what reduction in stiffness should be considered in design or evaluation of structures. 
Mr. Joel G. Bennett

The response of structures to low (OBE level) earthquakes falls into a "grey zone" between mostly the precracked state and where opening of the microcracks have clearly reduced the structural stiffness.

6. Yes, in my opinion, because of the variables that exist in construction.

I apologize for being late in responding. I will be glad to discuss further the basis for my response.

Very truly yours,

TENNESSEE VALLEY AUTHORITY

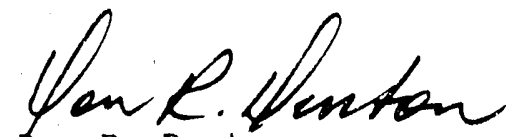

bon R. Dentón

Senior Civil Engineer 


\author{
Extra Urbanam Nihil \\ Room 1245 \\ 208 N. Romine \\ Urbana, IL 61801 \\ 217-333-3929
}

15 January 1988

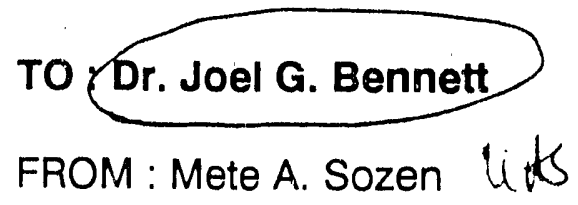

RE: Objectives and Progress of the "Selsmic Category I Structures Program"

It would have been a time-saver for both of us for me to be able to answer your questions with curt yeas and nays. But your six questions in the context of the six objectives listed in the draft FY 1986 report cover a lot of fertile ground. Before I attempt brief answers I should make an attempt to expose the roots of my prejudgments.

I should also record my appreciation of the effort you and your co-workers have put into the documents you sent me. The documents show both the breadth and depth of the project clearly. I think they are very well done and deserve detailed if not always positive comment. I shall do that informally and in bits and pieces after I finish this note and the one on aggregate. I wish you could locate me on the computer network (my address is sozen@cevax.ce.uiuc.edu) because that medium does encourage quick written exchange.

To start, lei me quote from the engineering market place. It is stated in the Commentary to the ACl Building Code 318-83 (Section A.2.1, p.318R-134) that 
"As a properly detailed reinforced concrete structure responds to strong ground motion, its effective stiffness decreases and its capability to dissipate energy increases. These developments tend to reduce the response acceleration or lateral inertia forces with respect to those forces calculated for a linearly elastic model of the uncracked and lightly damped structure."

That the effective stiffness of a reinforced concrete structure is likely to decrease from its initial value at the beginning of strong ground motion is a generally held belief from observation. There is no contrary evidence. The reasons for the reduction in stiffness are explicit. Concrete cracks. Reinforcing bars yield and slip. Surfaces bounding cracks slide with respect to one another.

Initial stiffness of the reinforced concrete structure is another question. For building structures, initial stiffness is often polluted by effects of base fixity and nonstructural components. The stiffness of the structural system on rigid base could be estimated closely by calculations based on uncracked sections.

Within my experience, l expect the effective stiffness of structural building models in very-low amplitude vibration to be less than three quarters of the calculated stiffness (based on gross section) about half the time. For simple one-element models, the ratio of measured initial to calculated stifness based on gross section is likely to be closer unless of course, the model was mishandled.

The initial stiffness of an actual building (stiffness of the elements above the foundation) could also be close to that based on uncracked section. But we cannot assert that to be correct in every case. Volume-change cracking (caused by effects such as temperature, shrinkage, cieep, and corrosion of reinforcement) is likely to reduce the effective stiffness even if the structure has not been loaded or deformed by external effects before the occurrence of the strong ground motion.

If energy transmission through the structure at different frequencies is a critical design factor, it is proper to estimate the "floor spectra" for a credible range of effective stiffnesses. In my opinicn, the "Seismic Category I Structures program" has established the magnitude of the stiffness-change problem for very stiff reinforced concrete structures (for which the available information in the dynamic domain is, at best, meager). It seems now to be time for projecting these results to the target structures and assess the possible ranges of effects on design calculations. If design calculations indicate problems, then we could go back and refine the input (coming out of this investigation) and/or re-evaluate the design calculatioris. As an engineer, I am resigned to making design decisions without knowing evarything. I think the time has come to investigate systematically the immact of the stiffress-reduction factor on design decisions. It would be very usoful to have an estimate of whether equipment design will be affected by the acknowledgment of stifness change and, if so, what (in terms of dollars) its impact is ikely to be 
I indulge in the obvious only to expose my low-brow approach to the problem. I am willing to turn to practice from the laboratory without having methods to give me one hundred percent of the truth. Your experiments have confirmed that stiff box-like structures soften and that their initial stiffness may not be exactly that which is indicated by calculations based on observations on undisturbed samples. The same experiments also show that the equivalent viscous damping factor may be in the range from 0.05 to 0.1 . I concede that available information does not enable us to specify the exact value of the initial stiffness for every structure in the field, but we do have a handle on the credible range. It is time to probe the effects on design.

(1) Are the tests in this program valid for addressing the program objectives?

Yes. The tests do provide information on changes in stiffness of stiff reinforced concrete structures and their ability to dissipate energy at various levels of applied stress. Consequently, they provide useful information related to "floor response spectra."

A simple point needs reinforcement here in relation to validation of computer programs (objective 3). The most optimistic result to expect from such an enterprise is that the test data will not invalidate a computer program in the range of the test parameters. The likely result is that the experimental results will help calibrate the numerical model over a given range of the parameters. To refer to "validation of computer programs" sets up unfulfillable expectations.

(2) In light of the program objectives, are the model test data obtained applicable to nuclear power plant structures?

Yes. 
(3) Have the technical issues of scaling, instrumentation and model fabrication issues been resolved?

With respect to overall impact of the results, yes. Details remain to be resolved, but it would be inefficient to focus on detail when there are some important implications to be studied.

(4) Should there be another "carefully handled" dynamic test to address the possible "dynamic effects" issue? If so, what configuration?

It would be preferable to decide on the use of resources for experimental analysis after the design impact studies have been carried out and evaluated.

(5) Have we obtained enough data and have we tested the correct configurations to meet the program objectives?

No. Sufficient data have been obtained to confirm the need for re-evaluating state-ofthe-art floor response calculations and their impact on design of equipment.

(6) Would the variability in stiffness observed in the models be observed in real nuclear piant structures at comparable load levels?

Yes, if the structure in question is reinforced concrete. 


\section{STEVENSON \& ASSOCIATES}

a structural-mechanical consulting $\in$ ngineering firm

9217 Midwest Avenue $\cdot$ Cleveland, Ohio 44125 • (216) 587-3805 • Telex: 980101

$0204 \mathrm{~F}$

$87 C 7409$

December 17,1987

Dr. Joe 1 Bennett

Advanced Engineering Technology

Los Alamos National Laboratory

Los Alamos NM 87545

Dear Joe 1:

My apologies for not responding to MEE-13: 87:567 by 4 December 1987 but apparently your letter to me got lost in the ma11. I was at the NRC research Offices in Rocksville on 14 December 1987 and ran into Roger Kenneally who asked me about my response to your letter. He gave me the package and asked that I respond to your six questions ASAP.

Question \#1- Are the tests in this program valid for addressing program objectives?

Yes, unless you really wish to evaluate the difference in stiffness between cracked and uncracked shear walls which I do not recommend. In the 11 imit, in response to a damaging strong motion earthquake, it should be assumed that concrete shear walls of the nuclear plant bullding structures will be cracked. The 1iterature on behavior of heavy industrtal equipment and building structures in damaging strong motion earthquake supports the belief that building structures are more susceptible to earthquake damage than the equipment they contain. This suggests that nuclear power plant structures would at least be cracked before the safety related equipment contained therein would be susceptible to damage.

Question \#2 Are the model test data obtained applicable to nuclear power plant structures?

A qualified yes. In my opinion the "stiff" shear wall data is from uncracked specimens. The less stiff data would be applicable to "cracked" specimens. I also believe the data developed for the uncracked specimen would be applicable to earthquakes well below the damage threshold for safety related equipment in the plant hence of little practical use. The more limited "cracked" data is applicable to seismic evaluation of shear walls and equipment at response levels nearer those levels which could course damage to the structure itself and the safety related equipment contained therein. 
Mr. Joel Bennett

December 17, 1987

Page 2

Question \#3 Have the technical issues of scaling, instrumentation and model fabrication effects been resolved?

Except for the question of whether or not the seismic tests models were cracked prior to testing. I belleve scaling, instrument and model fabrication effects have been resolved. However, this is not my area of spectal expertise. I would defer to the opinion of others such as Meta Sozen on this question.

Question \#4 Should there be another "carefully handled" dynamic test to address the possible "dynamic effects" issue?

No. I belfeve the money would be better spent in developing a consenses method of analytically mociling real nuclear plant shear wall structures which probably should consider the concrete cracked.

Question \#5 Have we obtained enough test data?

In my opinion, yes.

Question \#6 Would the variability in stiffness observed in the models be observed in real nuclear plant structures?

Even more variabllity in stiffness would be observed in real nuclear plant structures. This is due primarliy to soil-structure interaction effects which includes both gaps between the structure and the support media as well as the non-linear behavior of the support medla as a function of media strain levels. Also effecting real nuclear plant structures, would be cracking due to differential settlement, shrinkage and differential temperature effects. I believe it is imperative that we educate structure engineers to understand that linear elastic dynamic analysis of structure at best is an indice of seismic loads and it does not with any degree of accuracy predict the seismic stresses in real structure or equipment. We broaden our design response spectra which has the effect of adding significantly more energy than any one earthquake's time history would generate. This conservatism in my opinion more than compensates for any frequency shift that may exist as a result of 
Mr. Joel Bennett

December 17,1987

Page 3

actual and vartable versus computed constant structural stiffness. This is true also for design of equipment in the butlding as well as the butlding itself.

I hope this letter reaches you in time to be of some use. Please advise if you require any clarification of this letter.

Sincerely,

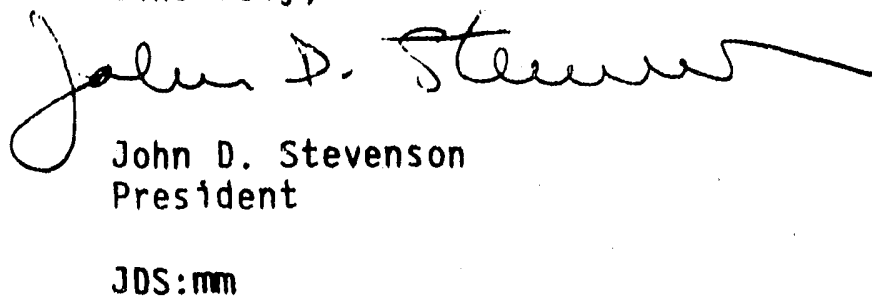

CC: R. Kenneally-NRC

Ref. (1) Draft Report "Development of Criterion for Determining OBE Excuedance" in preparation for EPRI 


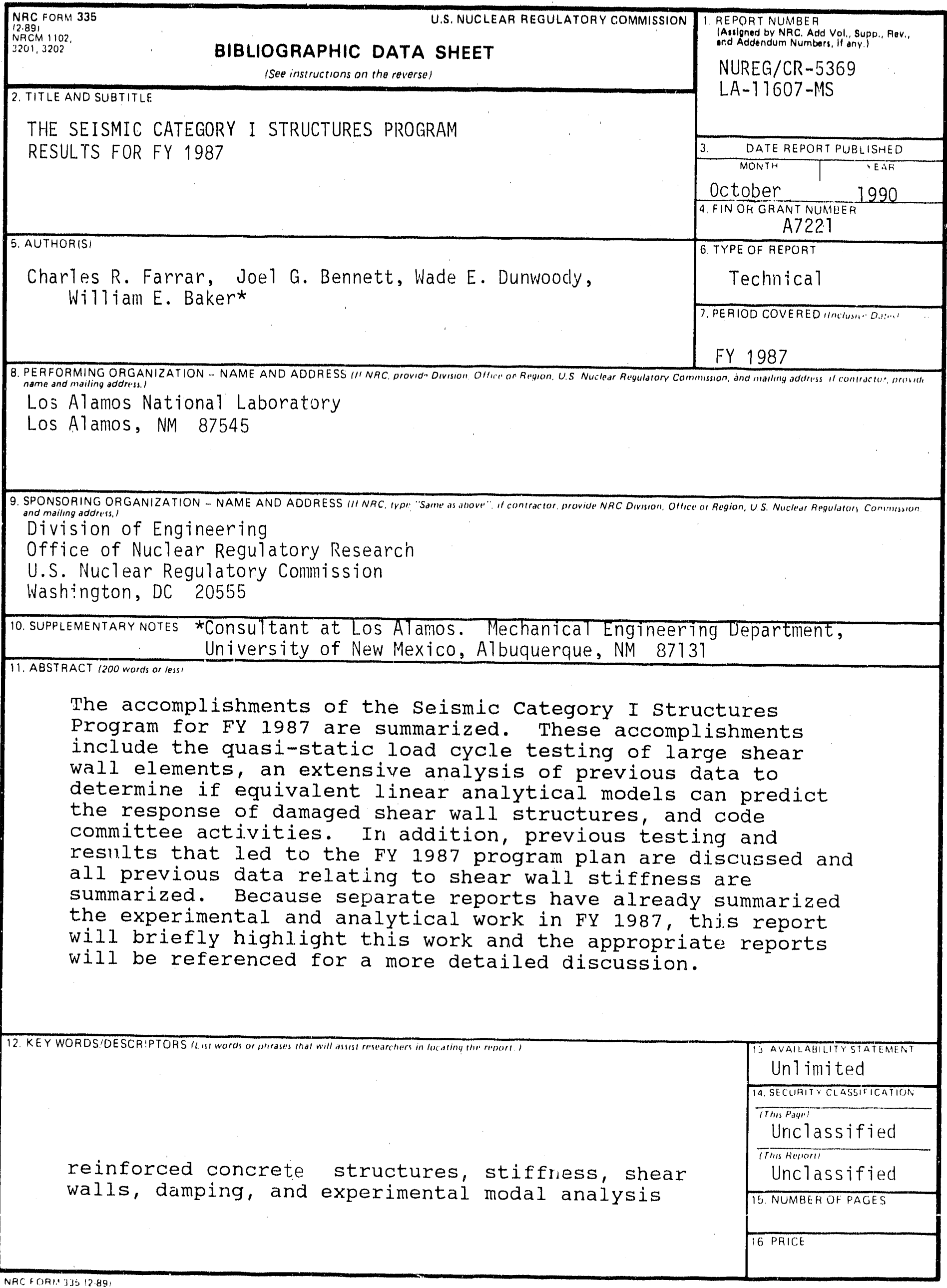



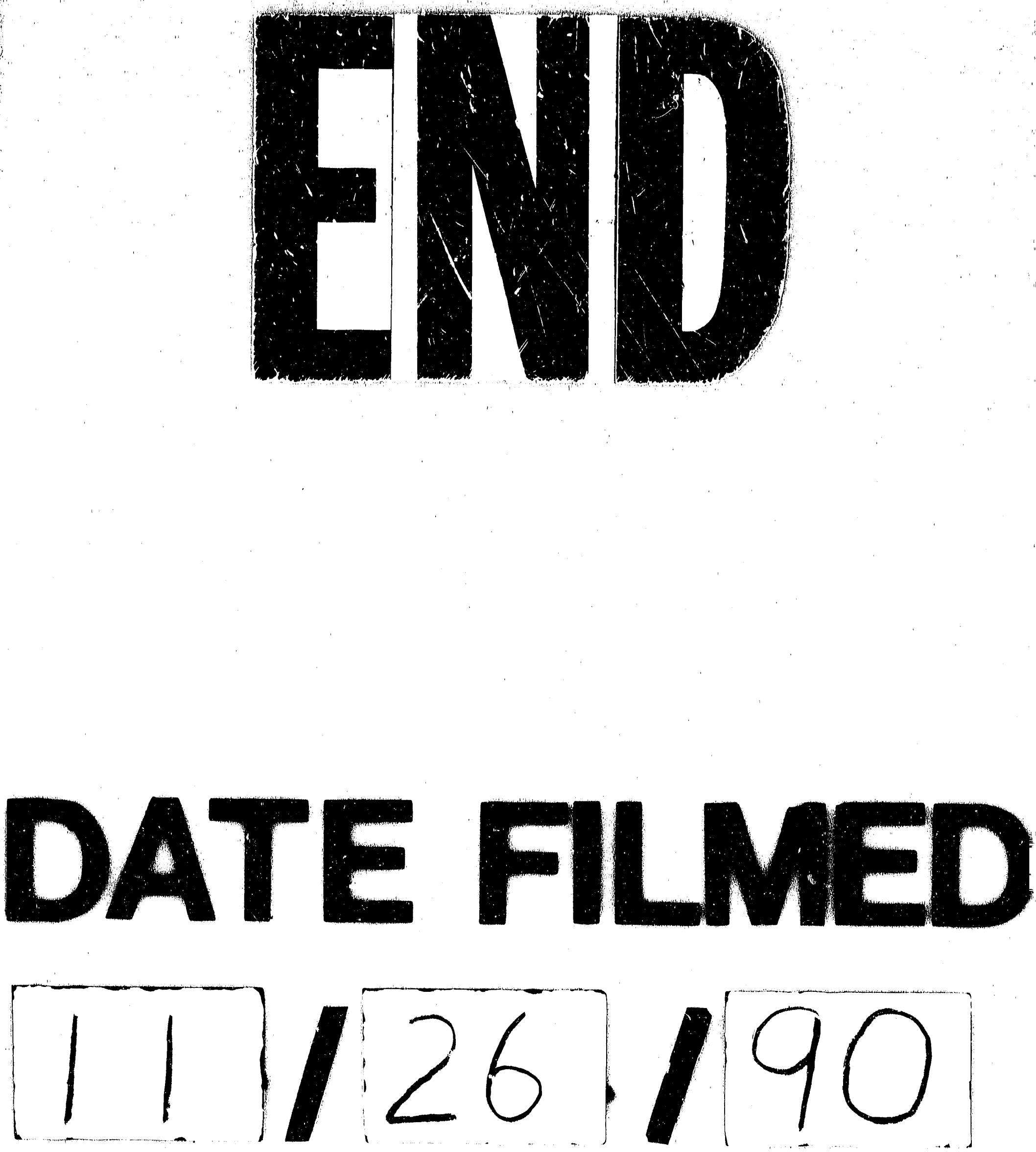